\title{
Stability analysis of partially filled tanker trucks using a finite element modeling approach
}

\author{
Matthew Aquaro \\ West Virginia University
}

Follow this and additional works at: https://researchrepository.wvu.edu/etd

\section{Recommended Citation}

Aquaro, Matthew, "Stability analysis of partially filled tanker trucks using a finite element modeling approach" (1999). Graduate Theses, Dissertations, and Problem Reports. 941.

https://researchrepository.wvu.edu/etd/941

This Thesis is protected by copyright and/or related rights. It has been brought to you by the The Research Repository @ WVU with permission from the rights-holder(s). You are free to use this Thesis in any way that is permitted by the copyright and related rights legislation that applies to your use. For other uses you must obtain permission from the rights-holder(s) directly, unless additional rights are indicated by a Creative Commons license in the record and/ or on the work itself. This Thesis has been accepted for inclusion in WVU Graduate Theses, Dissertations, and Problem Reports collection by an authorized administrator of The Research Repository @ WVU. For more information, please contact researchrepository@mail.wvu.edu. 


\title{
Stability Analysis of Partially Filled Tanker Trucks Using a Finite Element Modeling Approach
}

\author{
By \\ Matthew Aquaro \\ A Masters Thesis \\ Submitted to \\ The College of Engineering and Mineral Resources \\ at \\ West Virginia University \\ in partial fulfillment of the requirements \\ for the degree of \\ Master of Science \\ in \\ Mechanical Engineering \\ Victor Mucino, Ph.D., Chair \\ Mridul Gautam, Ph.D. \\ Kenneth Means, Ph.D. \\ Department of Mechanical and Aerospace Engineering \\ Morgantown, West Virginia \\ 1999
}

Keywords: Tanker Truck, Fluid Slosh, Rollover, Stability 


\section{TABLE OF CONTENTS}

Table of Contents ......................................................................................... ii

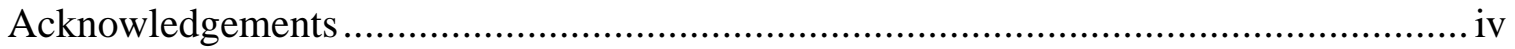

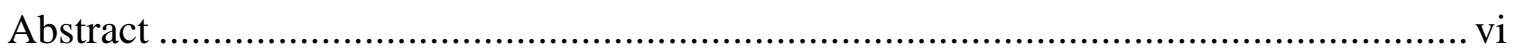

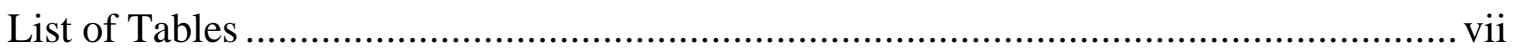

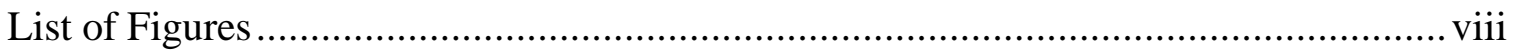

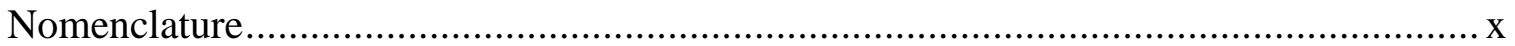

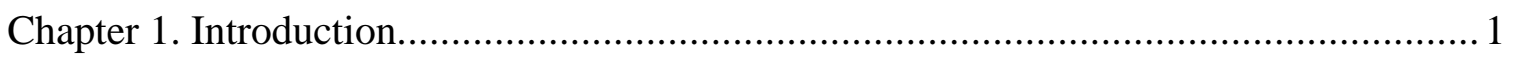

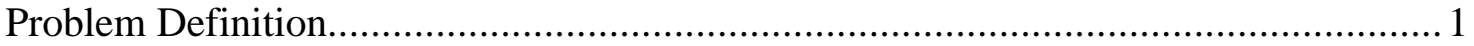

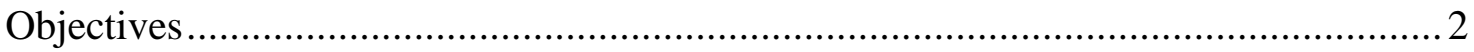

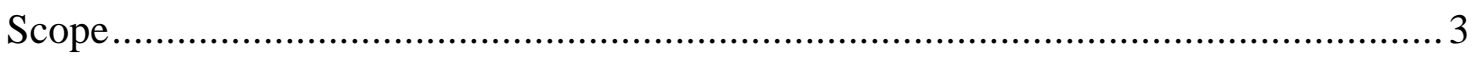

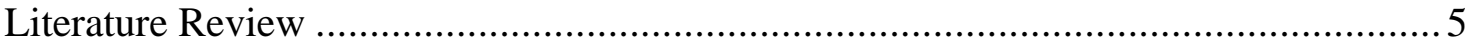

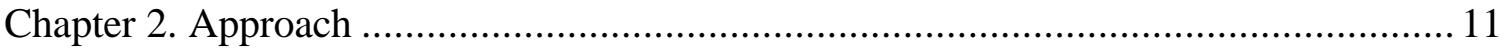

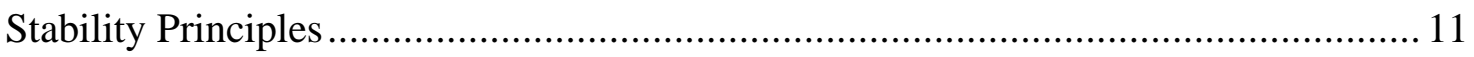

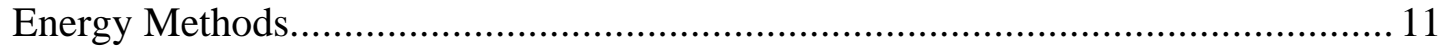

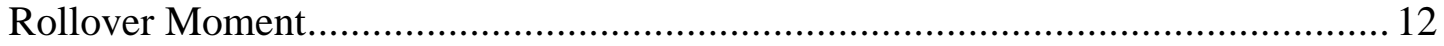

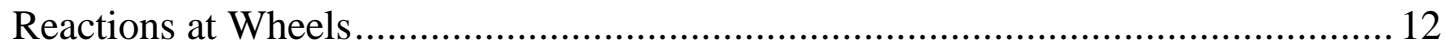

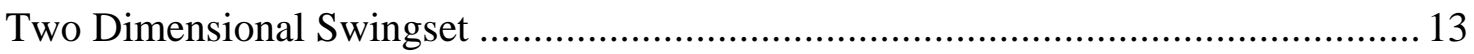

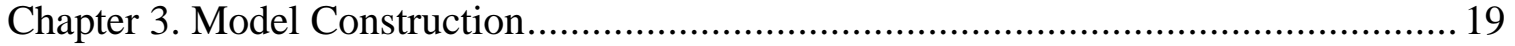

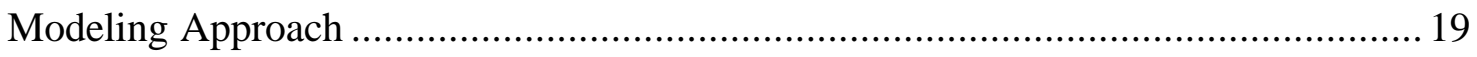

Model Construction Validation with Actual Truck ................................................ 24

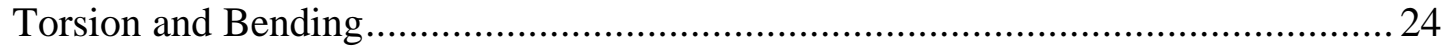

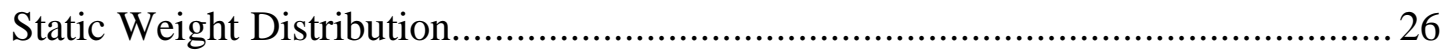

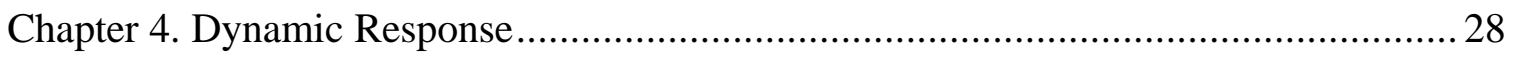

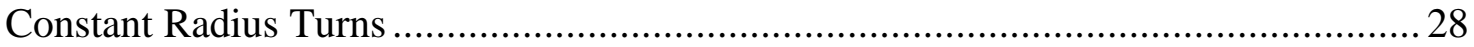

ATC Double Lane Change Maneuver .................................................................. 30

Cycloidal Double Lane Change Maneuver ...................................................... 37

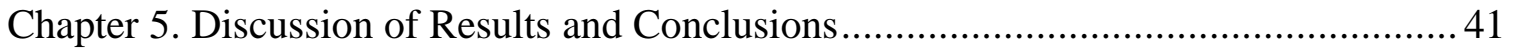

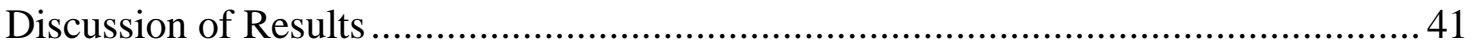

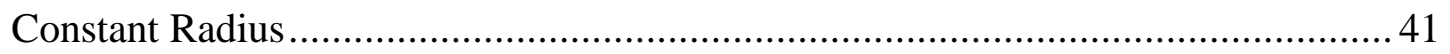




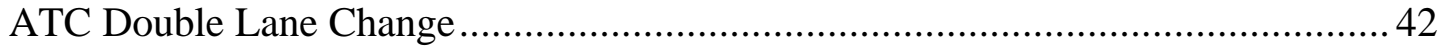

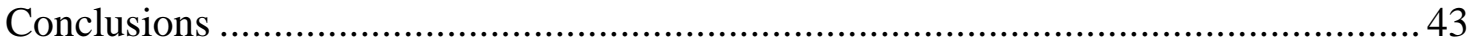

Recommendations for Future Work .......................................................... 44

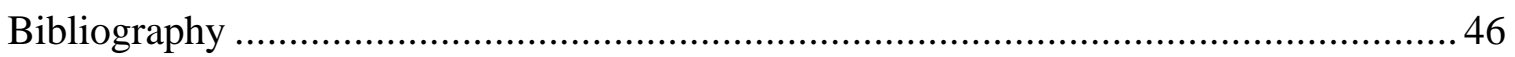

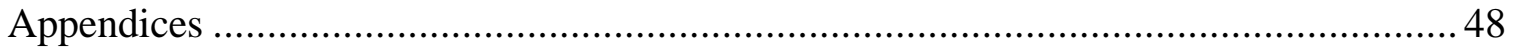

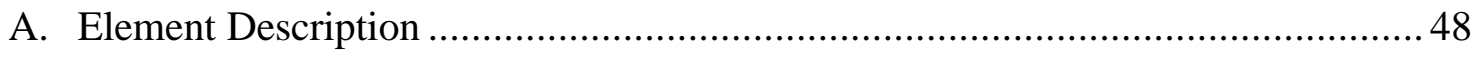

Nonlinear Transient Dynamic Analysis .......................................................... 48

Nonlinear Structural Analysis ................................................................ 48

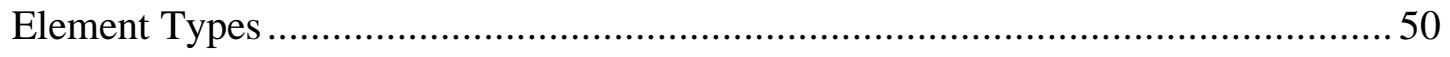

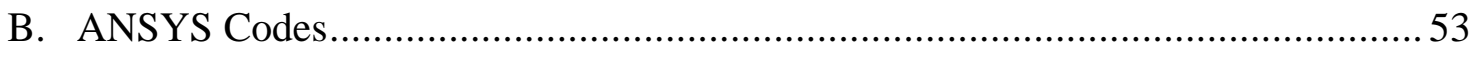

Full Truck 3D Cylindrical Pendulum Model ..................................................53

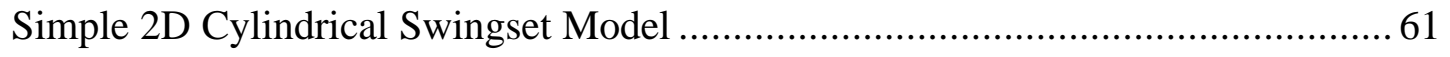

C. Codes from Other Computer Programs .................................................. 64

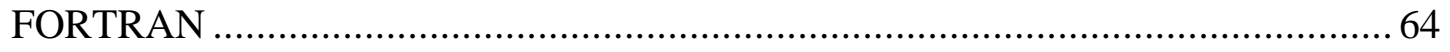

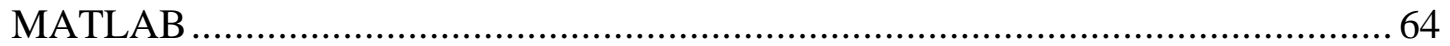

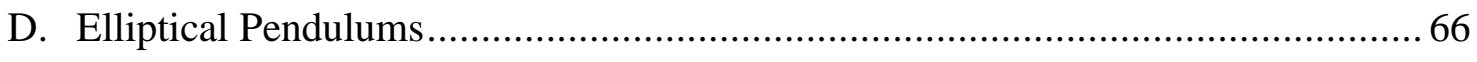

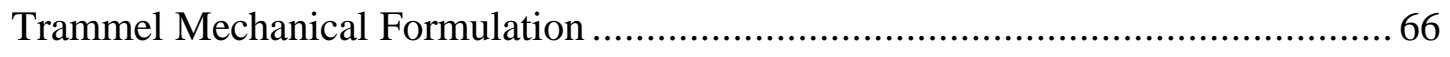

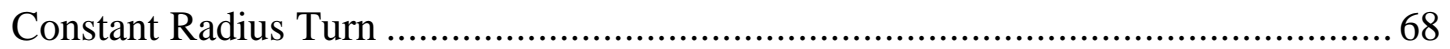

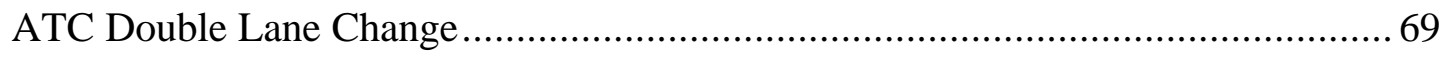

ANSYS Code for Elliptical Pendulum 3D Model........................................... 71

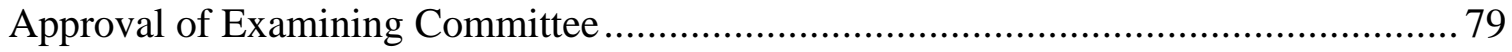




\section{ACKNOWLEDGEMENTS}

I would like to primarily thank Dr. Victor Mucino, my research advisor. A few years ago, Dr. Mucino invited me, a mediocre undergraduate student, to be his partner in establishing an Industrial Outreach Program between the United States and Mexico. There were far superior candidates that could have been selected, but he favored me.

The credit that Dr. Mucino did to me was placing commitment, dedication and heart above a strong technical competency and good GPA. Two years later, I am completing the requirements for a Master of Science degree in Mechanical Engineering. I have learned the disciplines in the technical areas that I once lacked, by applying the traits that lead Dr. Mucino to choose me to assist in his project.

I am eternally grateful to him for giving me the opportunity to discover my place as an engineer. Without his foresight, my life would have a dramatically different shape than it has today. He had the patience to teach, the faith that I would learn, and the supportive heart of a genuine and close friend which gave me confidence in myself. He has inspired me to reach beyond myself and explore my field to a higher stratum. He is one of my heroes, a title all too uncommon in today's world.

The roads of our lives are divided with the forks that we chose to take. When I look backward at the roads that I have traveled, I find that one of those forks was only available because of the generosity of a kind professor. I hope that I have made him as proud of me by the work that I have done as I am of him for his outstanding character, integrity and leadership. 


\section{ACKNOWLEDGEMENTS}

I would also like to credit Mohamed Salem and Eric Saunders for their support and inspiration. The work presented in this report is only a fraction of the work that was done towards this research effort. The team that put forth this effort is extraordinary. Few times in my life have I been given the opportunity to work with such astute individuals who recognize the power of working as a team.

Lastly, Dr. Kenneth Means and Dr. Mridul Gautam receive my thanks. Dr. Means has been an excellent instructor, both inside and outside of the classroom. His lectures have given me a firm grasp of the fundamentals of dynamics, vibrations and kinematics. Dr. Gautam has been a pivotal member of the research team. Without his efforts, this research project would not have culminated into the strong venture that it is today.

Without the support, love and motivation provided by my family, this work and my life would not be as they are today. I owe tremendous gratitude to my parents for persevering through the difficult years of my youth, when I failed to realize the power of education. I have accomplished more than I had ever realized was possible of me, and this is only true because other people knew what I was capable of and perpetually pushed me towards a higher echelon.

My new wife, Maggie, has been there to give the final push necessary for me to complete my masters degree, and for that I am grateful. I know she will be there to leap many more hurdles with me throughout our life together. 


\title{
ABSTRACT \\ Stability Analysis of Partially Filled Tanker Trucks Using a Finite Element Modeling Approach
}

\author{
By Matthew Aquaro
}

The point of rollover for a tanker truck carrying fluid cargo is of great importance due to the catastrophic nature of accidents involving such vehicles. Payloads are often toxic or flammable, thus, predicting the threshold of rollover effectively is of great value. Furthermore, the liquid load shift caused by fluid slosh amplifies the propensity of these vehicles to rollover.

This research presents an approach for determining the threshold of rollover stability of a specific tanker truck by using finite element analysis methods, specifically the software program ANSYS. This approach allows the consideration of many variables which had not been fully considered in the past, including nonlinear spring behavior and tank flexibility. The program uses simple mechanical pendulums to simulate the fluid sloshing affects, beam elements to match the torsional and bending stiffness of the tank, and spring damper elements to represent the suspension.

The finite element model of the tanker truck is validated using data taken by the U.S. Army Aberdeen Test Center (ATC) on a M916A1 tractor/ Etnyre model 60PRS 6000 gallon trailer combination. ATC tested the actual tanker truck both statically and dynamically to provide data as inputs for the tanker truck model. The outputs from the computer model and the real truck are shown to corroborate, thus validating the method of analysis. The approach is then expanded to include a double lane change maneuver derived from a cycloidal path.

The main conclusions are drawn in two forms. First, the model is shown to corroborate with the experimental data taken from the actual tanker truck. Secondly, a series of both actual and hypothetical simulations are made to determine the critical velocity for the given maneuver. These are presented for a constant radius turn and for double lane change maneuvers. 


\section{LIST OF TABLES}

Table 1. Rakheja's [5] rollover test parameters ..................................................... 7

Table 2. Parameters used in the swingset model including cylindrical pendulum

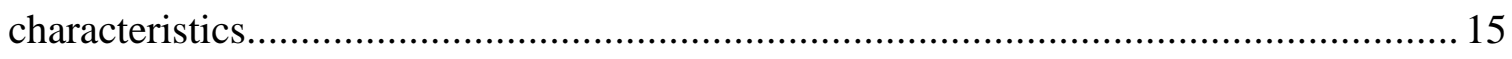

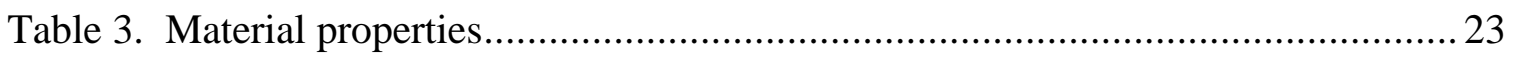

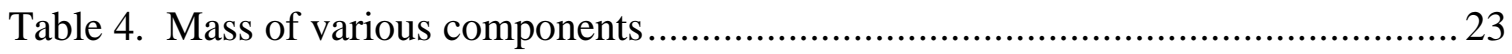

Table 5. Static weight distribution for empty truck ………..................................... 27

Table 6. Comparison of rollover accelerations between work done by Rakheja [5] and

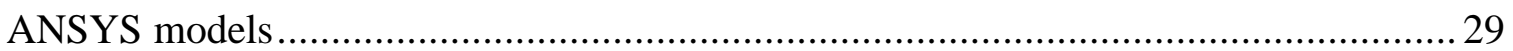




\section{LIST OF FIGURES}

Figure 1. Spring lash

Figure 2. Floating and fixed mass mechanical pendulum model developed by

Ranganathan [8] 9

Figure 3. Pendulum parameters for cylindrical cross section [8]

Figure 4. Plot of potential energy for a single degree of freedom system indicating points of stable and unstable equilibrium 12

Figure 5. Rollover moment diagram for a heavy truck with a compliant suspension ..... 13

Figure 6. Basic roll plane pendulum model...................................................... 14

Figure 7. Analytical swingset results for lateral acceleration of .3 g's [12].................. 16

Figure 8. ANSYS swingset results for lateral acceleration of $.3 \mathrm{~g}$ 's .......................... 16

Figure 9. Critical velocity curve for a planer swingset in a 30 meter radius turn solved using ANSYS.

Figure 10. Critical velocity curve for a planer swingset in 30 meter radius turn solved analytically.

Figure 11. Critical velocity for a swingset in a 30 meter radius turn with added suspension using ANSYS......

Figure 12. Full truck finite element model

Figure 13. Nonlinear spring performance curve.

Figure 14. IDEAS model torsional (left) and bending (right) solutions ...................... 25

Figure 15. ANSYS beam model torsional (left) and bending (right) solutions.............. 26

Figure 16. Radius of turn and articulation angle.

Figure 17. Critical Velocity of the tanker truck model in a 30.48 meter constant radius maneuver

Figure 18. Double lane change maneuver

Figure 19. Parameters input into the tanker truck model to determine the dynamic response for a double lane change

Figure 20. Comparison of the experimental and model wheel reactions from axle 45 combination in ATC double lane change

Figure 21. Comparison of the experimental and model wheel reactions from axle 23 combination in ATC double lane change 
Figure 22. Comparison of the experimental and model wheel reactions from axle 1 in

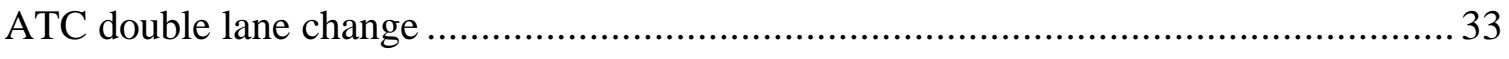

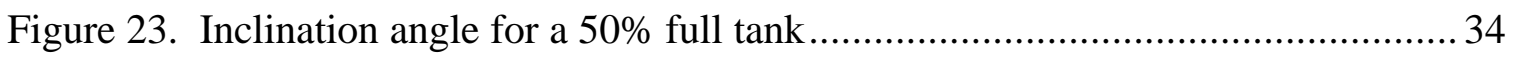

Figure 24. Comparison of the experimental and narrow inclined model load shift from axles 4 and 5 combined in ATC double lane change ................................................ 35 Figure 25. Comparison of the experimental and narrow inclined model load shift from

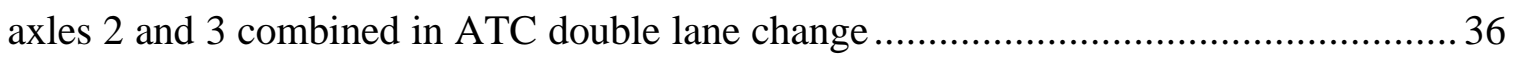
Figure 26. Comparison of the experimental and narrow inclined model load shift from axle 1 combined in ATC double lane change .................................................... 36

Figure 27. Critical velocity curves for a cycloidal double lane change with a gate length

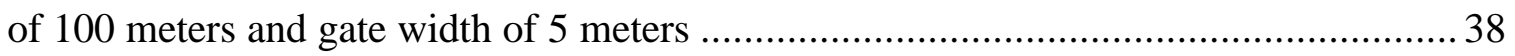

Figure 28. Axle 1 reaction forces for cycloidal maneuver corresponding to ATC gate

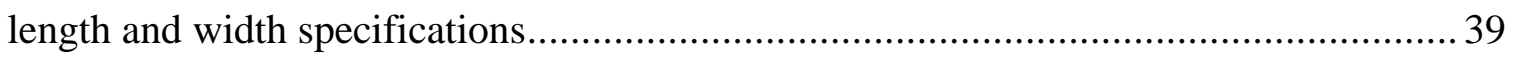

Figure 29. Axles 2 and 3 combined reaction forces for cycloidal maneuver corresponding to ATC gate length and width specifications................................. 40

Figure 30. Axles 4 and 5 combined reaction forces for cycloidal maneuver corresponding to ATC gate length and width specifications.................................... 40

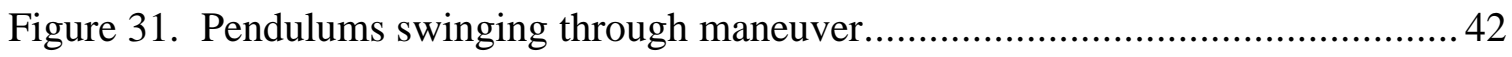

Figure 32. Possible modified wheel reactions with the addition of contact elements ..... 45

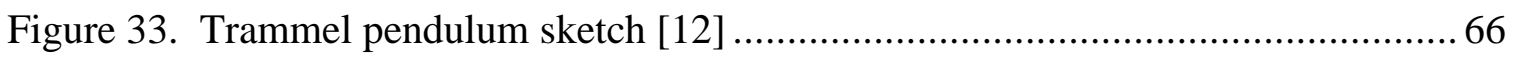

Figure 34. Trammel pendulum swingset model in ANSYS ....................................6 66

Figure 35. Critical velocity curve for elliptical 2D analytical model [12] ....................67

Figure 36. Critical velocity curve for elliptical 2D model in ANSYS ..........................67

Figure 37. Critical velocity curve for full truck model with elliptical pendulums ..........68

Figure 38. Comparison of reaction forces from experimental to elliptical tank model results on axle 1

Figure 39. Comparison of reaction forces from experimental to elliptical tank model results on axle 23 combined 70

Figure 40. Comparison of reaction forces from experimental to elliptical tank model results on axle 45 combined 70 


\section{NOMENCLATURE}
A $\quad=$ Acceleration
ATC = Aberdeen Testing Command
$\alpha=$ Articulation Angle
$\beta=$ Steering Angle
$\mathrm{CG}=$ Center of Gravity
$\mathrm{DOF}=$ Degree of Freedom
$\mathrm{E}=$ Modulus of Elasticity
$\mathrm{H}=$ Height of Cycloid Gate
IYY = Section Moment of Area in the Y Direction
IZZ = Section Moment of Area in the Z Direction
$\mathrm{k} \quad=$ Stiffness
$1=$ length
$\mathrm{L}_{\mathrm{T}} \quad=$ Length of Truck
$\mathrm{R} \quad=$ Radius
$\mathrm{R}_{\mathrm{C}} \quad=$ Radius to the $\mathrm{Cab}$
$\mathrm{R}_{\mathrm{T}} \quad=$ Radius to the Trailer
$\mathrm{V}=$ Velocity
$\mathrm{W} \quad=$ Track Width of Truck
$\omega=$ Rotational Acceleration of Truck 


\section{CHAPTER 1}

\section{Introduction}

\section{Problem Definition}

Heavy-duty trucks generally have a high center of gravity due to large size payload weights suspended high off the ground. This fact alone makes these vehicles hazardous in negotiating turns and lane change maneuvers. In the case of tanker trucks, the fluid payload often results in a dangerous dynamic behavior that may render the vehicle unstable. The combination of these two conditions (high CG and fluid payload) place tanker trucks in a very high-risk category on the roadways of America. In addition, tanker trucks carry some of the most volatile and dangerous cargo that travels across the open roads, making subsequent collisions more devastating. Unlike most tractor trailers, which transport solid material, the payload of a tanker truck is fluid, and its inertia is often large enough to dramatically reduce the rollover velocity threshold of the vehicle to a point lower than normal heavy trucks. The question raised is, how are we able to predict the likelihood that the vehicle will rollover?

To prevent rollover of these vehicles, safety modifications could be made to the truck, changing the suspension, the tank shape and design, or adding baffles to the insides of the tanks. Better driver training programs could be initiated to make drivers aware of the danger of driving a tanker truck. Even with modifications, however, a driver is not always prepared for the new challenges that accompany a truck with a dynamic payload.

What is needed to solve these problems is a model of a tanker truck that effectively characterizes the behavior of the vehicle. Vehicle dynamics and fluid sloshing must be coupled, to capture the overall behavior of the tanker truck system. This model 
would provide the virtual proving grounds for tanker truck testing and design. Vehicle dynamics characteristics could be changed and their effect on stability could be analyzed. In another use, the model could be used to simulate a truck driving through a prescribed course in an effort to see how stable it would remain through the maneuver at different speeds.

Thousands of dollars are spent every year on the cleanup of damage done when tanker trucks have collisions, not to mention the irreplaceable loss of human life. Experimental testing is costly, and is often held to the bare minimum required by law or knowledge. If a model could be computer tested comprehensively and inexpensively under a wide variety of scenarios, the physical experimental tests could be conducted more sparingly. Only the critical scenarios would need to be tested and the model would highlight problem areas, thus enabling analysts, designers and lawmakers to focus their attention on the problem of tanker truck rollover stability.

\section{Objectives}

The overall objective of this research is to make the roadways safer by increasing knowledge in the area of tanker truck rollover stability and to provide analysts and designers a tool that can be used effectively and expeditiously in determining the threshold of rollover stability. This tool is developed in the general form of a method to determine the threshold of rollover stability using finite element tools and methods. More specifically, the approach makes use of ANSYS, for a distinct tanker truck and validated primarily on a double lane change maneuver.

Where this research is different from previous work is in the nature of the method itself and the validation carried out with actual field tests performed at the U.S. Army 
Aberdeen Testing Center. This is one of the first attempts at using finite element analysis to investigate the threshold of rollover stability of a tanker truck with fluid slosh. A simple mechanical pendulum, validated by other researchers, is used to simulate the fluid behavior, and represents one set of inputs to the finite element model. The model is solved in both a constant radius turn and a double lane change path, and the critical velocity of the truck model is determined. Then, a cycloidal path is derived to fit a double lane change. The solutions for all of these maneuvers are presented and the results are discussed.

\section{Scope}

Making the roadways safer is an objective too large to conquer in this modest effort, but progress can be made on the subject of determining the threshold of rollover stability. A computer model is described, which is solved using the finite element analysis software, ANSYS, on a standard personal computer. The benefit of this model is its ability to effectively determine the threshold of stability. One particular feature of the model is its simplicity. The model can be easily modified and solves quickly in a few seconds.

The pendulum characteristics are determined from previous research. These pendulum characteristics are for a cylindrical shaped tanker, but a brief section is presented dealing with elliptical pendulums in Appendix D. The elliptical pendulum is a $16^{\text {th }}$ century idea inspired by Leonardo DeVinci, coined the "Trammel Mechanism." The formulation of the mechanism is discussed and applied to the tanker truck model, but the exact details of the pendulum as it relates to fluid sloshing are not yet known, and thus, 
await further work. Approximations to the elliptical pendulum can be made using the charts known for a cylindrical pendulum, and some examples are illustrated.

The tanker truck model is made of beam elements, lumped masses, and spring elements. The tire properties themselves are too complex to model with any sense of practicality and are beyond the scope of this work. A simple longitudinal stiffness is calculated and the tire is simply modeled by a spring with longitudinal (vertical) stiffness only.

The model is modified through a data file, where the suspension characteristics, level of fill, or course can be changed. Rollover is measured based on wheel reactions. When the reactions at the wheels become negative, the model has begun to roll, and the rollover limit has been exceeded. Critical velocity for a given maneuver is the main parameter to determine in this work. The actual values for rollover, as determined from the model, have been found to be reasonably close to experimental results, but the trends leading toward rollover are the pivotal results. 


\section{Literature Review}

The study of heavy vehicle dynamics began in the mid 1970's. At first, the dynamics of straight trucks received a great deal of attention, but the study quickly expanded to include the realm of articulated vehicles. While the study of heavy vehicle dynamics was both new and vital to the transportation world, it failed to encompass vehicles carrying fluid cargo.

In 1983, Robert D. Ervin [1] studied the influence of size and weight variables on the threshold of rollover stability using plane models. Ervin focused on axle loading, gross vehicle weight, track width, payload center of gravity (CG) height, and lateral offset of the payload CG. His research concluded that the $\mathrm{CG}$ height of the vehicle and it's track width were the two most important factors on the rollover of articulated vehicles. Ervin also studied the affects of suspension variables and noted that softer suspensions will roll more easily than firmer suspensions. He also found that spring lash (Figure 1) has an affect on the roll sensitivity of heavy vehicles. One item of interest in Ervin's work is that he lumped the reactions of wheel sets together. Ervin also notes that

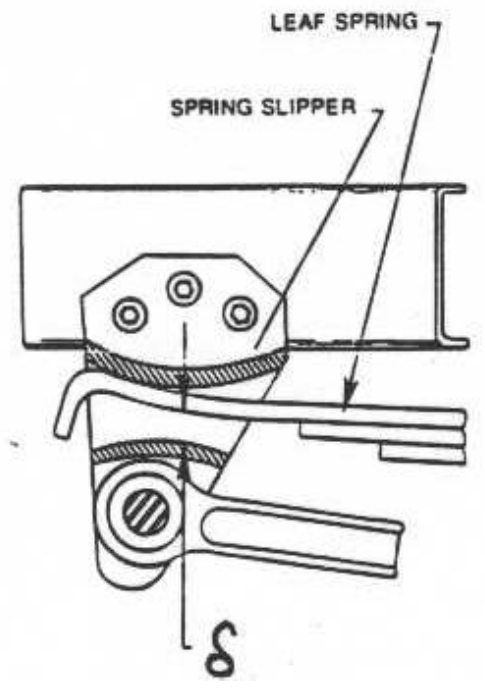

Figure 1. Spring lash. 
the free play in the fifth wheel coupling is negligible. Ervin's focus left tanker truck vehicles lumped together with all other types of road vehicles, and even eluded that tanker trucks could be more stable than rigid cargo trucks, provided the cg was closer to the ground.

In 1988, Leslie A. Laird [2] did a study on the measurement of roll stability properties on heavy vehicles and created a method for evaluating overall stability performance. Laird characterized what variables were critical to heavy vehicle suspensions and then used the plane model that Ervin had developed to evaluate stability. Laird came up with four parameters that are most critical to the suspension: roll stiffness, roll-center height, lateral compliance, and suspension height. He measured these properties using a tilt test and added lateral compliance to the models used by Ervin. Again, the subject of tanker trucks and fluid slosh was not considered.

It wasn't until 1989 that an effort was made to address and understand the behavior of a tanker truck with an active vehicle/payload interaction. Ranganathan [3] studied the affects of fluid slosh on the static roll stability of tanker trucks by coupling a kineto-static roll plane model of an articulated vehicle with a fluid slosh model. The results of this work described fluid slosh affects on the overall static rollover threshold of an articulated vehicle. The conclusions of this paper were that the effects of fluid slosh could not be overlooked due to their significance in reducing the rollover limit of the vehicle. Ranganathan also mentioned that spring lash could affect rollover by as much as 25\%. The fluid free surface in this study was assumed to be a straight line and the mass of the fluid was assumed to be concentrated at the fluid cross sectional CG. 
In 1990, Ranganathan [4] continued this work with a study on the directional stability of a tank vehicle. A tank vehicle is subject to destabilizing forces that cause the vehicle to deviate from its intended path. He concluded that the directional response characteristics of a tank vehicle are affected by the liquid load shift of the fluid.

Following this work, Rakheja performed a study into the development of an early warning safety monitoring system for articulated freight vehicles [5]. While the study focused on rigid cargo vehicles, it proves useful in validating the work of this paper for the tanker truck in either the completely empty or mostly full condition. Rakheja used a plethora of different truck combinations, varying center of gravity, vehicle width, and suspension spring rates. For the case of validating this work, only one case is considered. The specifications are given in table 1 . The lateral acceleration limit in a steady turn for a CG height of 1.52 meters was found to be $4.9 \mathrm{~m} / \mathrm{sec}^{2}$. For the cases of 1.78 meters and 2.03 meters GC heights, the lateral acceleration limits determined are $4.0 \mathrm{~m} / \mathrm{sec}^{2}$ and 3.4 $\mathrm{m} / \mathrm{sec}^{2}$ respectively. Since the specific path parameters for the lane change maneuver were not given in the literature, this test cannot be validated.

\begin{tabular}{|l|c|}
\hline Width & 2.44 meters \\
\hline Center of Gravity Height & $1.52,1.78$, and 2.03 meters \\
\hline Tractor front suspension & $53 \mathrm{kN}$ \\
\hline Tractor rear suspension & $84 \mathrm{kN}$ \\
\hline Trailer suspension & $93 \mathrm{kN}$ \\
\hline
\end{tabular}

Table 1. Rakheja's rollover test parameters.

A field test of a two axle truck with a tank body was later done by Rakheja [6]. This test compared the results of a three dimensional tanker truck model incorporating a quasi-dynamic roll plane fluid slosh model to the results obtained through field testing. The model data and the experimental data correlated well. The analytical model was able to predict the load transfers, roll rates, and lateral accelerations accurately. The testing 
was done for a lane change maneuver with a gate width of 3.3 meters, gate lengths of $15 \mathrm{~m}, 18 \mathrm{~m}$, and $21 \mathrm{~m}$ and velocities of $35 \mathrm{~km} / \mathrm{hr}, 39 \mathrm{~km} / \mathrm{hr}$, and $45 \mathrm{~km} / \mathrm{hr}$. The testing was also done for a constant radius turn of 30 meters for speeds of $29 \mathrm{~km} / \mathrm{hr}, 35 \mathrm{~km} / \mathrm{hr}$, and 90 $\mathrm{km} / \mathrm{hr}$. Unfortunately, the details of the truck tested are not available to validate the model proposed in this work.

In 1993, Rakheja again studied the rollover threshold of tanker trucks [7]. For this study, a combination of the work done in the kineto-static rollover analysis and Ervin's models [1] were used. Rakheja balanced the total overturning moment and the restoring moments, paralleling Ervin's earlier work, but he also added the offset payload moment due to fluid slosh. In this work, Rakheja placed the entire fluid mass at the end of the pendulum and positioned it as a function of the CG of the fluid. The results from this method were compared to the kineto-static rollover model [3]. The simplified approach performed reasonably well for the cylindrical tank, but it failed to give strong correlation for low fill levels in the elliptical and modified oval shaped tanks.

In that same year, Ranganathan [8] made an important development in the area of fluid slosh when he computed an equivalent mechanical system to the complex fluid slosh in a circular tank. This mechanical system (Figure 2) consisted of a simple pendulum with a mass attached to the end and an additional fixed mass. This is the first study found that acknowledged that only a portion of the fluid inside the container sloshes, while another portion is fixed to the frame of the vehicle. Ranganathan validated his mechanical model by identifying the natural sloshing frequencies of the fluid and matching the natural frequency of the mechanical model to this data. Figure 3 shows the pendulum parameters for various fill levels of a cylindrical shaped tank. The level of fill 
was calculated by measuring the fluid free surface height and taking a percentage of the tank height. In short, a $75 \%$ full tank is when the free surface is at $75 \%$ of the height of the tank. The other parameters are pendulum length, fixed mass height, fluid mass, and fixed mass.

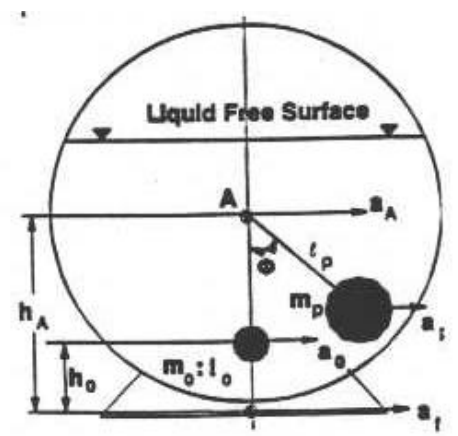

Figure 2. Floating and fixed mass mechanical pendulum model developed by Ranganathan [8].

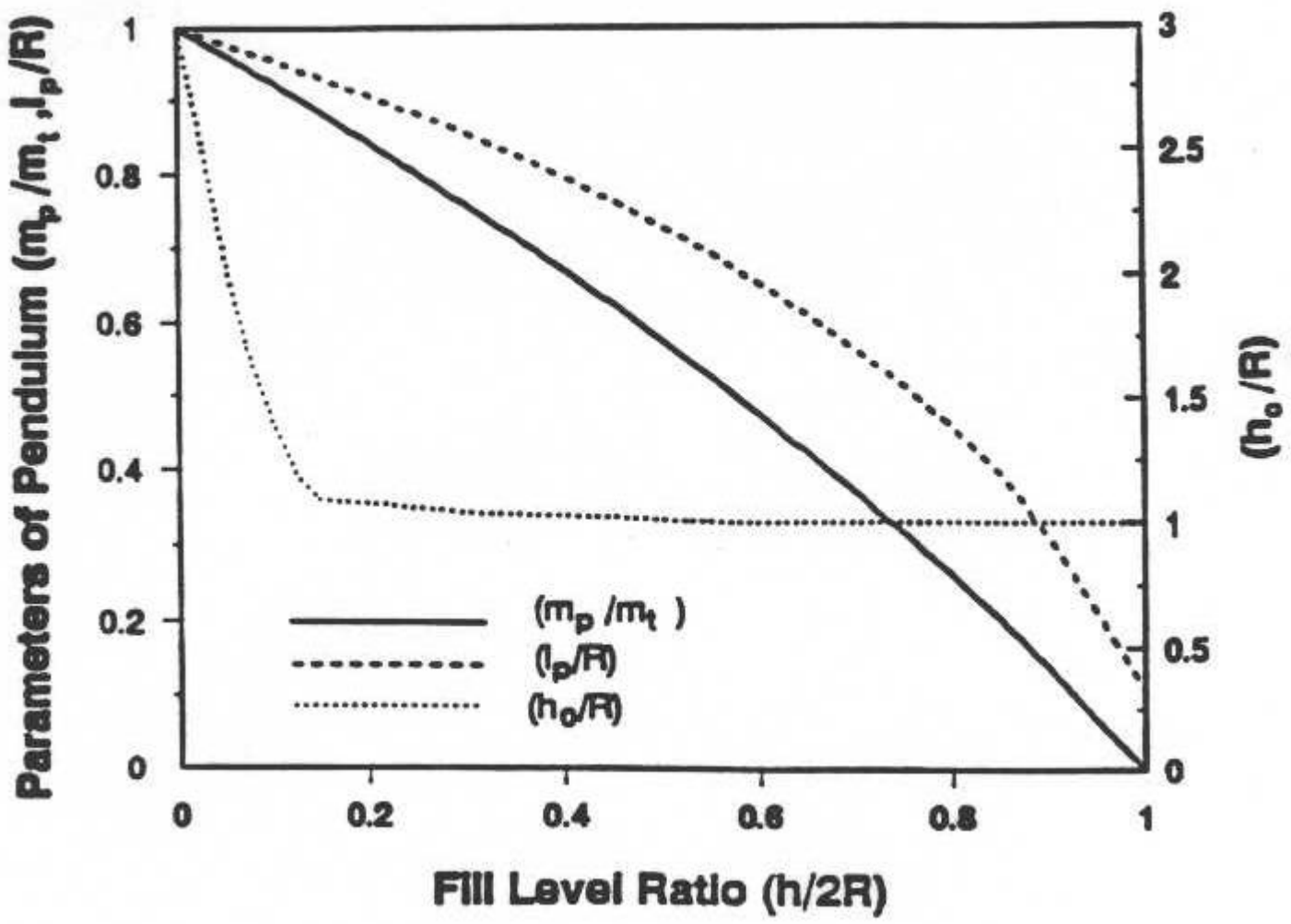

Figure 3. Pendulum parameters for cylindrical cross section [8]. 
The pendulum model showed oscillating wheel reactions, caused by the sway of the pendulum. The wheel reactions were used as an indicator of rollover. This represented a major breakthrough in this field.

Ranganathan [9] continued his work in 1994, but this time focused on the stability of the vehicle during braking maneuvers with longitudinal sloshing. He again used a mechanical model, but instead of a pendulum, he incorporated a spring mass system to model longitudinal sloshing.

In 1996, Sayers and Riley [10] from University of Michigan Transportation Research Institute published a paper discussing the modeling assumptions that went into simulations of the yaw and roll behavior of heavy trucks. Although the subject of dynamic payloads wasn't addressed, the paper gives a good description of the key parameters that are modeled by the current software. UMTRI used this methodology to develop a software package called TruckSim. This software solves the kinematic and dynamic equations of motion for both straight and articulated trucks. The models incorporate such truck parameters as suspension lateral and vertical spring forces, dampers, fifth wheel, tires, steering systems, and rigid body inertias and forces.

The work previously done leaves opportunities for further work. According to the literature study, there still exists a need for a program like TruckSim that takes fluid sloshing into account. 


\section{CHAPTER 2}

\section{Approach}

\section{Stability Principles}

\section{Energy Methods}

The principles of stability can be described in terms of energy methods. The total energy for a system is the sum of the potential and kinetic energies. In a single degree of freedom system, where $\mathrm{x}$ is the free variable, a plot of the potential energy $\mathrm{U}(\mathrm{x})$ can be used in determining the stability of the system [11]. The point where the first derivative of the potential energy is equal to zero identifies points of equilibrium. Figure 4 shows the potential energy plot of a single degree of freedom system. To determine whether these points are stable or unstable, the second derivative must be taken. If the second derivative is greater than zero, the system is stable at that point, if it is less than zero, the system is unstable. In the unlikely case that the second derivative is zero, indifferent equilibrium has been reached, and a higher order derivative must be evaluated.

$$
\begin{array}{ll}
\left(\frac{d U}{d x}\right)_{0}=0 & \text { Point of Equilibrium } \\
\left(\frac{d^{2} U}{d x^{2}}\right)_{0}>0 & \text { Stable Equilibrium } \\
\left(\frac{d^{2} U}{d x^{2}}\right)_{0}<0 & \text { Unstable Equilibrium } \\
\left(\frac{d^{2} U}{d x^{2}}\right)_{0}=0 & \text { Indifferent Equilibrium }
\end{array}
$$

This method is easy to derive for a single degree of freedom problem. In the case of a simple pendulum, for example, the stability can be determined by intuition. When 
the pendulum is pointing straight up in the air, the system is in unstable equilibrium. When the pendulum is hanging straight toward the ground, it is at a point

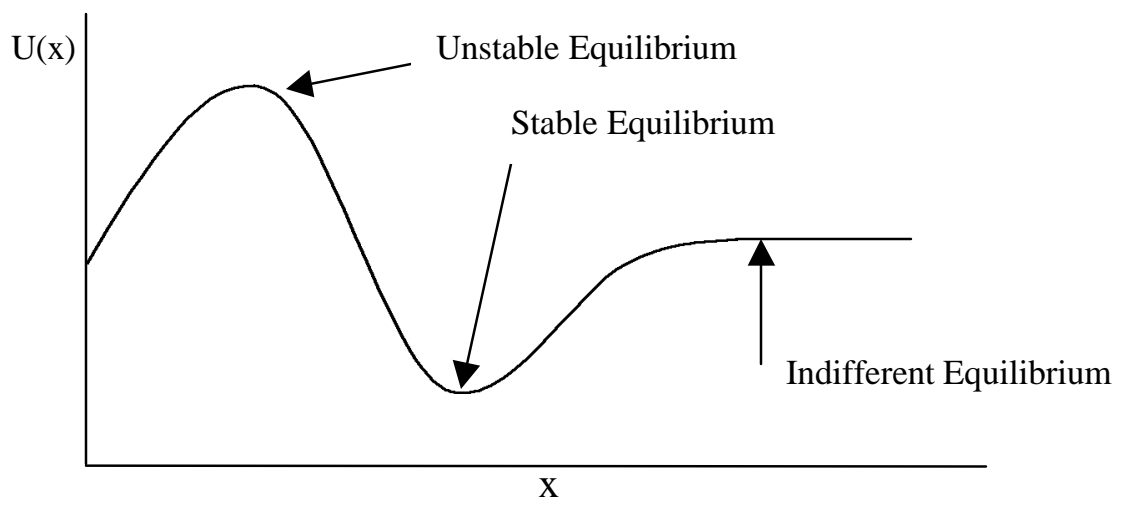

Figure 4. Plot of potential energy for a single degree of freedom system indicating points of stable and unstable equilibrium.

of stable equilibrium. In the case of the multi-degree of freedom tanker truck, however, this solution is cumbersome. Due to these complexities, another method must be adopted.

\section{Rollover Moment}

A very common method of determining the threshold of rollover stability is based on the rollover moment. This criterion says simply that when the lateral acceleration creates a force that exceeds the reacting moment, the vehicle will roll. For an illustration of the rollover moment criterion, see Figure 5. The source of intricacy for this method is in the suspension stiffness, which adds lateral stiffness and roll stiffness to the system. This method is outlined by several researchers in the literature. This method implies that rollover will only happen when the vehicle CG passes beyond an imaginary line extending vertically from the widest reaction support. Rollover can be predicted using this method, but this can not be used to alert the driver as he would lose control of the vehicle before this point is reached. This leads to the next method. 


\section{Reactions at wheels}

Another factor is being employed to determine when a tanker truck is unstable; wheel reactions. This criterion bases instability on the point at which one of the wheels losses contact with the road surface. This method is a practical way of concluding that the vehicle is nearing the point of actual rollover. Rakheja [5] studied the different methods of determining rollover and concluded that, "in order to ensure the detection of impending rollover, it is vital to consider tyre lift-off, even though the vehicle may be marginally stable."

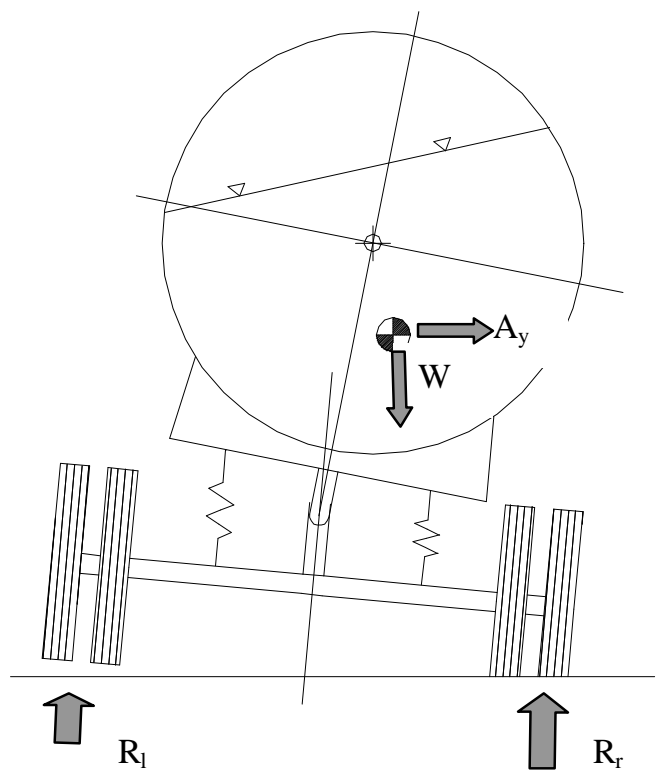

Figure 5. Rollover moment diagram for a heavy truck with a compliant suspension.

Many other researchers use wheel reactions to determine the loss of stability. It can therefore be concluded that wheel reactions can be a good indicator for determining the threshold of rollover stability. Experience has proved that even though it is possible to regain stability once a wheel has been lifted, the driver is often unaware of this occurrence [5] and is unable to correct for it until it is too late. 


\section{2-D Swingset}

The first step in the strategy to solve the problem was the solution of the "swingset" model. This model was a simple 2-D pendulum (Figure 6) modeled in the roll plane. The swingset provided us with our most basic formulation. The analysis was made in the transient dynamic solver of ANSYS. Beam elements were used to model the structure of the swingset. The pendulum was modeled from a link element that allowed free rotations. This simulated a pin joint at the point where the pendulum and the base met, allowing the pendulum to swing freely. Source code from the pendulum model is found in Appendix B. Element types are defined and explained further in Appendix C.

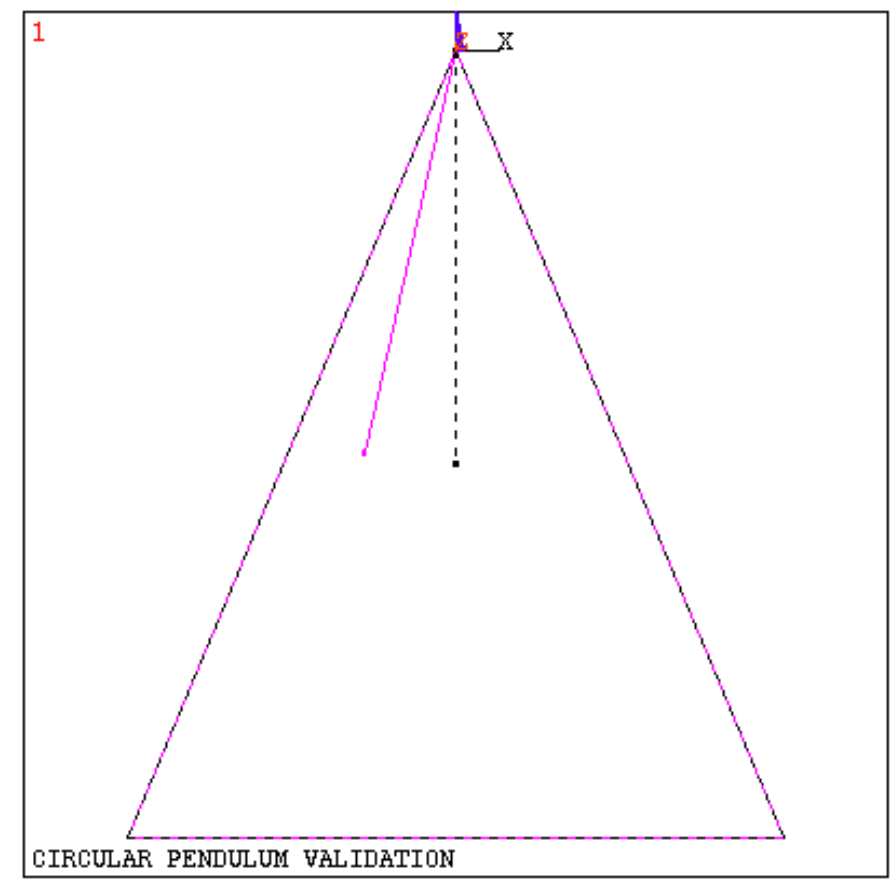

Figure 6. Basic roll plane pendulum model.

Using the parameters found in Table 2, the cylindrical pendulums were defined. This table was formed using Figure 3. As can be seen, the pendulum length, fixed mass height, pendulum and fixed masses were interpolated from the figure. Only the cases of $50 \%, 75 \%$ and $100 \%$ full trucks have been considered. The center of gravity, obtained 
from ATC in a fax sent on January 21, 1998 [13], of the truck combination was taken and also used in the modeling of the swingset. Table 2 shows the parameters used to model the swingset. The entire mass of the truck was lumped at its vertical center of gravity. Then the pendulum fixed and floating masses were placed in their appropriate vertical locations. The swingset was solved for rollover threshold under constant lateral acceleration of $.3 \mathrm{G}$ 's (.3 times the force of gravity). These results were compared to an analytical model that was derived [12].

\begin{tabular}{|l|c|c|c|c|c|c|}
\hline \multicolumn{1}{|l|}{ Circular } & \multicolumn{1}{l|}{} \\
\cline { 1 - 7 } General Data & $\begin{array}{l}\text { Fill } \\
\text { Level,h/2R }\end{array}$ & $\begin{array}{l}\text { Total Fluid } \\
\text { Mass Mt [kg] }\end{array}$ & $\begin{array}{l}\text { Pendulum } \\
\text { Mass Mp [kg] }\end{array}$ & Lp & Mo [kg] & ho=YAB \\
\hline $\mathrm{r}=0.85522$ & 0.5 & 11349 & 6537 & 0.626 & 4811 & 2.47 \\
\hline $\mathrm{m} 1=18969 \mathrm{~kg}$ & & & & & & \\
\hline $\mathrm{T}=2.413 \mathrm{~m}$ & 0.75 & 18311 & 5932.8 & 0.431 & 12378.2 & 2.47 \\
\hline $\mathrm{YAB}=2.47 \mathrm{~m}$ & & & & & & \\
\hline $\mathrm{h} 1=1.524 \mathrm{~m}$ & 1 & 21673 & 0 & 0 & 21673 & 2.47 \\
\hline
\end{tabular}

Table 2. Parameters used in the swingset model including cylindrical pendulum characteristics

The analytical model results for a simple pendulum without suspension are shown in Figure 7 [12]. The corresponding ANSYS model results are shown in figure 8. Both sets of simulations were done on similar models using the data from Table 2 with a 50\% full tank and a lateral acceleration of $.3 \mathrm{~g}$ 's. The results from both models are shown to agree very well.

A series of plots for this model were made under different lateral accelerations. These simulations are referred to as the critical velocity curves. It is worth noting that these critical velocity curves are used repeatedly in this work. They assume a maneuver or path and determine the maximum velocity that the model is able to negotiate the path without rolling over. In later sections of this work, critical velocity curves will be 
presented for a full truck model in both a constant radius turn and a double lane change maneuver.
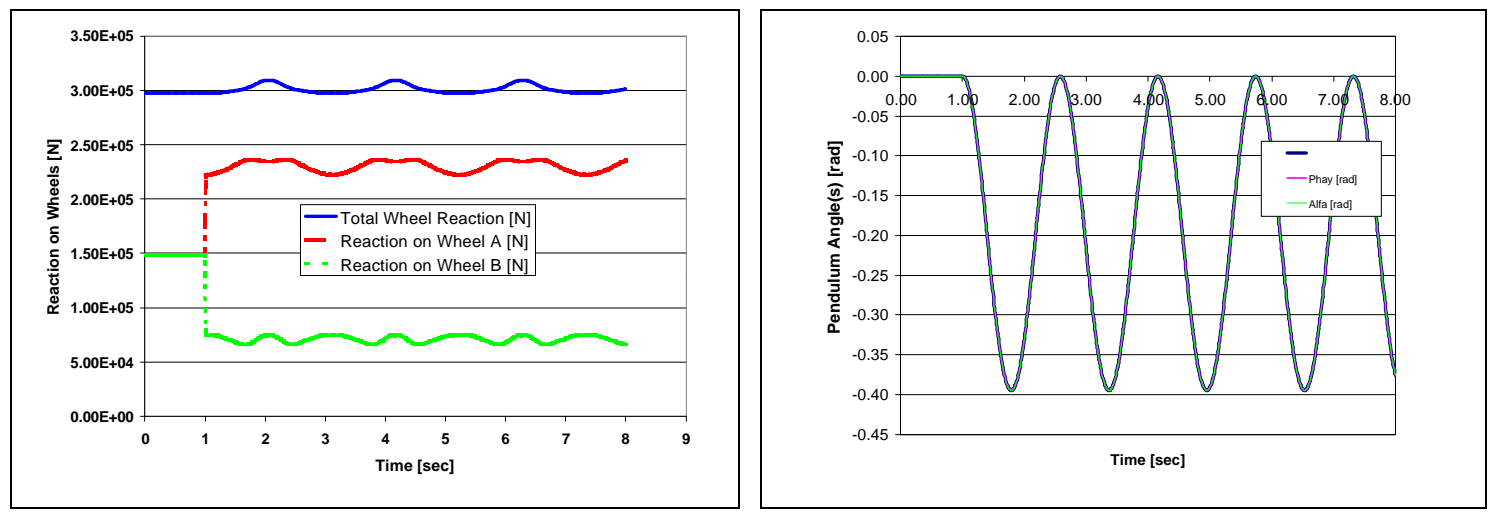

Figure 7. Analytical swingset results for lateral acceleration of .3 g's [12].
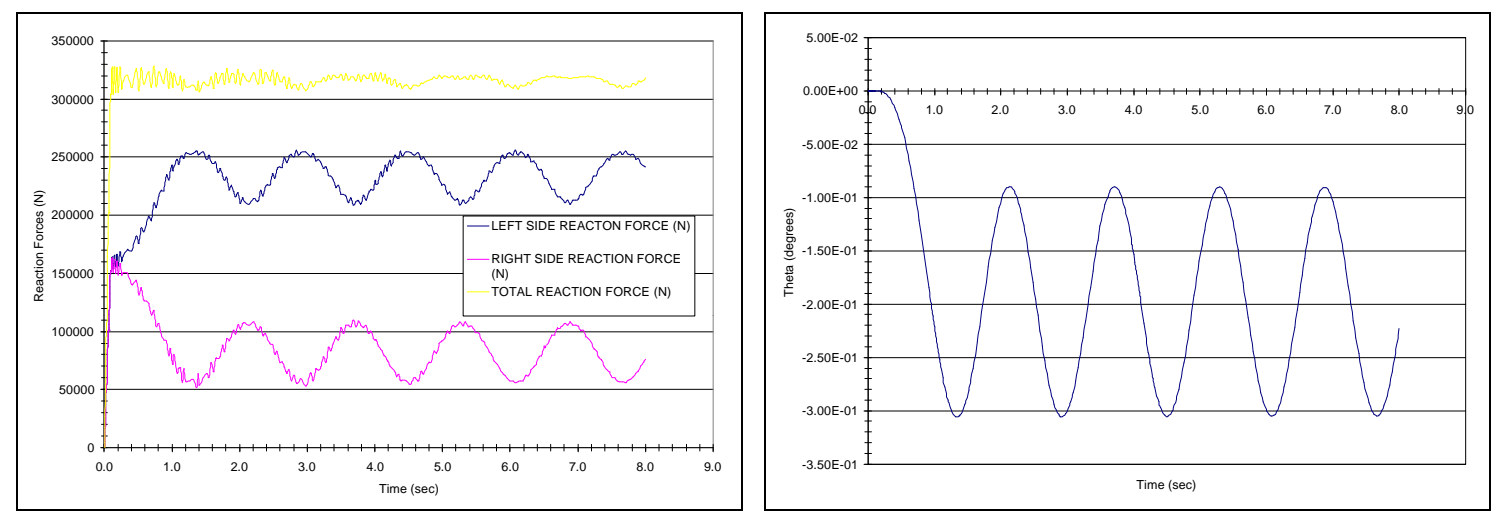

Figure 8. ANSYS swingset results for lateral acceleration of $.3 \mathrm{~g}$ 's.

The lateral acceleration was applied to the model corresponding to different vehicle speeds around a $30 \mathrm{~m}$ constant radius turn. In these cases, the swingset base is restrained to the ground. The wheel reactions are plotted against velocity. The lateral acceleration was derived using Equation 1. For fill levels of 50\%, $75 \%$ and $100 \%$, the critical velocity corresponding to rollover was determined from the model solution. The results are shown in Figure 9.

$$
A=\frac{V^{2}}{R}
$$




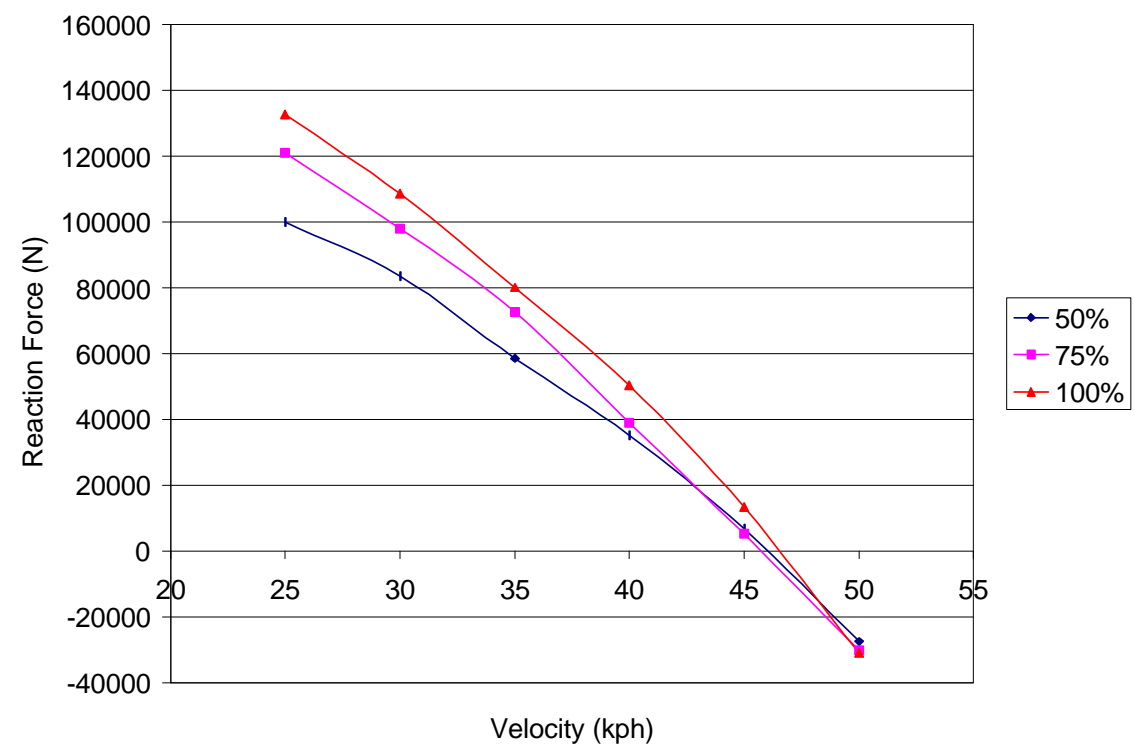

Figure 9. Critical velocity curve for planer swingset in a 30 meter radius turn solved using ANSYS.

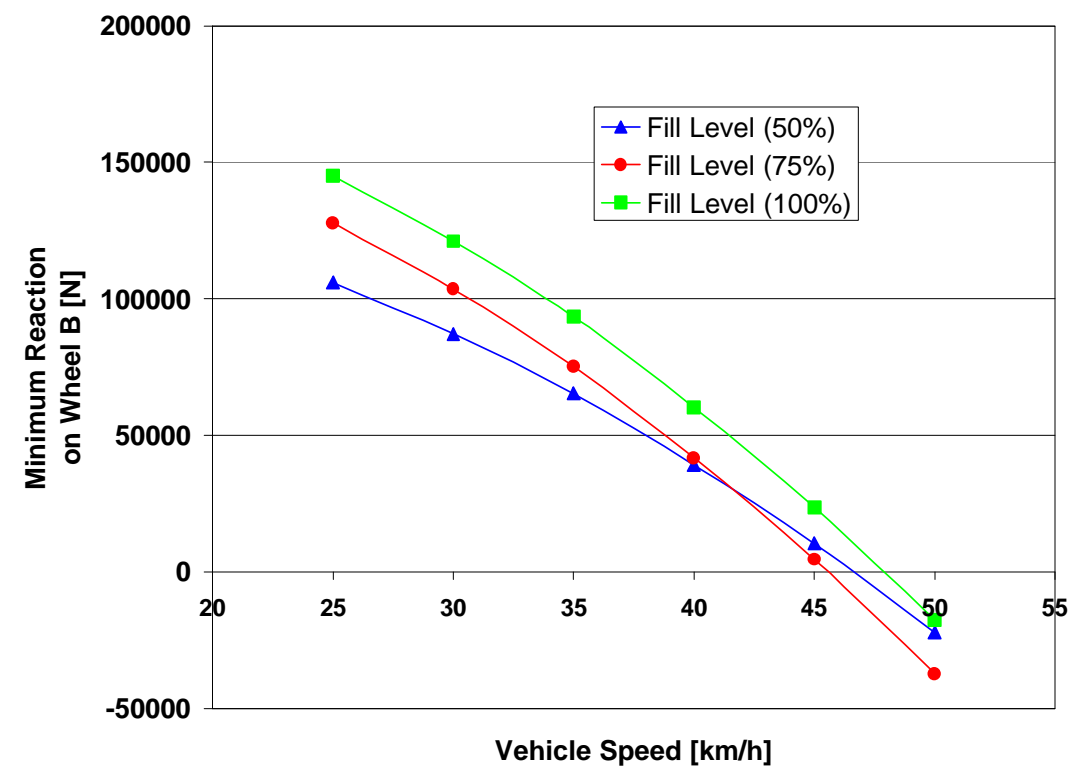

Figure 10. Critical velocity curve for a planer swingset in a 30 meter radius turn solved analytically.

The next step was to add a suspension to the swingset to establish the effect that vertical compliance would have on the solution. Simple longitudinal spring elements were used to simulate the suspension stiffness. The stiffness for the suspension was approximated at $16 \mathrm{E} 7 \mathrm{~N} / \mathrm{m}$. This model was also solved for the critical velocity loaded 
with 50\%, 75\% and 100\% tank fill levels. As Figure 11 indicates, a suspension has a definite effect on the lateral acceleration limits of a heavy vehicle, in this case a tanker truck. The vertical compliance reduced the rollover limits by about $1 \mathrm{kph}$.

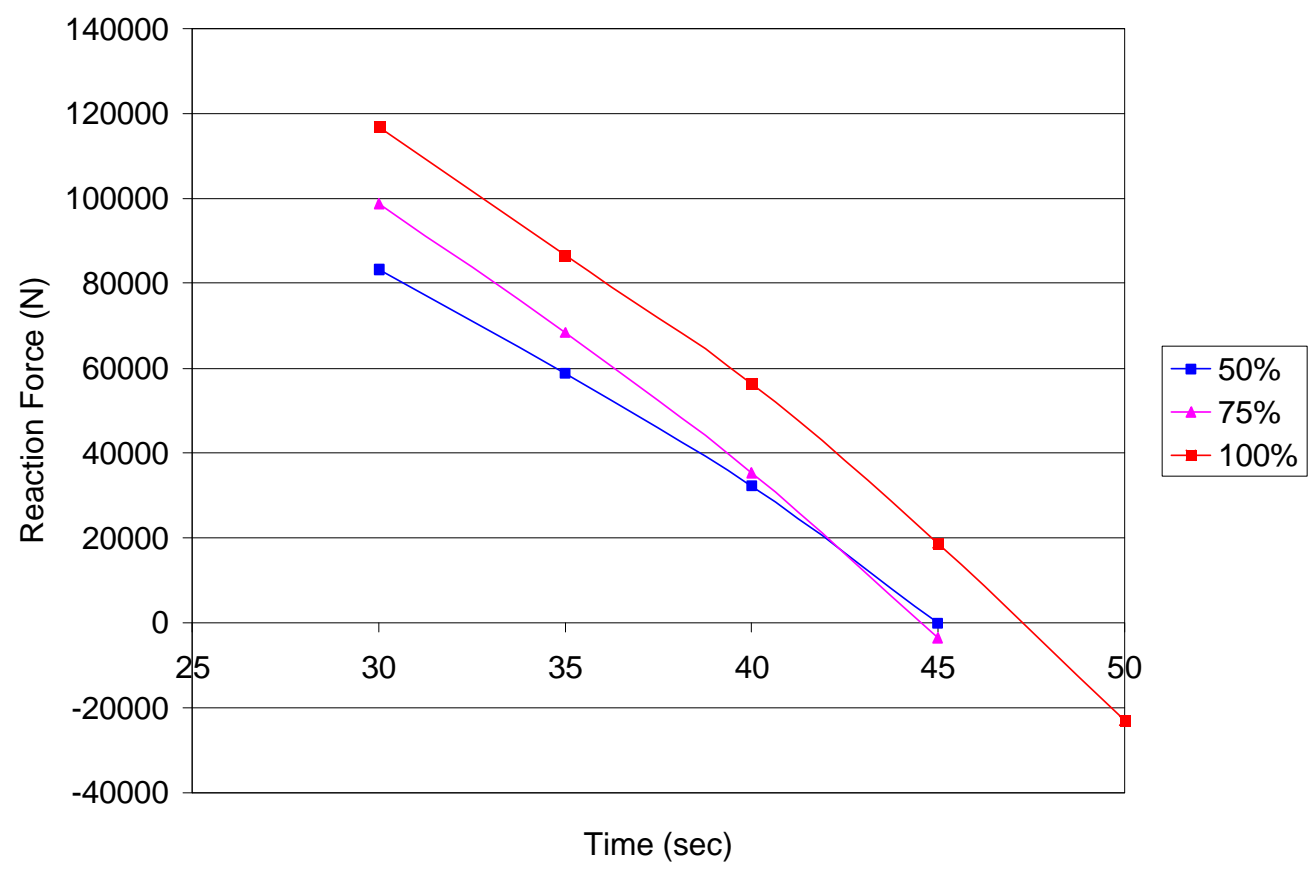

Figure 11. Critical velocity for a swingset in a 30 meter radius turn with added suspension using ANSYS. 


\section{CHAPTER 3}

\section{Model Construction}

\section{Modeling Approach}

Construction of the Finite Element Model (Figure 12) began with a very detailed study of the M916A1 tractor/ Etnyre model 60PRS 6000 gallon trailer combination. The truck was surveyed, and key information was noted for later measurement and calculation. The U.S. Army Aberdeen Test Center (ATC) was responsible for actual measurement of the truck according to the list of necessary dimensions provided by WVU. The information was received from ATC in a fax, sent on January 21, 1998 [13].

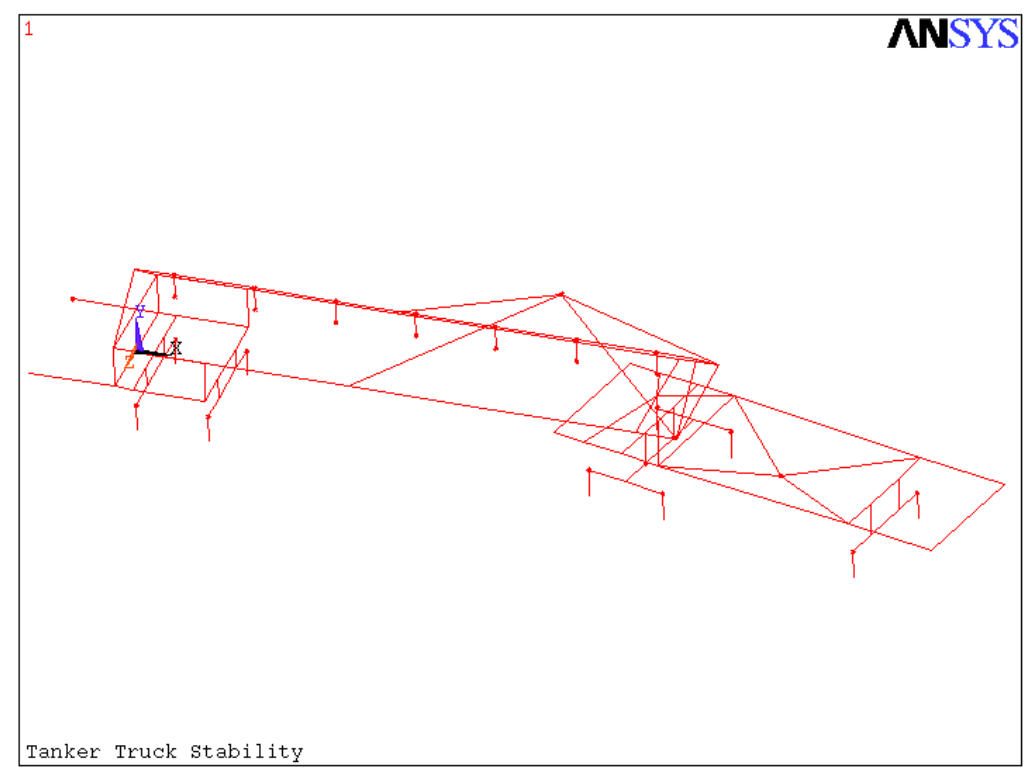

Figure 12. Full truck finite element model.

Finite element analysis software packages require nodes to define element connectivity. Nodes were entered to properly define the truck structure and the tank frame. In the case of the tractor, since it was assumed rigid, the actual dimensions were irrelevant. What was critical, however, was the basic length, width, and specific locations of the suspension mounting points, fifth wheel location, and center of gravity. 
Tank flexibility, however, was considered to be important so the tank dimensions were modeled more precisely. In the case of the tank, the shell was modeled as three longitudinal members. The kingpin was located, and the rear support box, to which the suspension mounts, was outlined. The suspension was modeled as precisely as possible.

The actual tank had an elliptical cross section. Elliptical pendulums were modeled using the Trammel mechanism to define the elliptical path of the floating mass. At the time of this work, however, the exact parameters of the elliptical pendulum are not known. The elliptical pendulum model was solved using approximated parameters based on known data for a cylindrical tank. These results are presented in Appendix D. It can be seen from the results reviewed later in this paper that the cylindrical pendulums provided an accurate assumption for the fluid slosh, even in the elliptical container.

Once the nodes had been defined, the next step was to define the element connectivity. Each element requires four parameters before it can be defined: coordinate system, material table, element type, and real constant table. Preceding the element definition with these parameter specifications, the elements were defined based on node connectivity. Element 1 , for example, is defined as a type 1 (BEAM4), real constant 1 , material 1, modeled in the global Cartesian coordinate system connecting nodes 68 and 30.

Several different types of elements were used to model the truck. Beam elements are the backbone of the model. They are three dimensional elastic beams with six degrees of freedom at each node. Two nodes are required to define an element.

Link elements are useful where rotational degrees of freedom are not desired. A link element can only support tension and compression because the rotational degrees of 
freedom are removed. Application of these elements is found in the pendulums and in the suspension. More detail will be given to the suspension further down.

Mass elements were placed in all areas of the truck model. When mass was needed without inertial affects, a mass element was used. If inertia was required, as in the tank itself, the subject was modeled using beams or other types of distributed mass elements. Mass elements comprised the wheels, cab mass, and pendulum fixed and floating masses, as well as other miscellaneous components.

The suspension was modeled using two types of spring elements: simple longitudinal springs and a special nonlinear spring. The nonlinear spring was used to model the leaf springs in the suspension of the trailer. These springs have a variable effective length (stiffness) which was deemed important to define properly. The load deflection curve was received from E.D. ENTYRE Co. [14] in English units. The curve has been converted to standard units and is shown in Figure 13. This performance curve was transferred to the nonlinear spring element.

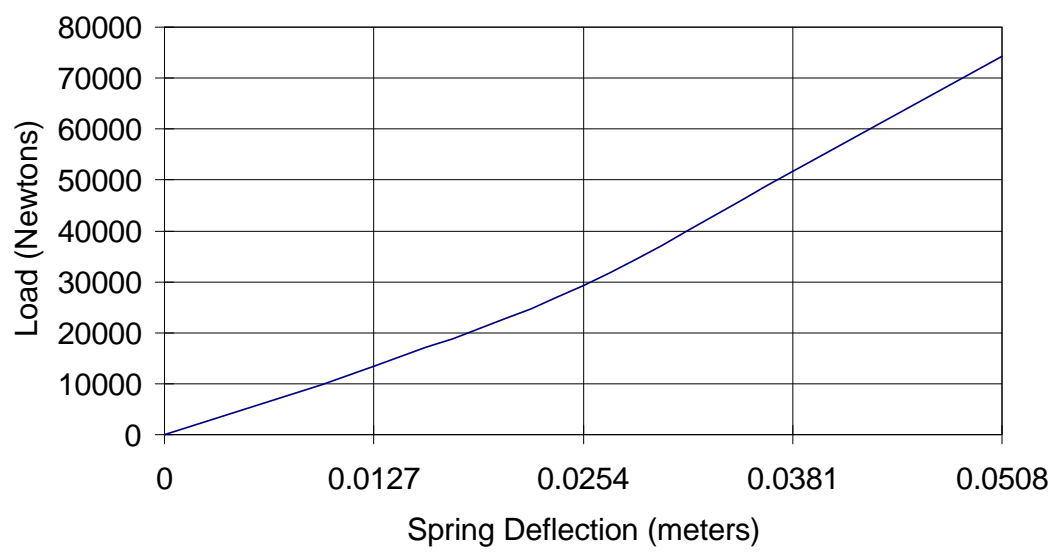

Figure 13. Nonlinear spring performance curve. 
The performance curve for the tractor suspension springs was not available, and so had to be approximated using equation 2 from the BOSCH handbook [15].

$$
k=\frac{\left(2+\frac{n^{\prime}}{n}\right) * E * n * b^{*} h^{3}}{6 * l^{3}}
$$

Where:

b Is the spring width (m)

E Is the modulus of elasticity for the spring material $\left(=206 \mathrm{e} 9 \mathrm{~N} / \mathrm{m}^{2}\right)$

$\mathrm{h} \quad$ is a leaf thickness (m)

$\mathrm{k} \quad$ is the spring stiffness $(\mathrm{N} / \mathrm{m})$

1 is half the distance between the spring supports ( $\mathrm{m}$ )

$\mathrm{n} \quad$ is the total number of leaves

n' is the number of leaves at the ends of the spring

Based on equation 2, and the data sent by ATC [13] the stiffnesses of the tractor suspension springs are:

$$
\begin{array}{ll}
\text { Tractor Front } & k_{f}=\frac{(2+1 / 10) * 206 e 9 * 10 * 0.1016 *(0.0127)^{3}}{6 *(0.762)^{3}}=337,805 \mathrm{~N} / \mathrm{m} \\
\text { Tractor Rear } & k_{r}=\frac{(2+1 / 13) * 206 e 9 * 13 * 0.1016 *(0.0127)^{3}}{6 *(0.4573)^{3}}=2,017,348 \mathrm{~N} / \mathrm{m}
\end{array}
$$

Several different material tables were used to model the truck. The first table was for normal steel. All of the other tables were modifications of normal steel. Two tables are for rigid material, used where flexibility was not desired, as in the tractor frame which was assume rigid. Table 3 lists the values used for all materials.

Modeling the tire stiffness by using longitudinal spring elements was unsuccessful, presumably because of an excess in degrees of freedom. Beam elements were used in order to reduce the number of degrees of freedom of the joint. This strategy didn't sacrifice accuracy because the beams were given the same longitudinal stiffness of the tire. A tire stiffness of $809 \mathrm{kN} / \mathrm{m}$ was used [16]. The cross sectional area of a beam 


\begin{tabular}{|l|l|}
\hline $\begin{array}{l}\text { Material 1 Normal } \\
\text { Steel }\end{array}$ & $\begin{array}{l}\text { Modulus of Elasticity }=2.07 \mathrm{E} 11 \mathrm{~N} / \mathrm{m}^{2} \\
\text { Poison's ratio }=0.29 \\
\text { Density = 7850 kg/m }\end{array}$ \\
\hline $\begin{array}{l}\text { Material 2 Massless } \\
\text { Steel }\end{array}$ & $\begin{array}{l}\text { Modulus of Elasticity }=2.07 \mathrm{E} 11 \mathrm{~N} / \mathrm{m}^{2} \\
\text { Poison's ratio }=0.29 \\
\text { Density =0 }\end{array}$ \\
\hline $\begin{array}{l}\text { Material 4 Rigid and } \\
\text { Massless }\end{array}$ & $\begin{array}{l}\text { Modulus of Elasticity }=2.07 \mathrm{E} 14 \mathrm{~N} / \mathrm{m}^{2} \\
\text { Poison's ratio }=0.29 \\
\text { Density = 0 }\end{array}$ \\
\hline Material 5 Rigid & $\begin{array}{l}\text { Modulus of Elasticity }=2.07 \mathrm{E} 14 \mathrm{~N} / \mathrm{m}^{2} \\
\text { Poison's ratio }=0.29 \\
\text { Density =7850 kg/m }\end{array}$ \\
\hline $\begin{array}{l}\text { Material 6 Heavy } \\
\text { Steel }\end{array}$ & $\begin{array}{l}\text { Modulus of Elasticity }=2.07 \mathrm{E} 11 \mathrm{~N} / \mathrm{m}^{2} \\
\text { Poison's ratio }=0.29 \\
\text { Density }=13000 \mathrm{~kg} / \mathrm{m}^{3}\end{array}$ \\
\hline
\end{tabular}

Table 3. Material properties.

to provide that stiffness using Material 1 was calculated using equation 3 . The cross sectional area corresponding to a tire stiffness of $809 \mathrm{kN} / \mathrm{m}$ was calculated to be $1.993 \mathrm{E}-6$ per tire.

$$
\text { Area }=\frac{k l}{E}
$$

Mass properties received from ATC are given in Table 4. Masses for key components were placed throughout the model. The objective of this was to correctly model the inertia and static weight distribution of the tanker truck.

\begin{tabular}{|c|c|}
\hline Axles & $145.5 \mathrm{~kg} / \mathrm{each}$ \\
\hline Wheels & $37.3 \mathrm{~kg} / \mathrm{each}$ \\
\hline Hub and Drum & $80 \mathrm{~kg} / \mathrm{each}$ \\
\hline Tires & $50.5 \mathrm{~kg} / \mathrm{each}$ \\
\hline Tractor & $10100 \mathrm{~kg}$ \\
\hline Accessories & $50 \mathrm{~kg}$ \\
\hline
\end{tabular}

Table 4. Mass of various components.

The fifth wheel coupling was wedged in place to eliminate free play in the joint for the testing done by ATC. This connection was modeled using Coupled Degrees of 
Freedom (DOF's). Since the fifth wheel was wedged, all degrees of freedom between the fifth wheel and the kingpin nodes were fixed except for the rotation about the $\mathrm{Y}$ axis.

Once the main frame was modeled, the process of validating the truck model to the real truck began. The first piece of information that was validated was the torsional rigidity and bending stiffness of the tank model.

\section{Model Construction Validation with Actual Truck}

\section{Torsion and Bending}

A Finite Element Model was made using IDEAS Master Series version 6.0. The model was made using the dimensions provided by ATC [13]. This model was taken to a higher level of detail than the model made for the dynamic response. The purpose of a more detailed model was to capture parameters from the truck that were unable to be obtained through experiment. These parameters are bending stiffness and torsional rigidity of the tank itself.

To obtain the bending stiffness, the IDEAS model was fixed at the front face of the tank body by restraining the nodes in all translations and rotations. A 273,000 N load was applied to the nodes on the back face of the tank in the positive Y direction. Other loading strategies could have been used if more specific information was needed, but for simple stiffness, this loading condition was considered adequate. A static analysis was made, and results were post processed. The maximum displacement in the positive $\mathrm{Y}$ direction at the front face equaled 9.4e-2 meters (Figure14).

The tank model was fixed again at the front face by applying the same restraint set. The load set was changed, however. Two $1000 \mathrm{~N}$ loads were applied on opposite sides of the back face of the tank. On the right quadrant of the ellipse, a $1000 \mathrm{~N}$ load was 
applied in the positive $\mathrm{Y}$ direction. On the left quadrant of the ellipse, a $1000 \mathrm{~N}$ load was applied in the negative $\mathrm{Y}$ direction. This created a moment about the longitudinal centerline of the tank. A static analysis was again made, and the results were post processed. The maximum rotation about the $\mathrm{Z}$ axis equaled $-2.17 \mathrm{e}-5$ radians and the maximum displacement in the positive $\mathrm{Y}$ direction equaled 2.57e-5 meters (Figure 14).

The beam model now had to be modified to match this data. The same boundary conditions were applied to the beam model. Beginning with the bending model, a solution was made, and results were compared to the results from the IDEAS model. The real constant value polar moment of inertial about the beam Y axis (IYY) was modified on a trial and error basis until the deflection in the $\mathrm{Y}$ direction approximately equaled 8.6e-2 meters. The deflection was .0918 meters (Figure 15). This is a $6.74 \%$ error. The value for polar moment of inertial about the beam $\mathrm{Z}$ axis (IZZ) was changed to get the torsional stiffness to correlate. The trial and error method produced a value for IZZ of $1.1 \mathrm{e}-3$ and IYY of 3e-3. These values produced a torsional displacement equal to $2.01 \mathrm{e}-5$ radians (Figure 15). The error between this value and the IDEAS model is only 7.37\%.

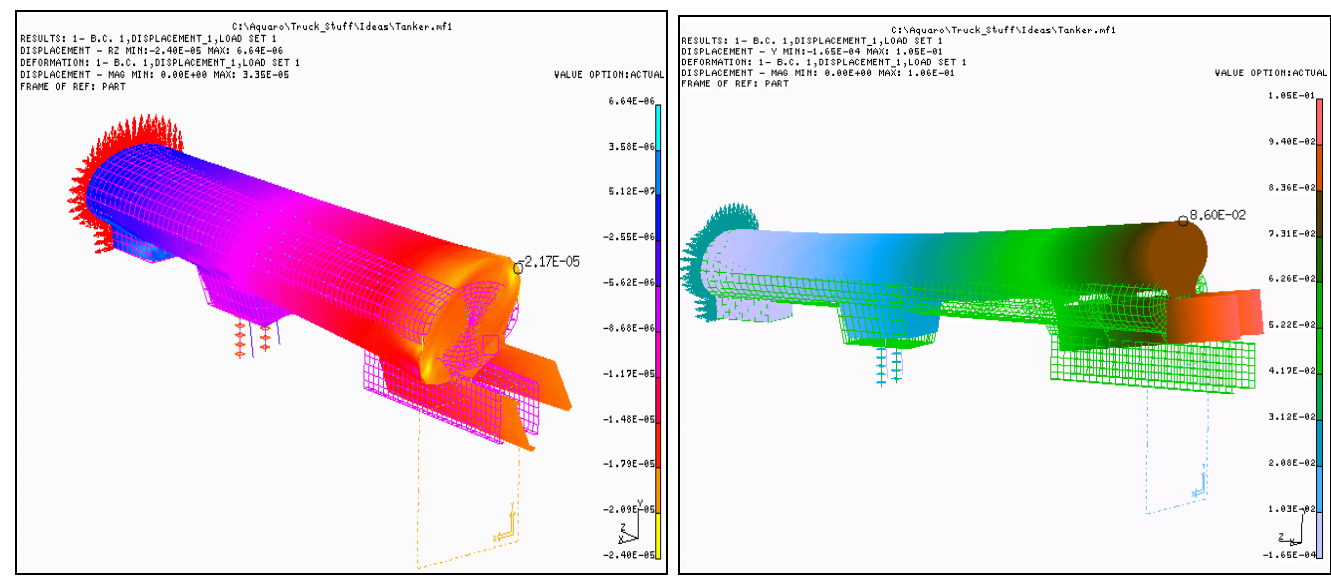

Figure 14. IDEAS model torsional (left) and bending (right) solutions. 

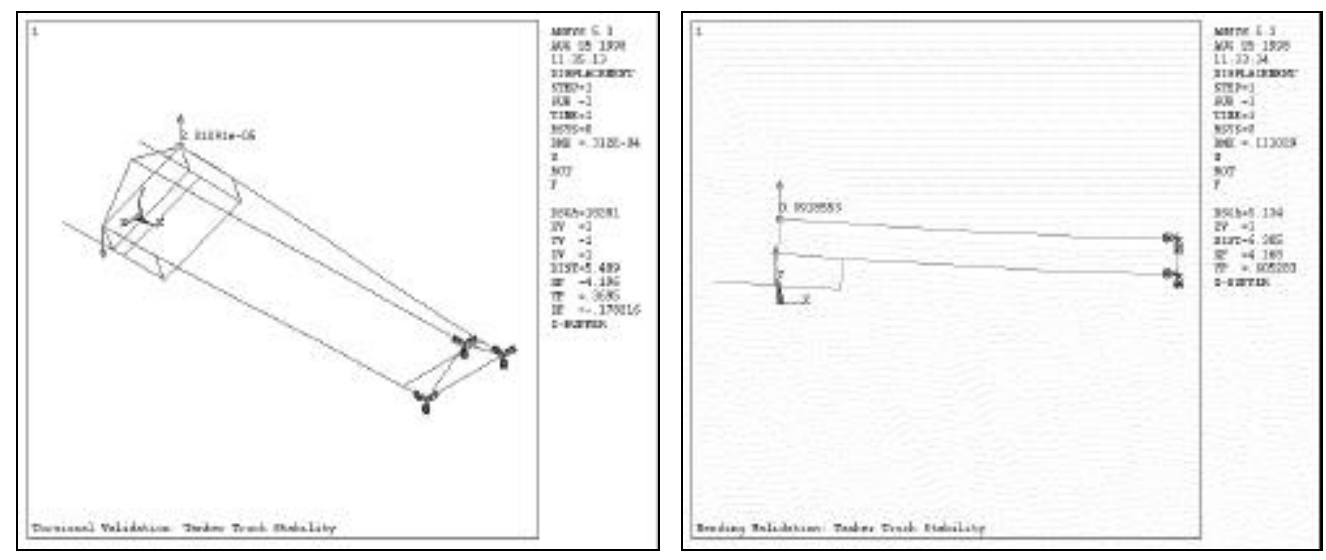

Figure 15. ANSYS beam model torsional (left) and bending (right) solutions.

\section{Static Weight Distribution}

The last piece of data that was necessary to validate was the static weight distribution of the model. This ensured that the nominal reactions at the wheels correlated with the actual truck. This step is crucial in the final product because if the nominal wheel reactions are too light then the model will show rollover prematurely, too heavy, and the model will predict rollover too late.

The mass of the tank was calculated to be $6818 \mathrm{~kg}$ [13]. In order to be able to vary the position of the CG of the tank as well as have a distributed mass, $80 \%$ of the mass was distributed through the beams of the tank. The remaining $20 \%$ was fixed to a point which could be moved to change the CG. The CG was located vertically and laterally by moving the floating mass. In order to locate the CG horizontally, the variable mass of the tank and the mass of the truck were changed using trial and error method. In order to overcome the problem of statically undetermined beams, the wheel reactions on tandem axles were lumped together. The reactions on axles four/five and two/three were summed, transforming our five axle vehicle into an equivalent three axle vehicle. Before the summation, the solution for static weight distribution showed one axle of a set $30 \%$ 
heavy, while the other axle was $30 \%$ light. By summing, the reactions all axles were within $10 \%$ error from the actual wheel reactions measured by ATC [13]. Table 5 below summarizes the static loads on the wheels.

\begin{tabular}{|c|c|c|c|}
\hline Axle \# & Model Truck & Actual Truck & Error \\
\hline \# 1 RIGHT & 31497 & 31735 & $-0.75 \%$ \\
\hline \#1 LEFT & 31406 & 30852 & $1.80 \%$ \\
\hline \#2 RIGHT & 10758 & 19375 & \\
\hline \#2 LEFT & 10772 & 20209 & \\
\hline \#3 RIGHT & 25704 & 19816 & \\
\hline \#3 LEFT & 26119 & 18884 & \\
\hline \#2+3 RIGHT & 36462 & 39191 & $-6.96 \%$ \\
\hline \#2+3 LEFT & 36891 & 39093 & $-5.63 \%$ \\
\hline \#4 RIGHT & 11717 & 9467 & \\
\hline \#4 LEFT & 11981 & 10791 & \\
\hline \#5 RIGHT & 12209 & 13145 & \\
\hline \#5 LEFT & 12734 & 11870 & \\
\hline \#4+5 RIGHT & 23926 & 22612 & $5.81 \%$ \\
\hline \#4+5 LEFT & 24715 & 22661 & $9.06 \%$ \\
\hline \multicolumn{2}{c}{} & & \\
\hline TOTAL & 306891 & 309701 & $-0.91 \%$ \\
\hline
\end{tabular}

Table 5. Static weight distribution for empty truck. 


\section{CHAPTER 4}

\section{Dynamic Response}

\section{Constant Radius}

The full truck model was run through various dynamic maneuvers once it had been validated. The first step was to determine the rollover threshold in a constant radius turn. It was assumed that the truck approaches the turn from a steady state straight line maneuver. Figure 16 shows the articulation angle $(\alpha)$ determined geometrically for a given radius turn. It was assumed that the tires had negligible slip, and therefore, that the articulation angle remained constant, regardless of the velocity of the turn.

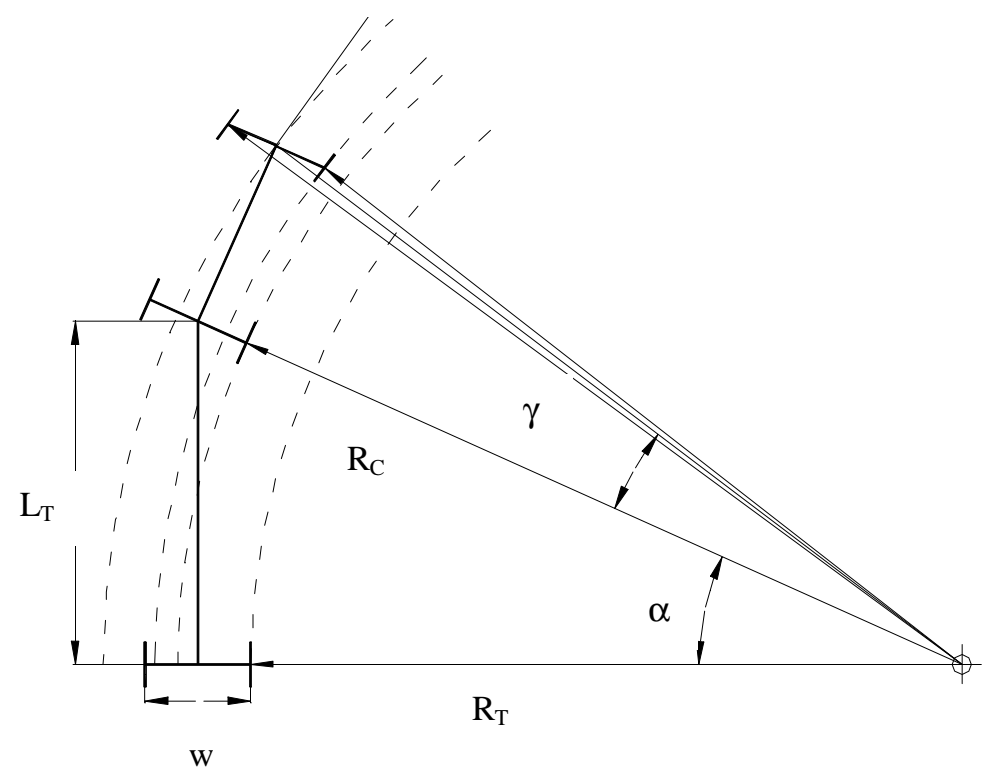

Figure 16. Radius of turn and articulation angle.

Where:

and

$$
\begin{gathered}
\tan \alpha=\frac{L_{T}}{R_{T}+w / 2} \\
R_{C}+w / 2=\sqrt{L_{T}^{2}+\left(R_{T}+w / 2\right)^{2}}
\end{gathered}
$$

The lateral acceleration corresponding to a 30.48 meter (100 foot) radius turn was calculated using equation 1. Before the pendulums were included, the truck model was 
validated using the information in Rakheja's paper [5] and Table 1. The CG was varied to match the CG locations in Table 1. Table 6 shows a comparison of the results from the tanker truck model and Rakheja's work. Although the results indicate that the model is more stable by an average of $12.4 \%$, the model was not modified to fit the data. It is important for this study to determine the feasibility of modeling a truck from statically measurable information and have an accurate model. For this sake, the model will be run through all of the simulations without alteration.

\begin{tabular}{|c|c|c|c|}
\hline $\begin{array}{c}\text { Center of Gravity } \\
\text { Height (meters) }\end{array}$ & $\begin{array}{c}\text { Rollover Acceleration from } \\
\text { ANSYS Model }\left(\mathrm{m} / \mathrm{sec}^{2}\right)\end{array}$ & $\begin{array}{c}\text { Rollover Acceleration from } \\
\text { Rakheja's Model }\end{array}$ & \%Error \\
\hline 1.52 & 5.4 & 4.9 & 10.2 \\
\hline 1.78 & 4.5 & 4.0 & 12.5 \\
\hline 2.03 & 3.9 & 3.4 & 14.7 \\
\hline
\end{tabular}

Table 6. Comparison of rollover accelerations between work done by Rakheja [5] and ANSYS models.

Next, pendulums were included in the solution. A critical velocity plot was made to determine the critical rollover velocity for different levels of fill. Level of fill was varied to $50 \%, 75 \%$ and $100 \%$. The minimum wheel reaction from each solution was recorded. The results are plotted in Figure 17.

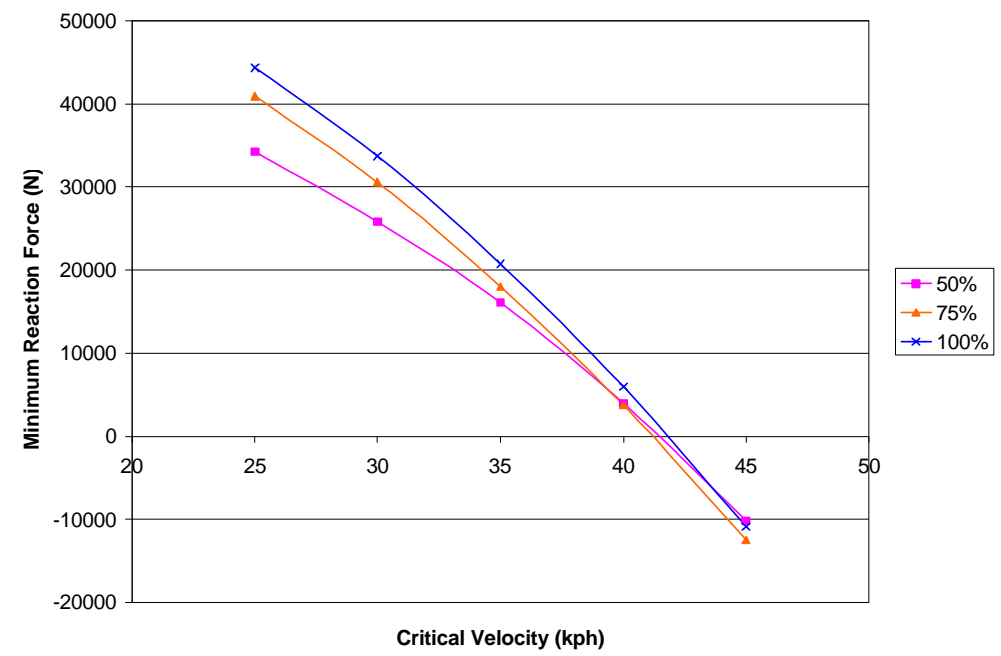

Figure 17. Critical Velocity of the tanker truck model in a 30.48 meter constant radius maneuver. 


\section{ATC Double Lane Change}

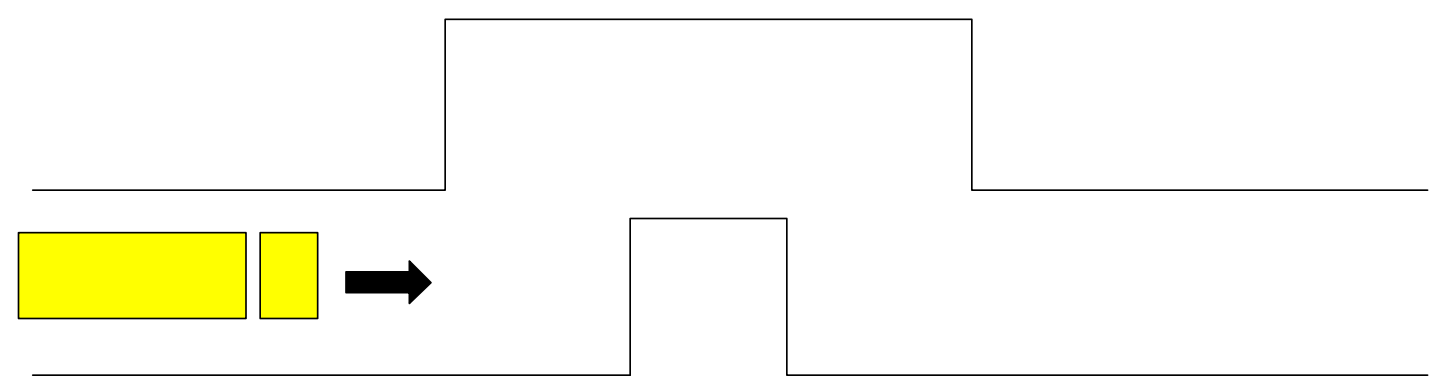

Figure 18. Double lane change maneuver.

The next step in the validation of the truck model was to determine the correlation in a double lane change maneuver (Figure 18) with results from the experimental test provided by ATC which was run using a 50\% full truck. The data was processed and three critical parameters were determined and used as the inputs for the truck model [12]. These parameters are the lateral acceleration normal to the trailer longitudinal axis $(A)$, the yaw acceleration on the trailer $(\beta)$ and the articulation angle $(\alpha)$, all shown in Figure 19. The data was processed and written into the appropriate form for use in ANSYS by a Fortran program available in Appendix B.

ANSYS read the data in terms of global accelerations for both the tangential and the yaw acceleration and rotation of the fifth wheel. The data was broken up into 833 time steps to give a smooth curve for the inputs. The model was solved in the transient dynamic mode.

The data was postprocessed to determine the reactions at the wheels. A filtering routine needed to be run on the data because of numerical noise from the direct solution. The filtering program was written in Matlab and is also included in Appendix B. Once the data was filtered, it was compared to the wheel reactions found from ATC's experimental tests. There was a strong correlation between the experimental data and the 


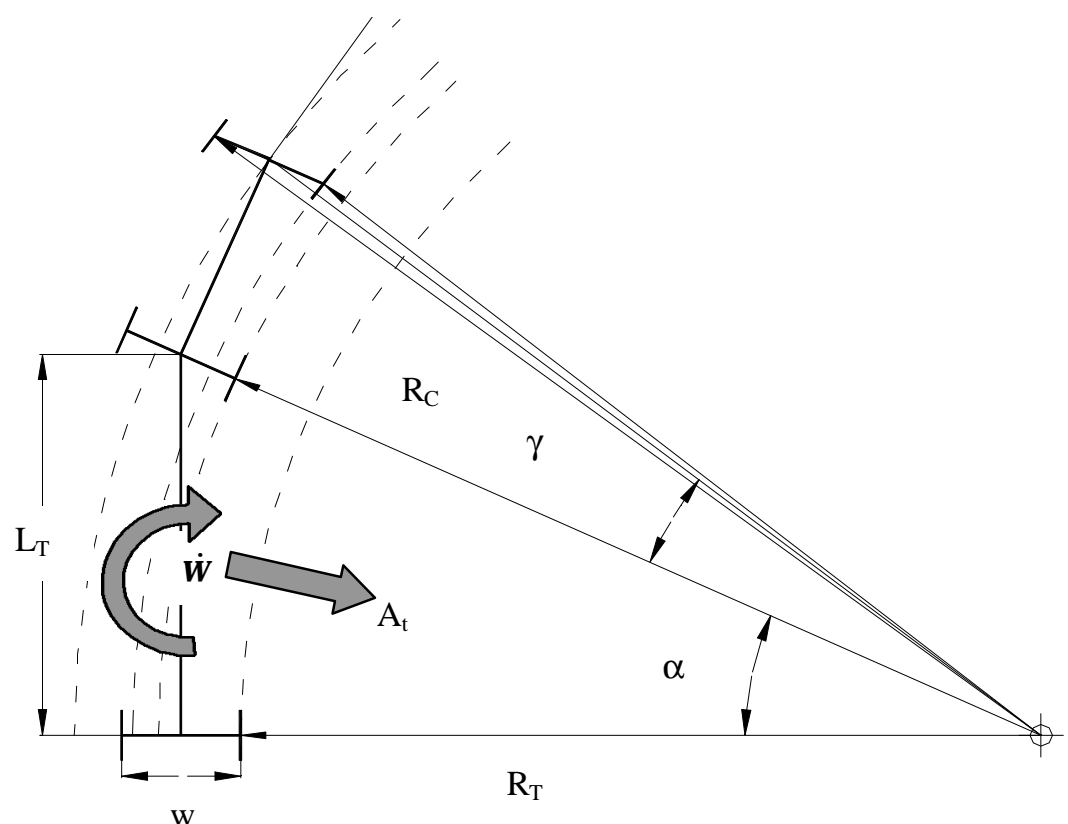

Figure 19. Parameters input into the tanker truck model to determine the dynamic response for a double lane change.

truck model solutions. Figure 20 superimposes the experimental and model results for axles four and five summed. According to the literature, the rearmost axle set is nearly always the axle that initiates rollover. This fact is backed up by the truck model, which shows liftoff in the rearmost set of axles first. Figures 21 and 22 are plots for axles two and three combined and axle one. The plots superimpose the experimental and the model data onto one another so that the correlations can be best seen. As the plots indicate, the model predicted the trends of rollover nearly exactly with a discrepancy only in the amplitude of the weight shift. The crossover points from side to side nearly coincide. The truck model indicates rollover in a premature point in the maneuver. According to the experimental data, rollover occurred at about 5.06 seconds. The truck model, however, shows rollover at 3.4 seconds, and again at 5 seconds. Had the static weight distribution been better controlled, the model would have predicted the point of rollover nearly precisely by raising the premature dip above zero. 
It is worth mentioning at this point that the experimental results do not mirror each other from side to side. When the reactions on one side of and axle go into the negative region, the reactions on the other side do not go equally high into the positive region. The outriggers absorbing the load on the wheels when the vehicle rolled over can explain this. It is important to have these outriggers in place because without them, there would be no way to tell if rollover had begun without endangering the life of the test driver.

After carefully reviewing the data, several points of interest manifested themselves. The rollover track was assumed to be equal to the outside track of each wheel set. In actuality, as the tires deform under the lateral and compressive loads, they roll about a point inside from the outside of the tire. This point is not known, and could

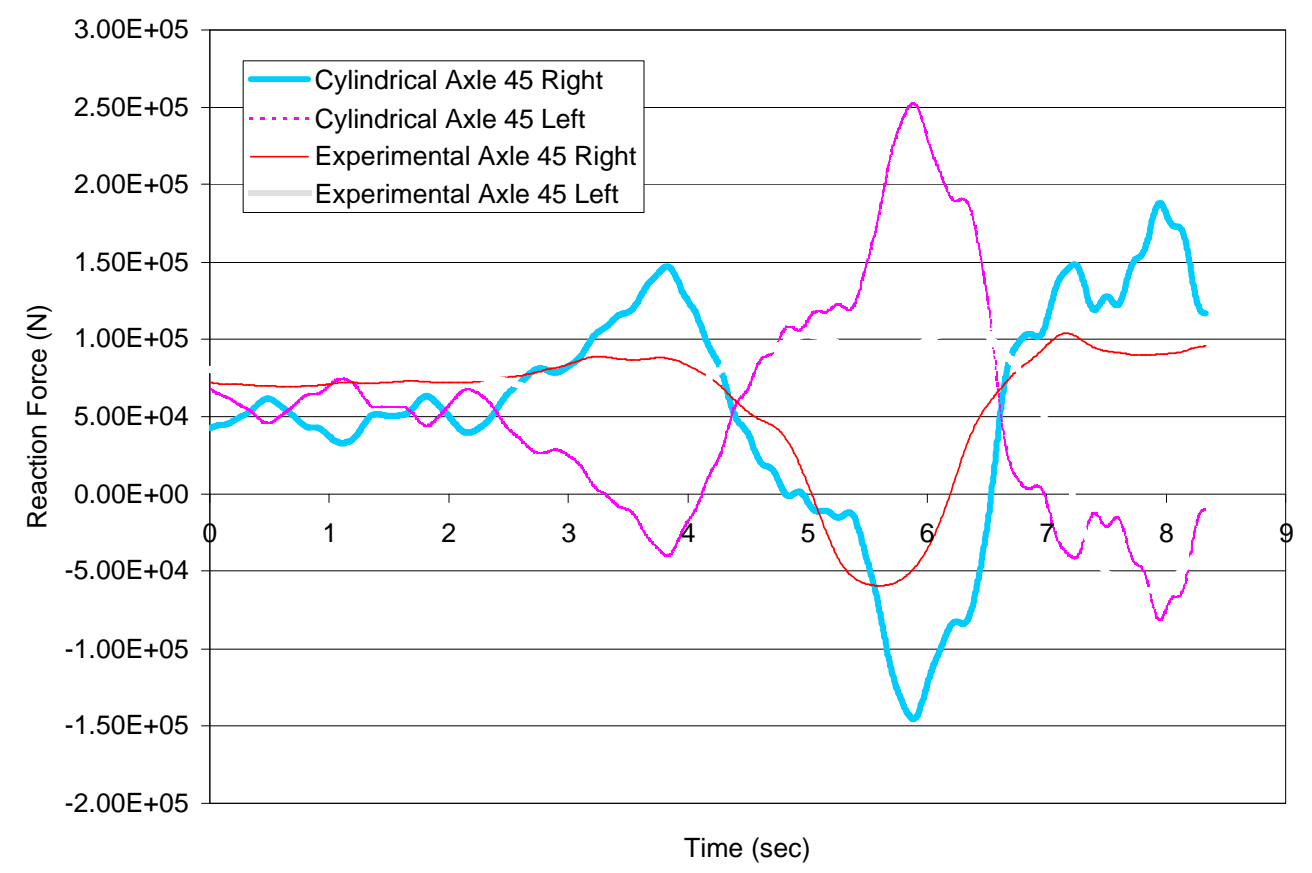

Figure 20. Comparison of the experimental and model wheel reactions from axle 45 combination in ATC double lane change. 


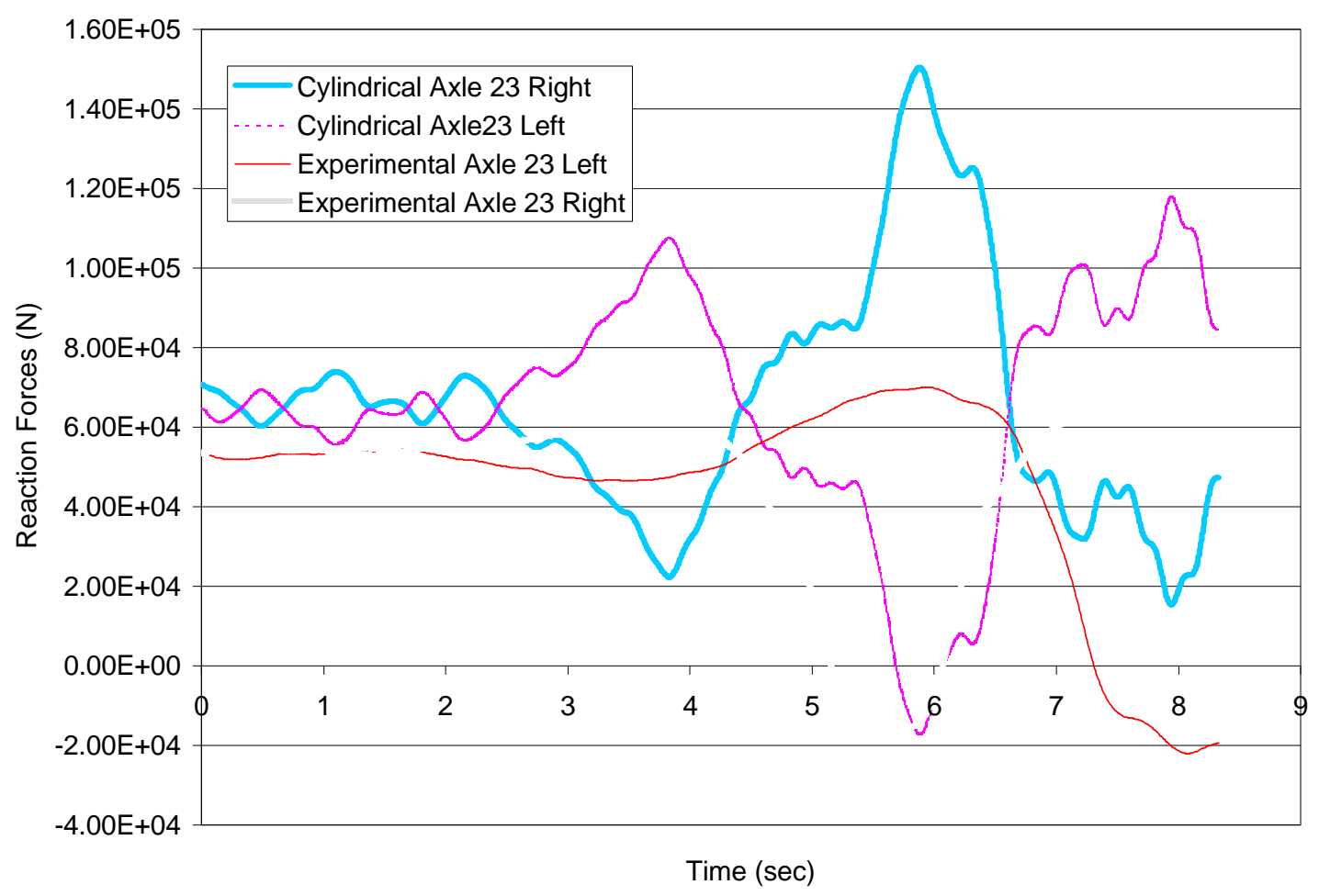

Figure 21. Comparison of the experimental and model wheel reactions from axle 23 combination in ATC double lane change.

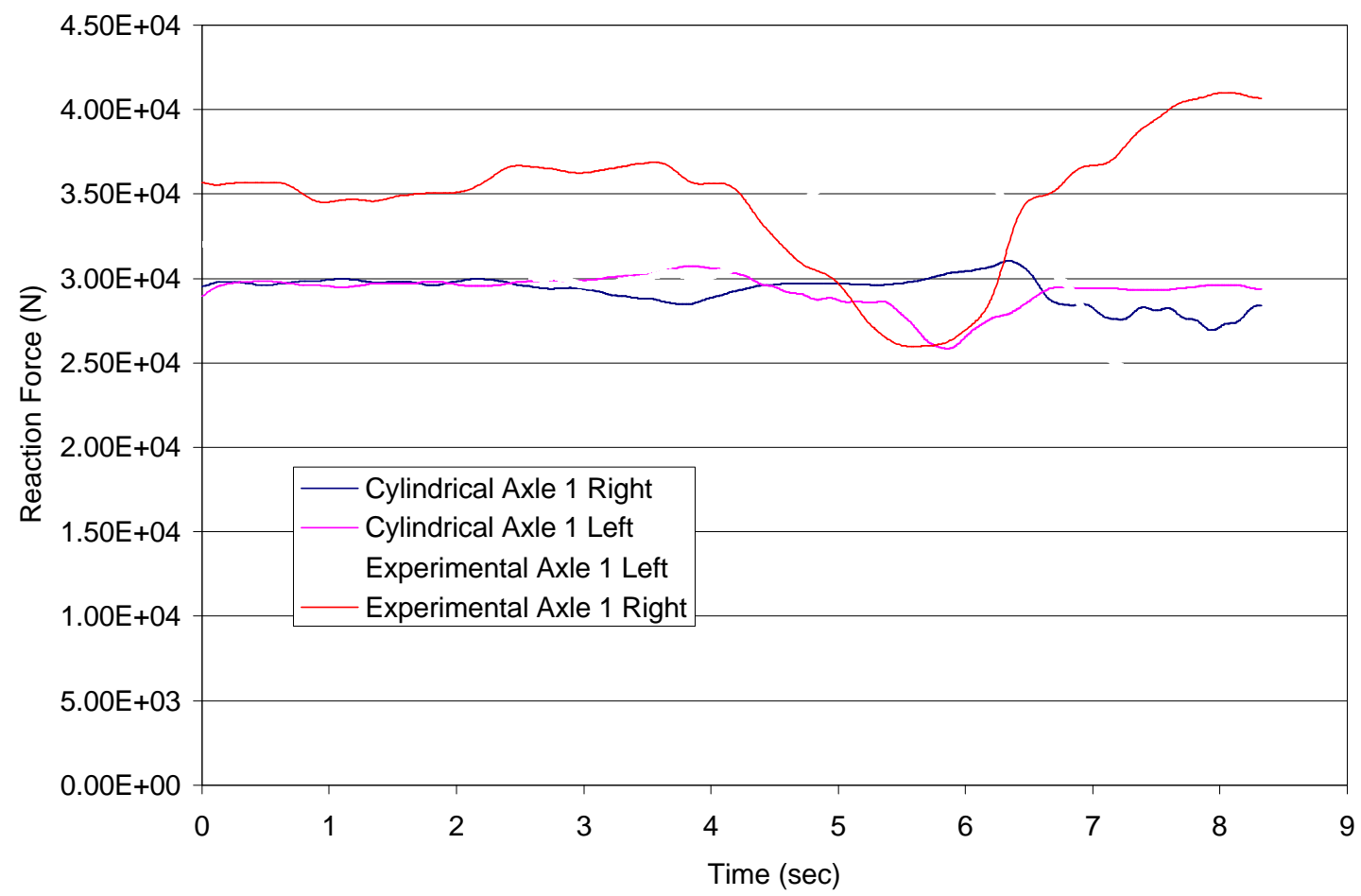

Figure 22. Comparison of the experimental and model wheel reactions from axle 1 in ATC double lane change. 
constitute a study in and of itself, so an assumption was made. The rollover point was now assumed to occur about the center of the outermost wheel in a wheel set. This narrowed the track width of the truck slightly.

The next question comes in regards to suspension properties. For the trailer suspension, the spring compression curve was provided by the manufacturer. This information, however, is not enough to produce the actual force deflection curve. In a dynamic test, the spring has different loading and unloading curves [17]. For the tractor suspension, no performance curves were available, so the theoretically calculated stiffnesses were used. Also, the spring lash was neglected. If more detailed information were available with regards to the true suspension characteristics, the suspension parameters could be corrected, but at this time, the assumptions must stand.

Lastly, the inclination angle (Figure 23) of the tank may have a significant affect on the amount of fluid sloshing from the front to the rear compartments of the tank. The inclination angle for the tank was calculated from the data received from ATC [18]. ATC provided the level of fill of the fluid at the front and rear compartments of the tank. This data gave an inclination angle of 0.73 degrees. The new pendulums parameters were calculated for each compartment in the tank and the model was updated.

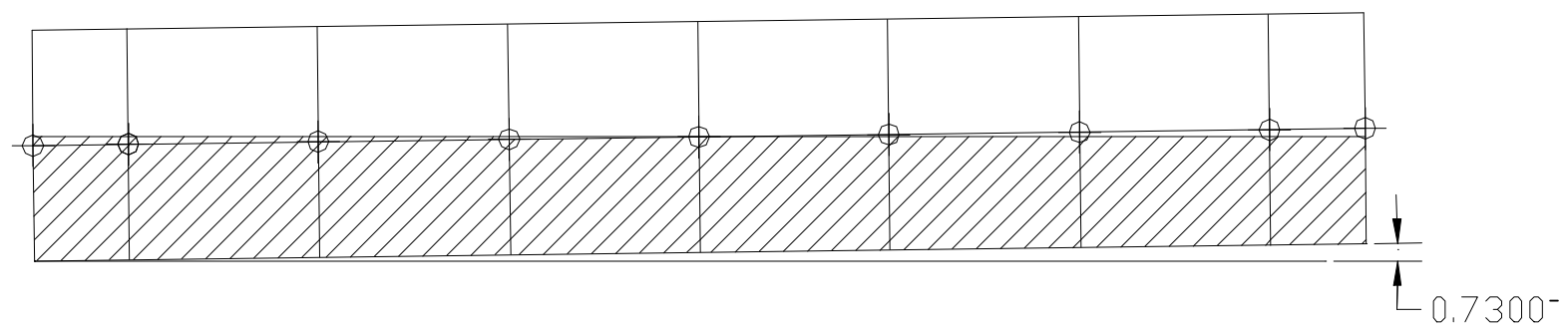

Figure 23. Inclination angle for a 50\% full tank.

The track was narrowed by .127 meters on each side of the vehicle. This corrected the rollover track, making it fall at the middle of the outside tire, instead of the 
outside of the outside tire. The pendulums were also changed to account for the inclination angle. With these changes, the model was solved and postprocessed for reaction forces again. Figure 24 shows the new reaction forces for axles four and five combined, compared with the experimental data. Figures 25 and 26 show the wheel reactions for axles two and three combined and axle one.

These figures show a modest improvement in the trend of rollover, but not a significant improvement. More detailed modeling of the suspension and tire properties could lead to more significant improvements in the accuracy of the model.

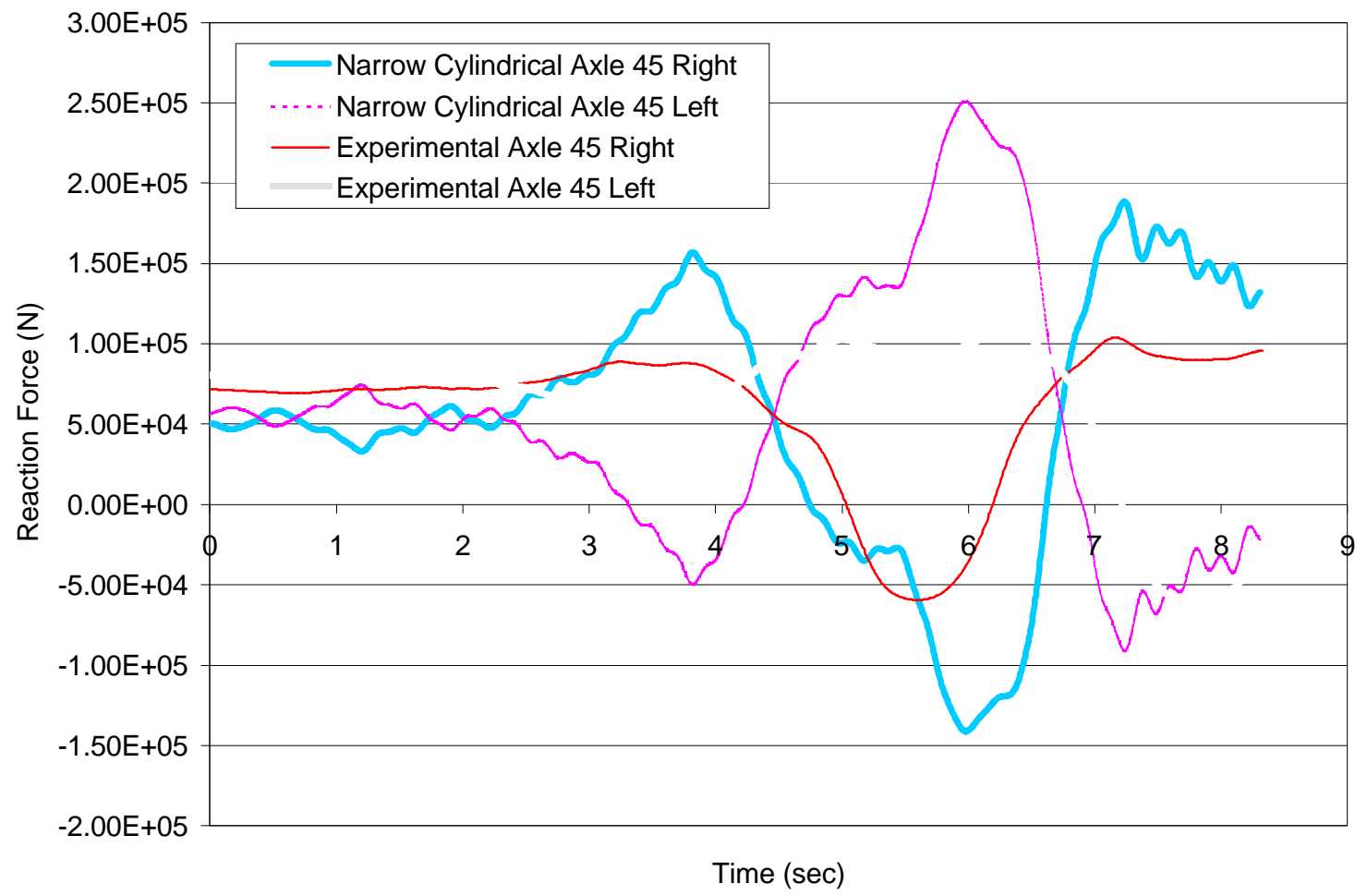

Figure 24. Comparison of the experimental and narrow inclined model load shift from axles 4 and 5 combined in ATC double lane change. 


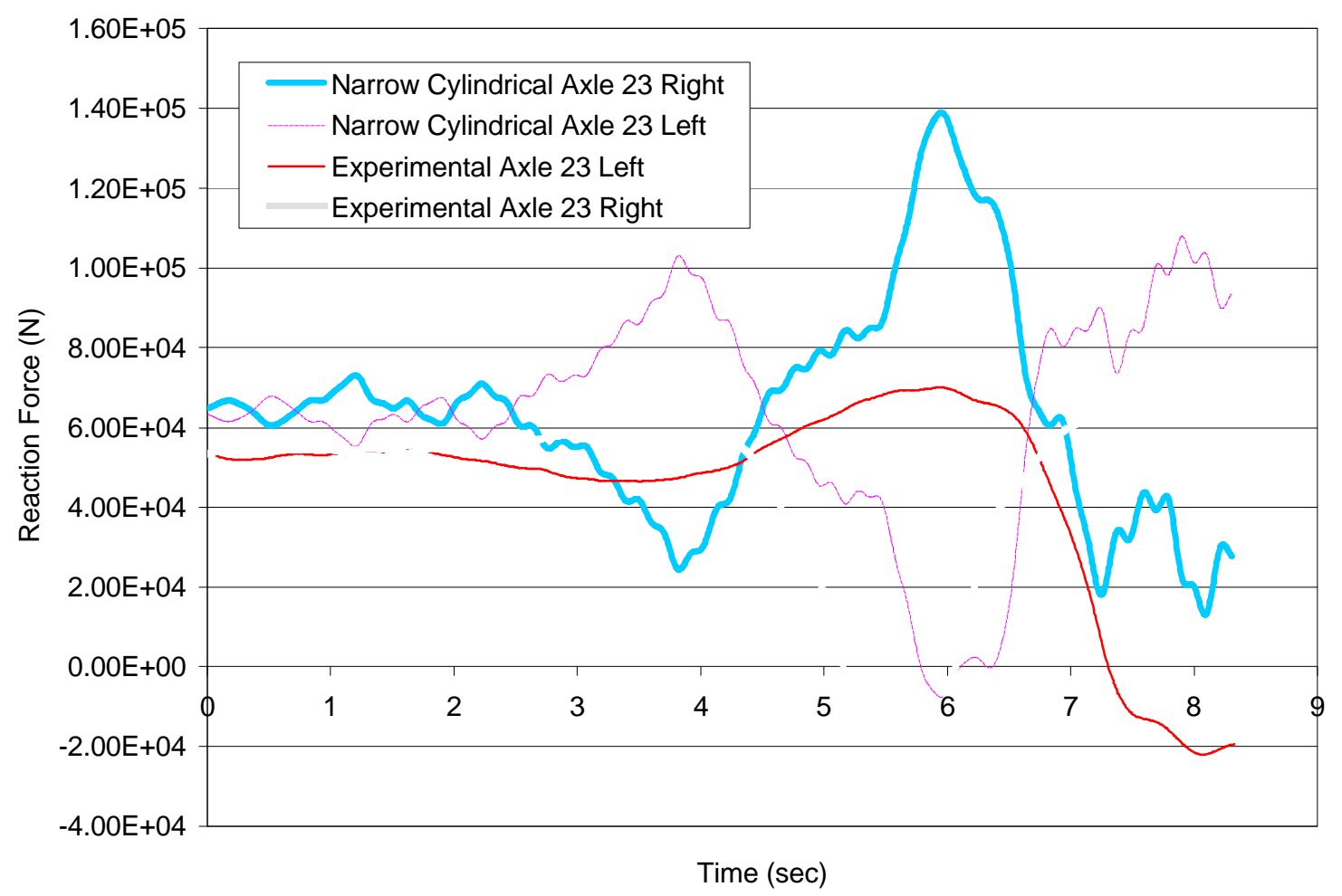

Figure 25. Comparison of the experimental and narrow inclined model load shift from axles 2 and 3 combined in ATC double lane change.

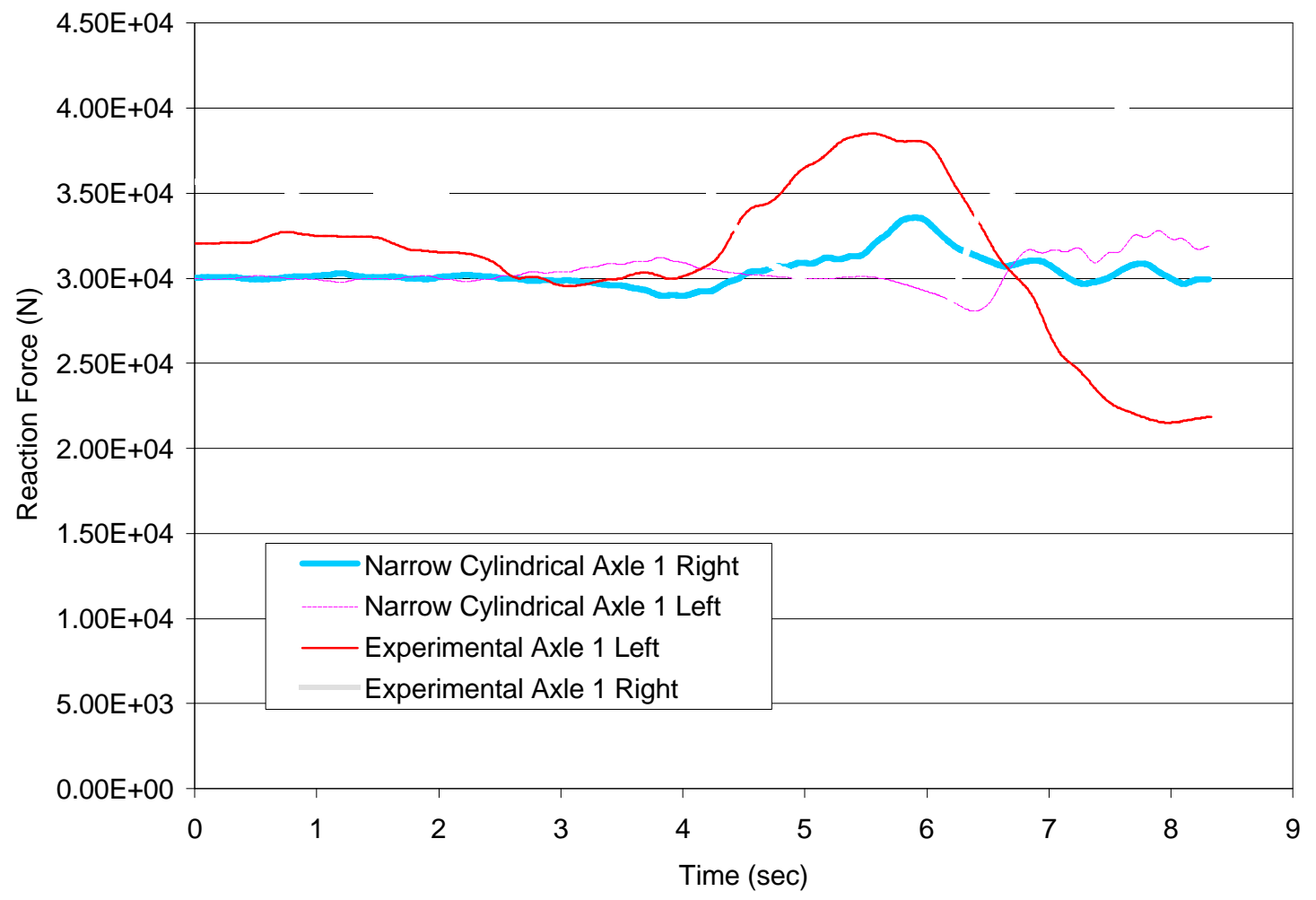

Figure 26. Comparison of the experimental and narrow inclined model load shift from axle 1 combined in ATC double lane change. 


\section{Cycloidal Lane Change Maneuver}

A more repeatable means of performing a double lane change test was sought out. The data collected by ATC in the experimental test was the best source of lane change information available because it is taken from a driver on a real course, but for future work, this experiment can't be repeated. In fact, the model is of little use if it relies on experimental tests for each new simulation. The question was asked, "How are we able to determine the accelerations and articulation angle of some generic lane change?" Ideally, a method could be developed which uses different velocities to determine the threshold of rollover stability, and as before, the critical velocity for each maneuver could be calculated.
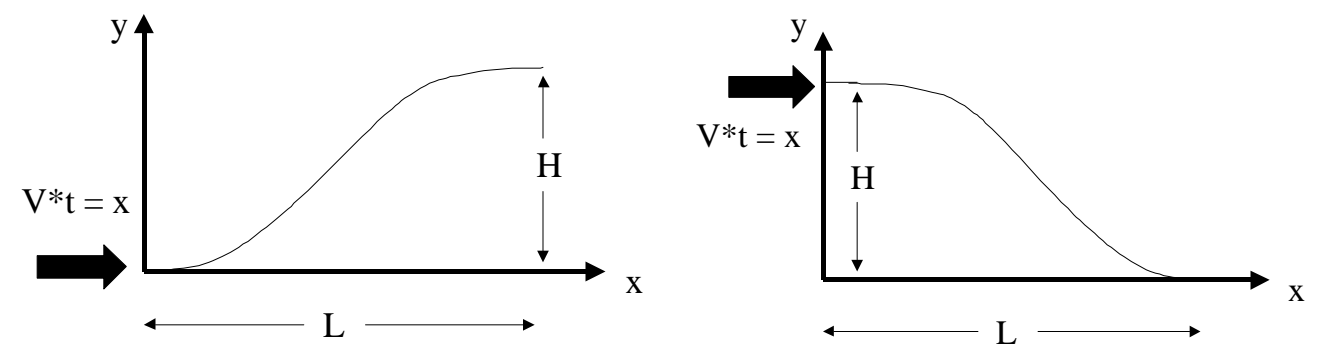

$$
\begin{aligned}
& y(x)=\frac{H x}{L}-\frac{H}{2 \pi} \sin \left(2 \pi \frac{x}{L}\right) \\
& y^{\prime}(x)=\theta=\frac{H}{L}-\frac{H}{2 \pi} \cos \left(2 \pi \frac{x}{L}\right) \\
& y^{\prime \prime}(x)=A(t)=\left(\frac{V}{L}\right)^{2} 2 \pi H \sin \left(\frac{2 \pi V t}{L}\right) \\
& \theta^{\prime \prime}(t)=\alpha(t)=\left(\frac{V \pi}{L}\right)^{2}\left(\frac{4 H}{L}\right) \cos \left(\frac{2 \pi V t}{L}\right)
\end{aligned}
$$

$$
y(x)=H\left(1-\frac{x}{L}-\frac{1}{2 \pi} \sin \left(2 \pi \frac{x}{L}\right)\right)
$$$$
y^{\prime}(x)=\theta=-\frac{H}{L}+\frac{H}{L} \cos \left(2 \pi \frac{x}{L}\right)
$$

$$
y^{\prime \prime}(t)=A(t)=-\left(\frac{V}{L}\right)^{2} 2 \pi H \sin \left(\frac{2 \pi V t}{L}\right)
$$

A cycloidal curve was used to derive the accelerations for the double lane change where the maneuver length, lane width, and vehicle speed are the three inputs, and the 
accelerations and articulation angle are the main outputs. The equations for these parameters are given in Equations 6 through 13. After applying the cycloidal load curve corresponding to a maneuver with a gate length of $100 \mathrm{~m}$, width of five meters and varying tank fill levels, the critical velocity curve was made. The critical velocity curves are presented in Figure 27.

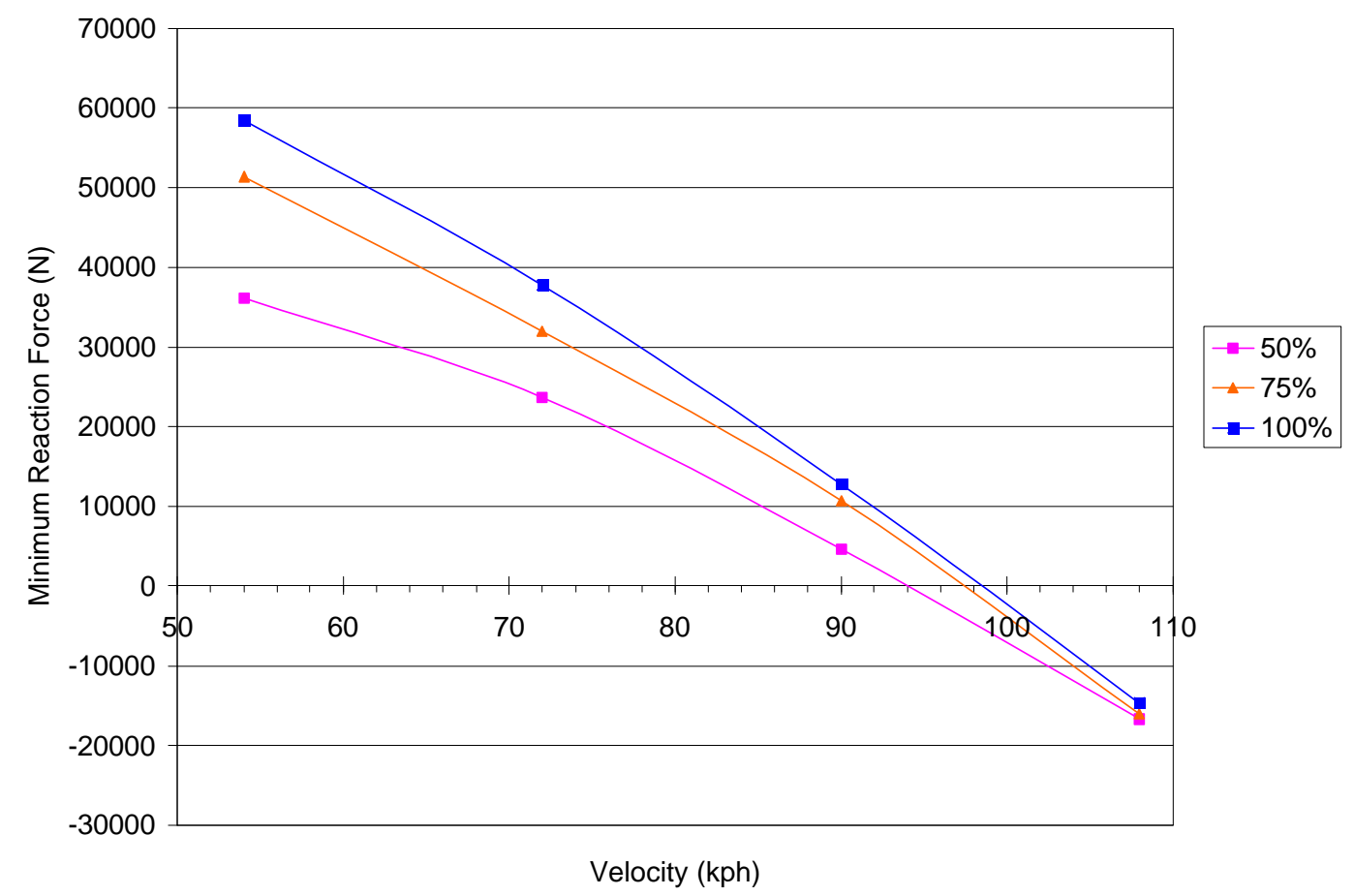

Figure 27. Critical velocity curves for a cycloidal double lane change with a gate length of 100 meters and gate width of 5 meters.

Another interesting case can be found by assuming a cycloid that matches the gate spacing that the ATC test data was run to. Although there are an infinite number of possible maneuvers through a specific gate, if a cycloid is assumed and the load curve is applied, the rollover thresholds can be found with the truck model. Hopefully, the truck model will indicate rollover in the cycloid, giving confidence that the cycloid is a good approximation in the absence of experimental data. Figures 28 through 30 show the 
reactions of axles one, 2 and 3 combined and 4 and 5 combined for the tanker truck model run through a gate corresponding to the ATC test maneuver. The dimensions of the cycloid are: length, 42.6 meters; width, 3.10 meters and a velocity of 56 kilometers per hour.

As can be determined from the graphs, the model correctly indicates rollover at the last axle during the maneuver. This demonstrates another way that this method and this model can be used as a tool in determining the threshold of rollover stability of a tanker truck.

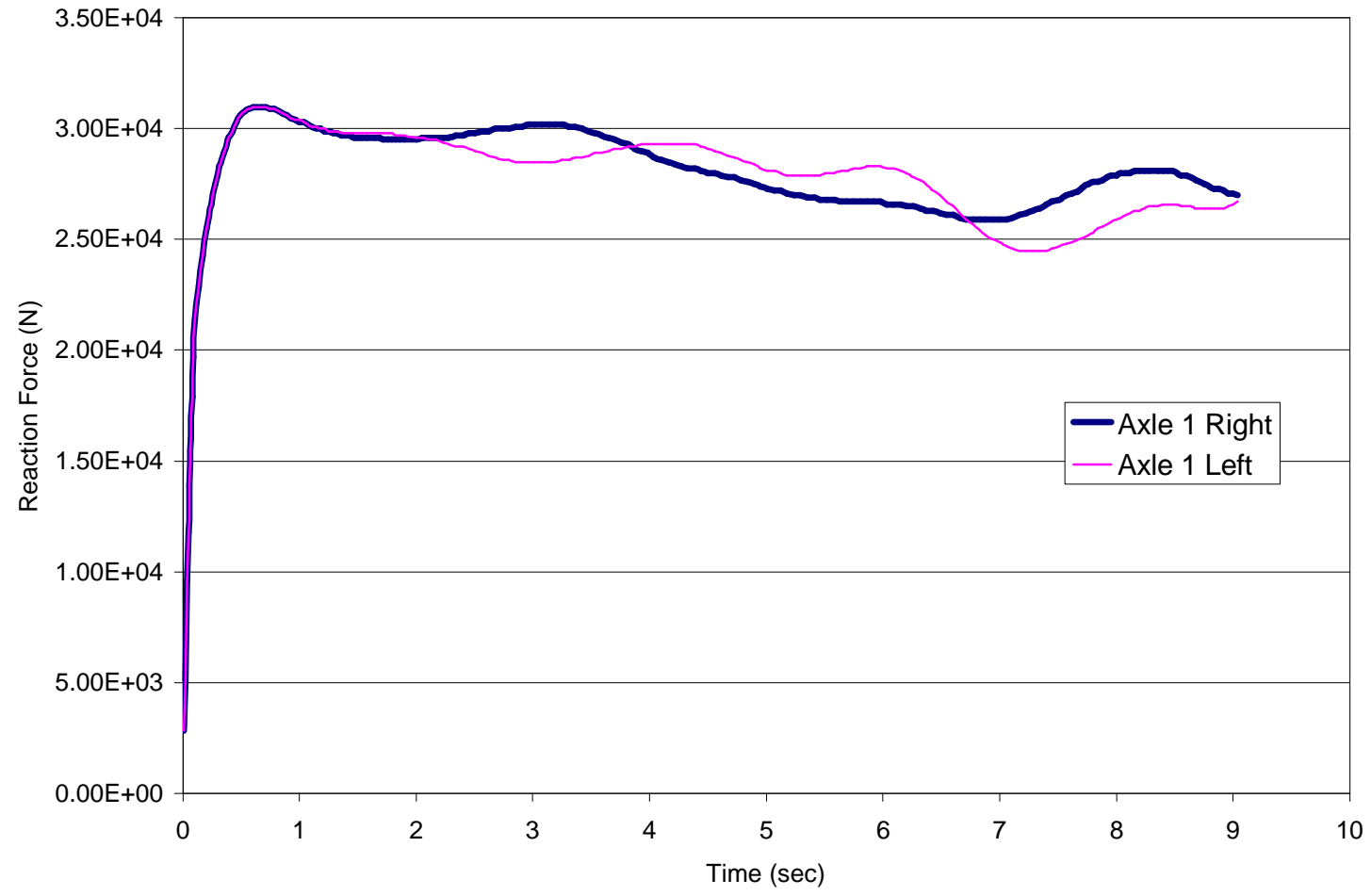

Figure 28. Axle 1 reaction forces for cycloidal maneuver corresponding to ATC gate length and width specifications. 


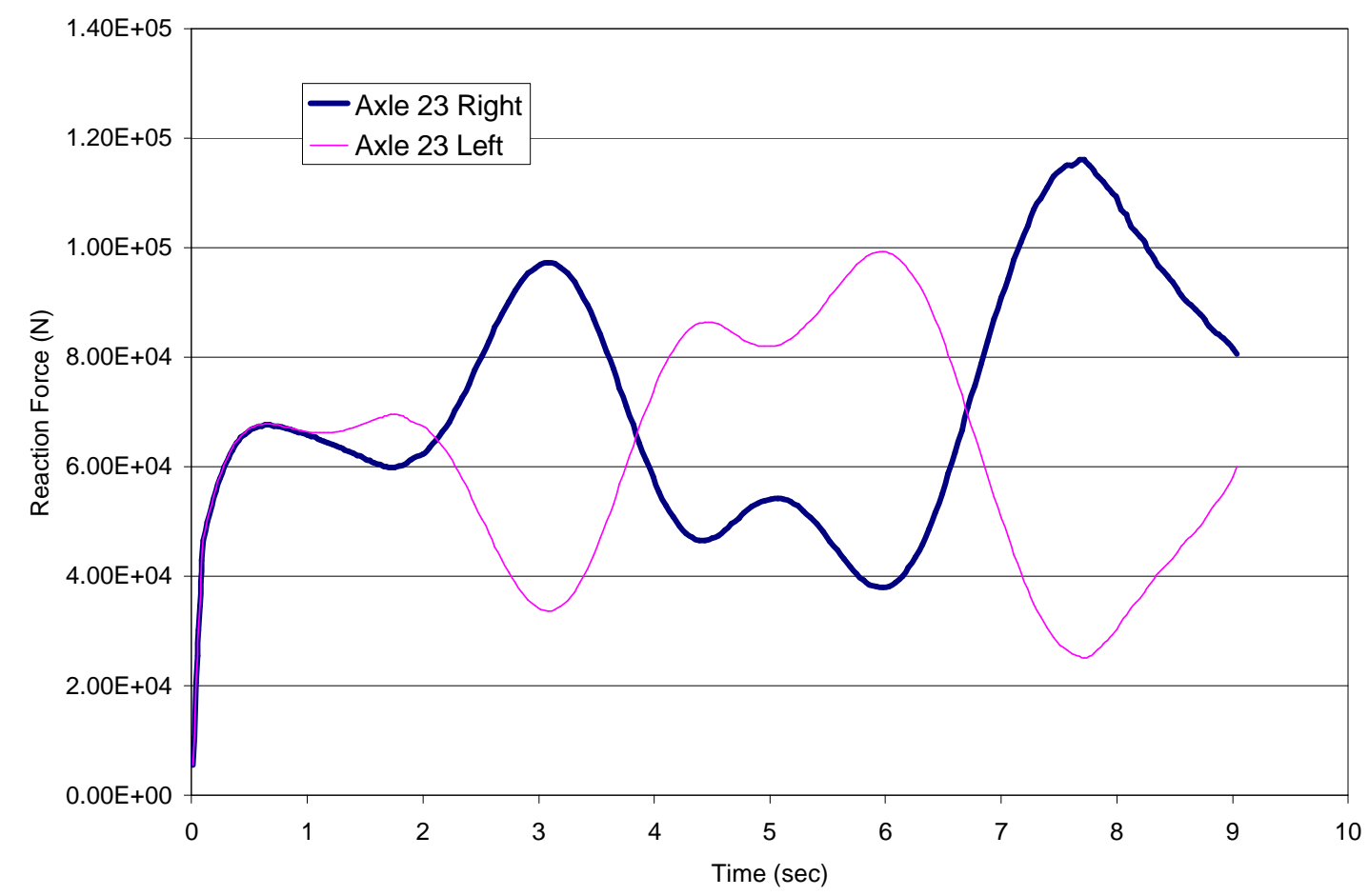

Figure 29. Axles 2 and 3 combined reaction forces for cycloidal maneuver corresponding to ATC gate length and width specifications.

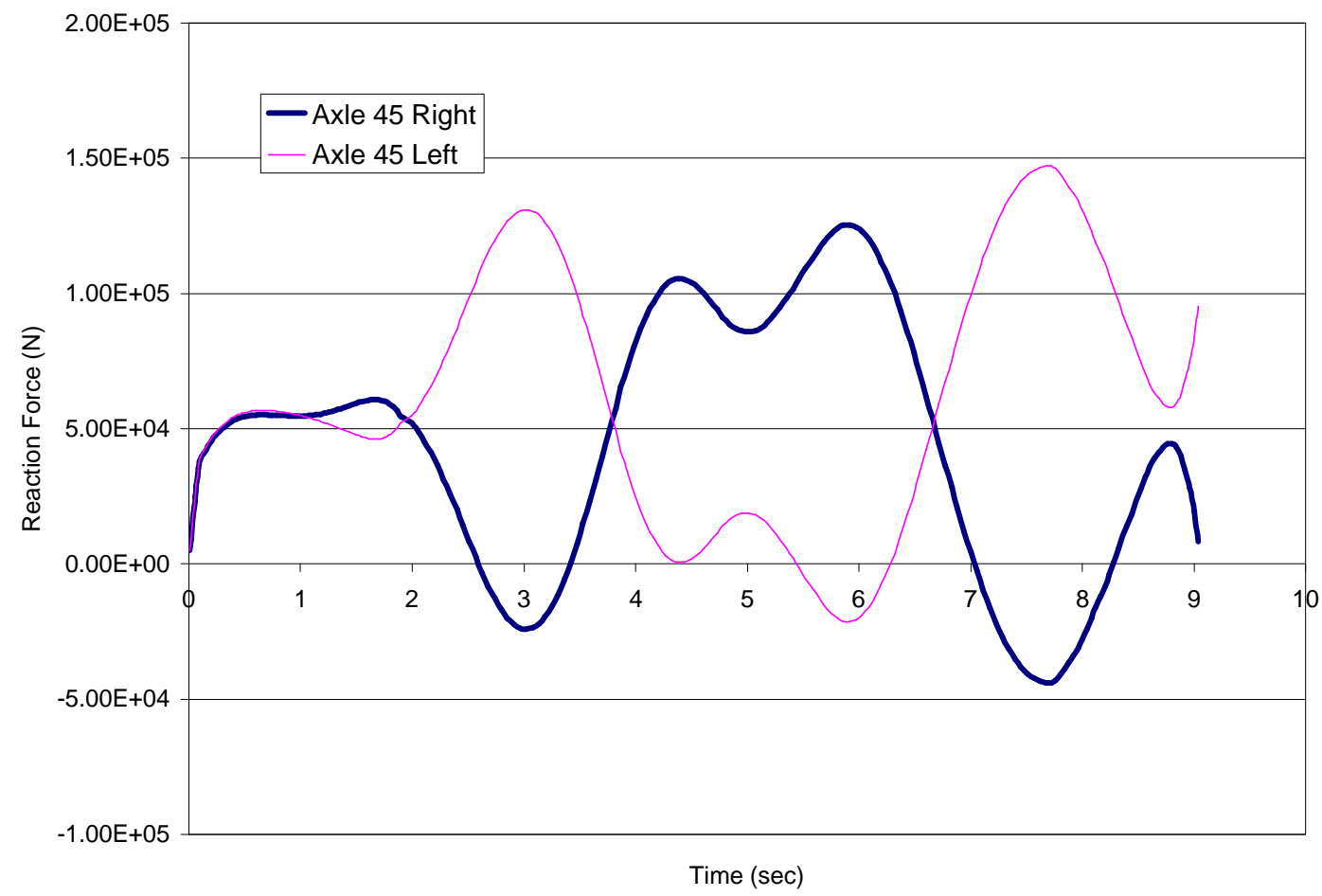

Figure 30. Axles 4 and 5 combined reaction forces for cycloidal maneuver corresponding to ATC gate length and width specifications. 


\section{CHAPTER 5}

\section{Discussion of Results and Conclusions}

\section{Discussion of Results}

The results from the tanker truck dynamic response tests indicate that the model is effective in its ability to predict rollover. The truck model shows strong correlation with the experimental data provided. The following section analyzes the errors found in each maneuver and gives possible explanations for all sources of error.

\section{Constant Radius Turn}

The experimental testing concluded that rollover occurred at approximately 38 $\mathrm{kph}$ for all fill levels tested [19]. The simulation yielded a rollover velocity of approximately $43 \mathrm{kph}$ for the $100 \%$ full case, giving a maximum error of $13 \%$. The error was reduced for the other fill levels. At $75 \%$ and $50 \%$ the error was approximately 10.5\%. This correlates with the experimental data in its consistency. In this particular case, level of fill had only a minor roll in the threshold of rollover stability.

One possible reason for this is that the $\mathrm{CG}$ of the tank was 1.7 meters above the ground when the vehicle is $100 \%$ full. This extremely high CG is not affected by the fluid slosh as heavily as a more inherently stable truck would be. The rollover problem with this truck goes beyond fluid slosh causing an offset payload. There are design flaws associated with this tractor trailer combination adding to its instability. This conclusion is supported by ATC in their report on the experimental stability analysis of the tanker truck. 


\section{ATC Double Lane Change}

In the case of the ATC double lane change, an exact match of the wheel reactions was not expected. What was important, though, was the trend that lead to rollover and the verification that the pendulum analogy was correct and could be used to simulate fluid slosh in a finite element model. In all of these areas, the model was successful. By reviewing Figures 24 through 26, it is evident that the truck model correctly predicted the trends leading toward rollover. A combination of the pendulum action, the lateral accelerations and suspension compliance shifted loads throughout the simulation at the correct times and in proportional magnitudes. Figure 31 clearly shows the pendulums swinging under the lateral accelerations acting on the truck. Please note that the pendulums are not all of the same length, due to the inclination angle of the tank. This explains why the pendulums are different lengths in the figure.

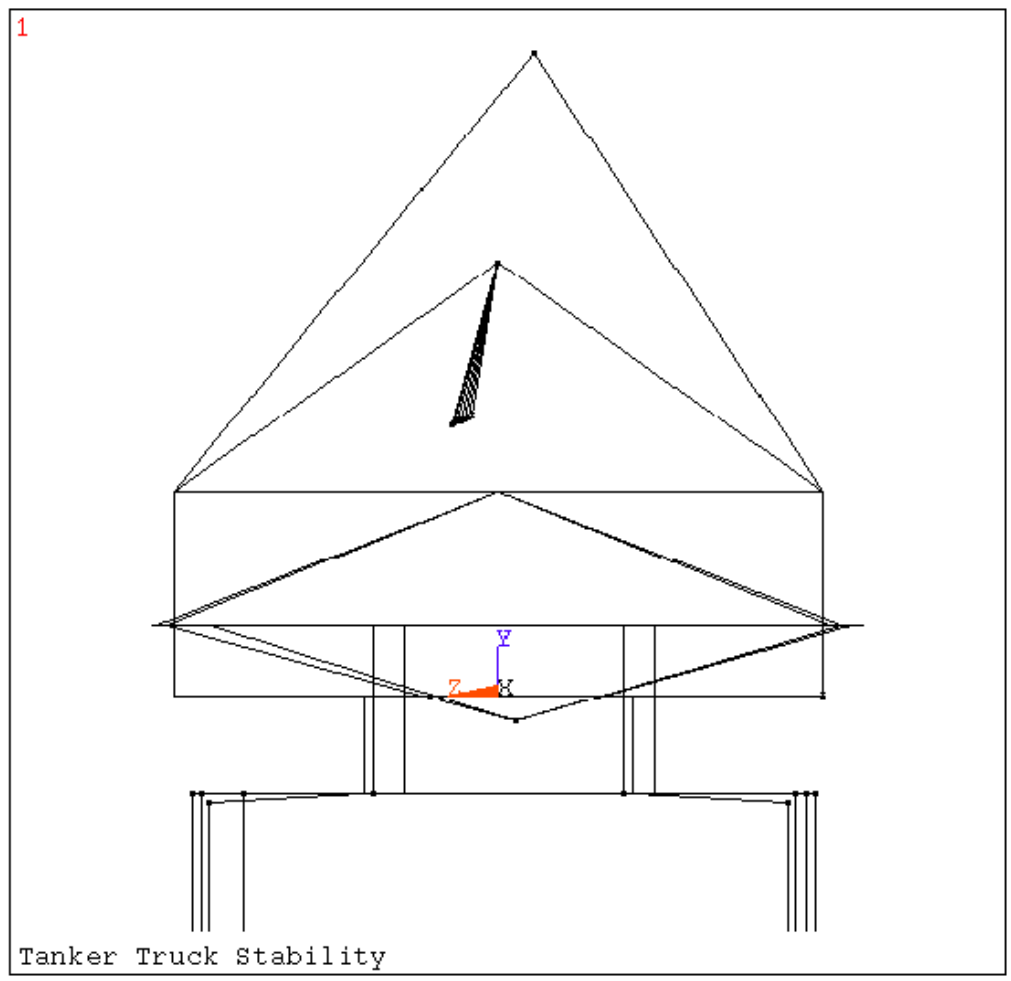

Figure 31. Pendulums swinging through maneuver. 
Although the model predicted rollover at an earlier point in the maneuver where the experimental model did not predict rollover, the model's success can not be discounted. Corrections would need to be made to correct the static weight distribution of the truck. This would involve simply, but tediously, correcting the mass distribution of the model to reduce the errors to below one or two percent, as opposed to the ten percent tolerance allowed in this exercise. Other, more significant improvements could be made in properly modeling the true suspension and tire properties. Unfortunately, measuring these properties is difficult and expensive.

\section{Conclusions}

Based on the models and analyses presented in the previous sections, the following conclusions can be drawn:

1. A finite element modeling approach can be used to predict the threshold of rollover for a compartmentalized tanker truck.

2. A generic approach for modeling the dynamics of partially filled tanker trucks in both constant radius and lane change maneuvers has been developed.

3. Using cylindrical and trammel pendulums is an effective way of replacing the sloshing fluid for stability assessment of tanker trucks.

4. A model which is easy to use, manipulate, and parameterize has been developed which solves quickly and effectively determines the rollover threshold in terms of critical velocity or critical path. 


\section{Future Work}

The modeling of the tanker truck is an area which could receive further attention. It was not the objective of this research to model a tanker truck to the highest degree of accuracy possible. The truck was modeled to a level which would give good results, yet the model was kept small in a deliberate effort to keep it simple, easy to manipulate, and quick to solve. With proper attention given in the future to modeling certain aspects of the tanker truck, most notably the suspension, the model may see a next generation of refined and more accurate successors.

One area of particular interest is the contact between the tire and the ground. In this generation of models, the tire-ground interface is modeled as a fixed joint. This is not the best way to model this interface. A contact element could be added which would allow the joint to loose contact when the wheel reactions become negative. The addition of this gap should have a significant affect on the solution results, in particular, to the amplitude of the wheel reactions as well as the tank bending and torsional stiffness.

When the wheels see a negative reaction, which is not present in real life, the opposing wheel must have a greater positive reaction, to balance the negative force. With a contact element, this negative reaction would be replaced with a zero reaction, thus reducing the reaction force on the opposite wheel. Figure 32 shows a possible example of this effect.

The elliptical trammel pendulum is another area which deserves more attention than it received in this study. The pendulum parameters need to be solved, which requires solving the Navier-Stokes equations for fluid slosh in the elliptical tank. This is an elaborate and involved solution which is pertinent to modeling an elliptical pendulum. 


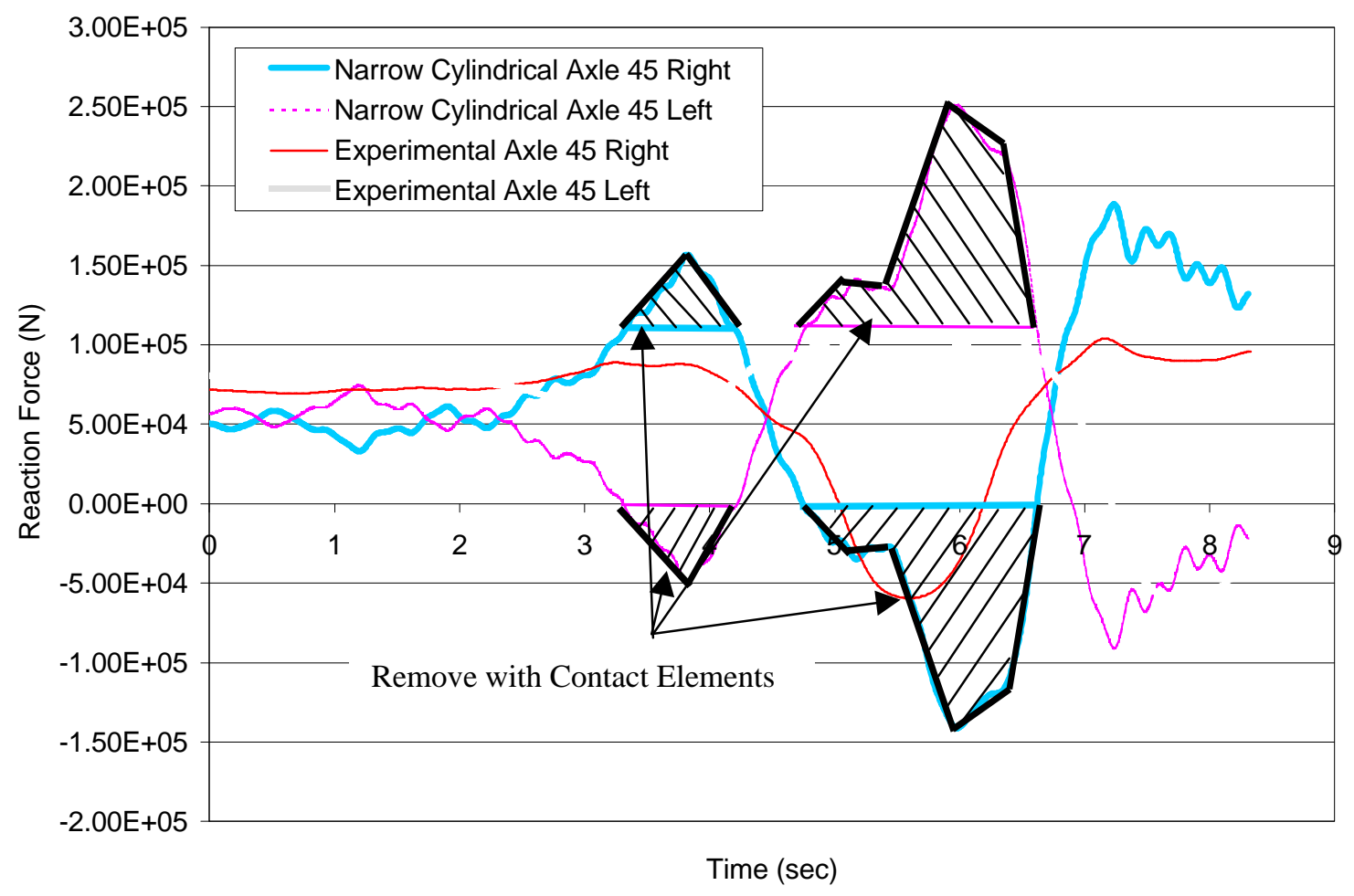

Figure 32. Possible modified wheel reactions with the addition of contact elements.

Lastly, the model needs to be tested against more experimental data. A part of what makes this study unique is the availability of experimental data for use in validating the model. As different evasive maneuvers are tested with the model and compared to experimental data, the model will become more trusted.

In the larger scope, this new method has made significant progress. Finite element methods have proven effective in simulating the dynamic response of a tanker truck model. This represents a beginning for this approach, and hopefully the overall objective of making the roadways safer will be achieved through more intensive research projects that follow the lines of this work. 


\section{BIBLIOGRAPHY}

[1] Ervin, R. D., (1983) "The Influence of Size and Weight Variables on the Roll Stability of Heavy Trucks," SAE Paper \# 831163

[2] Laird, Leslie A., (1988) "Measurement of Heavy Vehicle Suspenison Roll-Stability Properties, and a Method to evaluate Overall Stability Performance," SAE Paper \# 881869

[3] Ranganathan, R., Rakheja, S. and Sankar, S., (1989) "Kineto-static roll plane analysis of articulated tank vehicles with arbitrary tank geometry," Int. J. of Vehicle Design, Vol. 10, No. 1, pp. 89-111.

[4] Ranganathan, R., Rakheja, S. and Sankar, S., (1990) "Influence of Liquid Load Shift on the Dynamic Response of Articulated Tank Vehicles," Vehicle System Dynamics, Vol. 19. No. 4, pp. 177-200.

[5] Rakheja, S., Piche, A. and Sankar, T.S. (1991) "On the development of an early warning safety monitor for articulated freight vehicles", Int. J. of Vehicle Design, Vol. 12, No. 4, pp. 420-449.

[6] Rakheja, S., Sankar, S., Ranganathan, R., Billing, J. R. and Mercer, W., (1991) "Field Testing of a Tank Truck and Study of Fluid Slosh," SAE Paper \# 912679.

[7] Rakheja, S. and Ranganathan, R. (1993) 'Estimation of rollover threshold of heavy vehicles carrying liquid cargo: a simplified approach,' Heavy Vehicle Systems, Special Series, Int. J. of Vehicle Design, Vol. 1, No. 1, pp.79-98.

[8] Ranganathan, R., Ying, Y. and Miles, J. B., (1993) “Analysis of Fluid Slosh in Partially Filled Tanks and Their Inpact on the Directional Response of Tank Vehicles," SAE Paper \# 932942.

[9] Ranganathan, R., Ying, Y. and Miles, J. B., (1994) “Development of a Mechanical Analogy Model to Predict the Dynamic Behavior of Liquids in Partially Filled Tank Vehicles," SAE Paper \# 942307.

[10] Sayers, M. W. and Riley, S. M., (1996) "Modeling Assumptions for Realistic Multibody Simulations of the Yaw and Roll Behavior of Heavy Trucks," SAE Paper \# 960173.

[11] Marion, J. B. and Thornton, S. T., Classical Dynamics of Particles and Systems $4^{\text {th }}$ Edition., Harcourt and Brace Company (1995).

[12] Mucino, V., Gautam, M., Salem, M., Saunders, E., Aquaro, M., "Automotive Stability of Heavy-Duty Truck Tractor-Tanker Combinations," Final Report made to Frederick Manufacturing Division of SFA, December 1998. 
[13] Fax received from ATC to WVU on January 21, 1998, outlining vehicle parameters.

[14] Brien, O., "Information on the Model 60PRS Water Distributor," E.D. ENTYRE \& Co., fax dated January 23, 1998.

[15] BOSCH, Automotive Handbook, $3^{\text {rd }}$ Edition, SAE, ISBN 1-56091-372-X (1993).

[16] Wong, J., Y., Theory of Ground Vehicles $2^{\text {nd }}$ Edition, John Wiley \& Sons, Inc., ISBN 0-471-52496-4 (1993).

[17] Fancher, P., S., Ervin, R., D., MacAdam, C., C., and Winkler, C., B., (1980) "Measurement and Representation of the Mechanical Properties of Truck Leaf Springs," SAE Paper \#800905.

[18] Data file received by WVU from ATC in January 1998, outlining test results from TOP double lane change maneuver.

[19] Videotape \#M1040, (1998) "M916A1/ETNYRE 60PRS Fluid Tanker Stability Test," Aberdeen Test Center, Aberdeen Proving Ground, MD. 


\section{APPENDIX A}

\section{MODELING TECHNIQUES AND ELEMENT TYPES}

\section{Nonlinear Transient Dynamic Analysis}

A transient dynamic analysis is, as the name implies, a time based analysis that includes varying conditions of dynamic response or loading. In ANSYS, the analysis requires three main components:

- $\quad$ Build the model

- Define transient analysis and obtain results

- Review results

The solution of the models was made in the transient solver of ANSYS, and involved fluctuating acceleration loads applied at the trailer CG. Time is segmented into steps, called, as the name implies time steps. Each time step represents an opportunity for the load to change. The smaller the time steps, the smoother the changes in loading occur. Keeping the time steps small is beneficial in two ways. It allows for convergence of nonlinear behavior and it gives smoother and hence, less noisy results. If the loads are varied too quickly, the solution can have shock from the sudden changes in loads, even if these loads were meant to be smooth.

\section{Nonlinear Structural Analysis}

Nonlinearities are a routinely encountered problem in everyday life, and can be fundamentally defined as any system that exhibits a changing structural stiffness over time, load, displacement, etc. The plastic yield of a staple, for example, is a nonlinear system. Another case is the changing contact patch of a tire as the load on the vehicle is 
increased. In the case of the tanker truck problem being addressed here, the suspension springs increase in stiffness as they deform, a perfect example of nonlinearity.

What causes structures to behave nonlinearly? Changing status is one thing, such as the case of a wheel riding on the ground and suddenly loosing contact. Geometric nonlinearities are another example. In the case of a fishing pole, when the pole is slack, it has relatively weak stiffness, but as the load is applied, the pole flexes so much that the moment arm is decreased, causing the stiffness to increase appreciably. Lastly, material nonlinearities are formed when the stress-strain relationship of a material changes over time, load or temperature. Creep failure is an example of material nonlinear behavior.

In order for the analysis to account for nonlinearities, a linear approximation with error correction of the nonlinear behavior must be made. The solution is broken down into a series of load increments, called load steps. Each load step can be further broken into substeps, for a more detailed approximation. At the conclusion of each load step, the stiffness matrix of the model is changed to reflect its nonlinear nature. As error inevitably builds, the program uses the Newton-Raphson equilibrium iteration scheme. Before each solution, the Newton-Raphson method evaluates the out-of-balance load vector, which is the difference between the restoring forces (the loads corresponding to the element stresses) and the applied loads. The program then performs a linear analysis, using the out-of-balance loads, and checks for convergence. If convergence is not satisfied, the stiffness matrix is updated and a new solution is obtained, continuing until convergence is met. (From ANSYS manuals chapter 8, page 3-4) 


\section{Element Types:}

BEAM4:

Beam 4 elements are 3D, uniaxial, elastic beams capable of supporting tension, compression, and bending. The elements have six degrees of freedom, translations in the nodal $\mathrm{x}, \mathrm{y}$, and $\mathrm{z}$ and rotations about the nodal $\mathrm{x}, \mathrm{y}$, and $\mathrm{z}$-axes. The element is defined by 12 real constants: AREA, IZZ, IYY, TKZ, TKY, THETA, ISTRN, IXX, SHEARZ, SHEARY, SPIN, ADDMAS. For the purposes of this problem, only AREA, IZZ, IYY, TKZ, TKY, and ADDMAS are used. AREA is used to compute the cross sectional area of the element. IZZ and IYY are the area moments of inertia about the element $\mathrm{z}$ and $\mathrm{y}-$ axes. TKZ and TKY are the thicknesses of the beam in the respective axes. Lastly, the ADDMAS command is used in local areas of the mesh to add mass beyond the volume density mass of the element. This is done to correct the weight distribution and inertial properties of the tank. Beam 4 elements are also capable of supporting large deflection analysis.

Beam 4 elements are used to model almost the entire tanker truck structure. In the case of the tank, there are three main members forming a triangle with the top member being at the center of the tank. These three members are matched to have the same torsional and bending stiffness of the actual tank. The rear portion of the tank is also meshed with beam 4 elements as well as the axles. The truck portion of the model is meshed with beam 4 elements but the material is rigid, to eliminate the flexibility of the truck from the analysis. 


\section{LINK8:}

Link 8 elements are 3 - D spar elements capable of supporting only tension and compression with the key-options used. Link 8 elements are only capable of 3 degrees of freedom, translations in the nodal $\mathrm{x}, \mathrm{y}$ and $\mathrm{z}$-axes. This element can share a node with a beam 4 element, and is able to swing freely, as if it were ball jointed, thus making it a perfect element for modeling the pendulums. Link 8 has only 2 real constants, AREA and ISTRN. This problem only gives specifies an area for the element.

This element is also used to model control elements to eliminate excessive degrees of freedom in the suspension of the tanker truck. "Fake" A-arms are modeled which limit the axles from moving in any but the truck y-axis.

\section{COMBIN14:}

Combination 14 elements are longitudinal or torsional spring/damper elements used in 1,2 or 3 dimensions. The combination elements are capable of translational degrees of freedom only; no rotations are permitted if the elements are being used to represent a longitudinal spring/damper. The type of element that is being modeled is specified by key-options (KEYOPT). In the analysis, KEYOPT(2) equals 2, wielding a 1 - D longitudinal spring/damper with nodal UY degree of freedom.

\section{COMBIN39:}

Combination 39 elements are longitudinal or torsional nonlinear spring elements used in 1, 2 or 3 dimensions. In the longitudinal form, COMBIN39 elements are capable of translational degrees of freedom only; no rotations are permitted. The element is able to represent several combinations of nonlinear behavior. It is designed to be used in tension applications but works equally well in compression. The nonlinear 
force/deflection curve is defined by the real constant sets, by inputting D1, F1, D2, $\mathrm{F} 2, \ldots, \mathrm{DN}, \mathrm{FN}$. The $1^{\text {st }}$ quadrant of the force/deflection curve is required, and the third quadrant, if left blank, is mirrored into place from the data in the first quadrant. When the force/deflection passes beyond the range defined, the slope of the last input series is continued linearly. Loading occurs along the defined path, but by using KEYOPT(1), unloading may occur along a line parallel to the slope at the origin of the loading curve. KEYOPT(4) is set to one, giving the elements 3 - D longitudinal degrees of freedom.

\section{MASS21:}

Mass 21 elements are lumped mass elements that only require one node to define. They have up to six degrees of freedom, translations in the nodal $\mathrm{x}, \mathrm{y}$ and $\mathrm{z}$-axes, and rotations about the nodal $\mathrm{x}, \mathrm{y}$ and $\mathrm{z}$-axes. Real constants are: MASSX, MASSY, MASSZ, IXX, IYY, IZZ. Mass 21 elements are used wherever a lumped mass is needed. The pendulum masses, representing the fluid inside the tank, are modeled using mass 12 elements. The lumped mass of the tractor is also a mass 21 element. Lastly, these elements are used to model the mass of the wheels and are used to simulate the weight of the differentials on the rear axles of the truck. 


\section{APPENDIX B}

\section{SOURCE CODES FROM ANSYS}

\section{FULL TRUCK 3D CYLINRICAL PENDULUM MODEL}

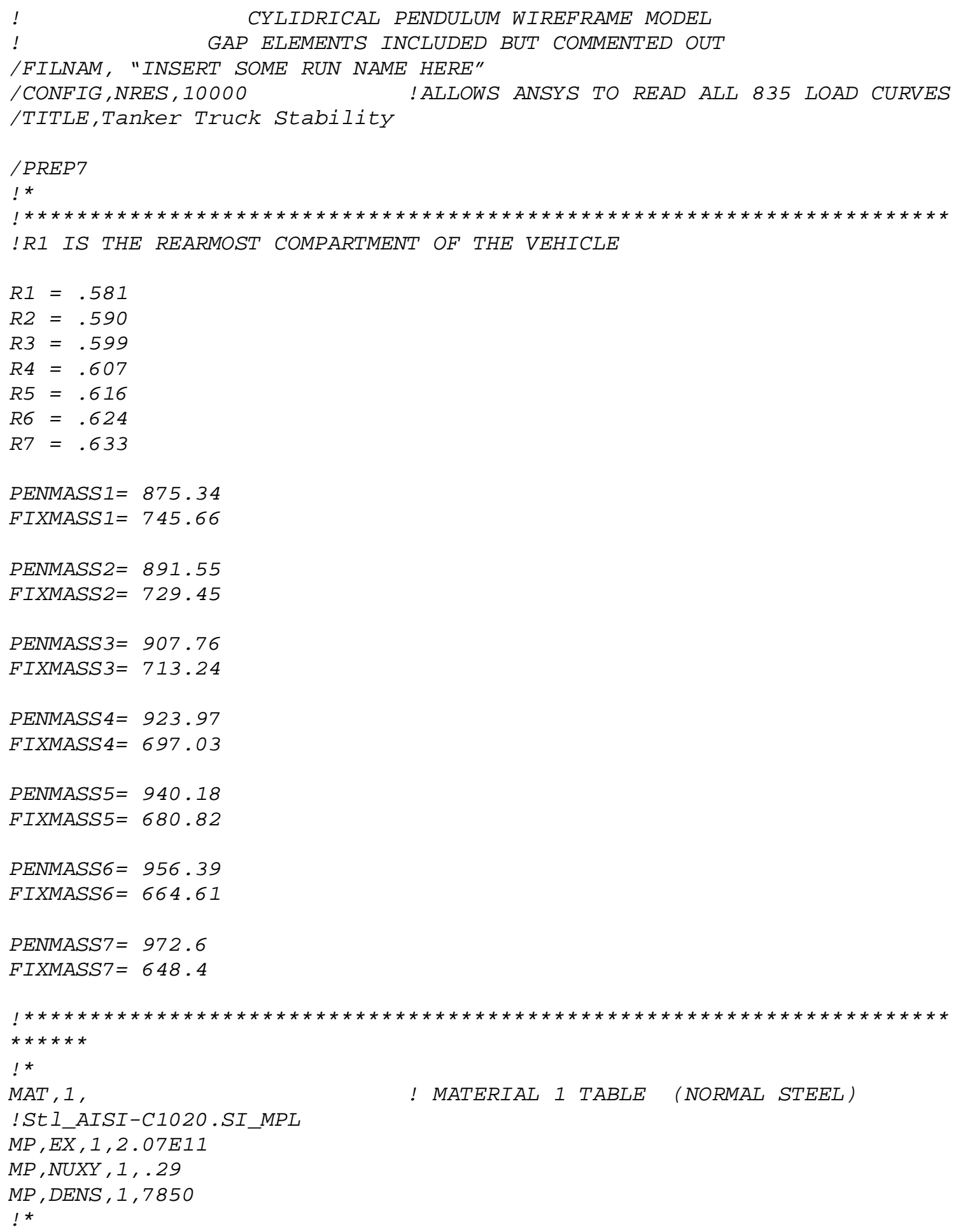




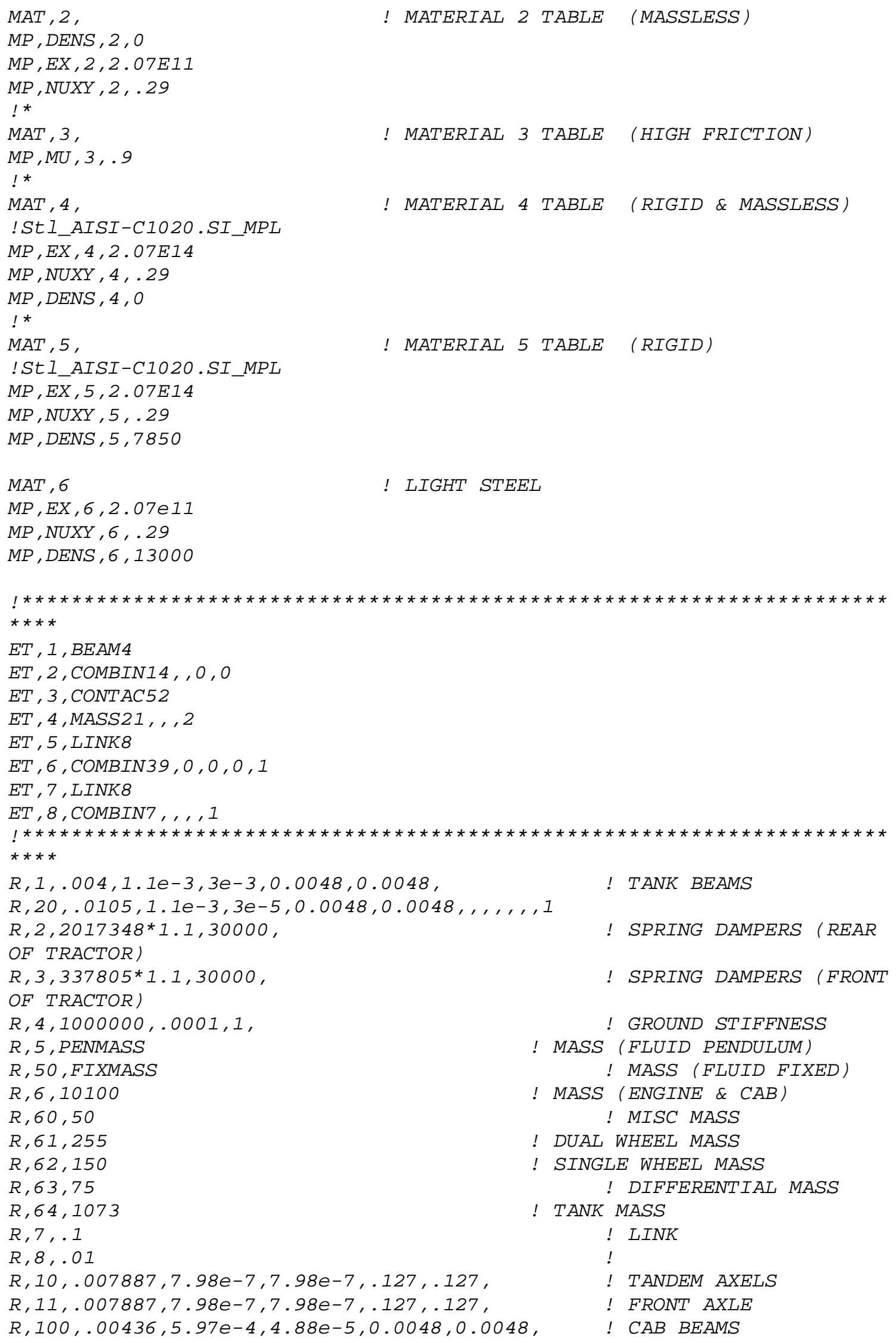




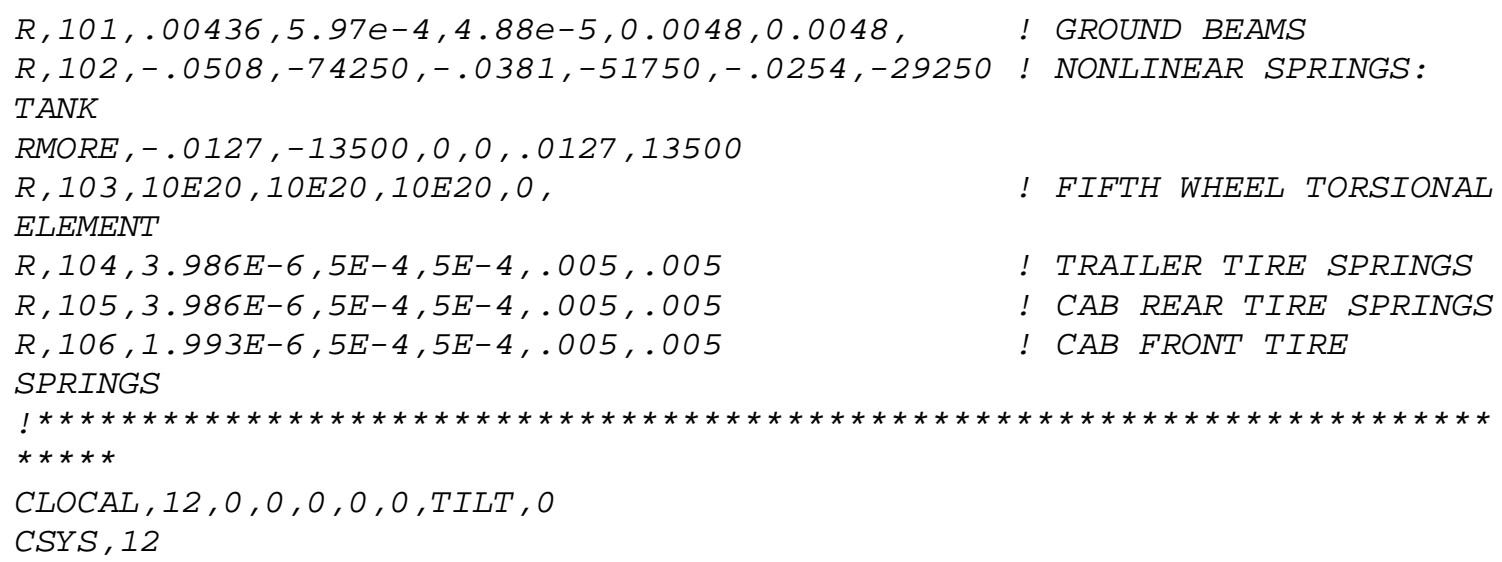

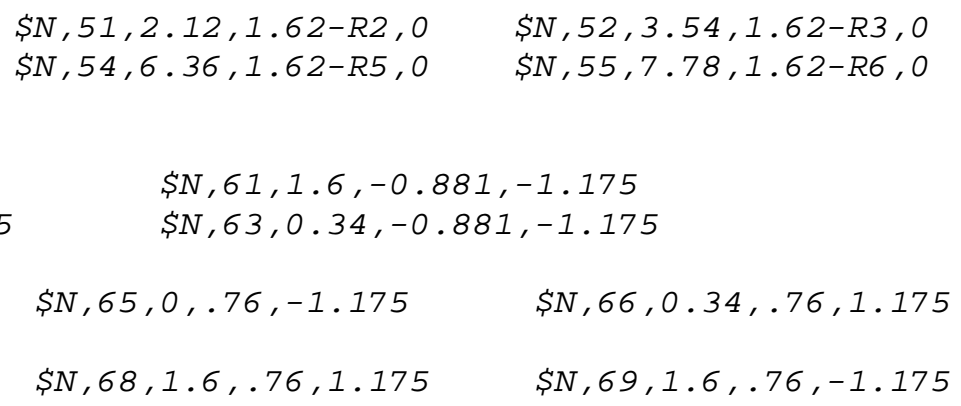




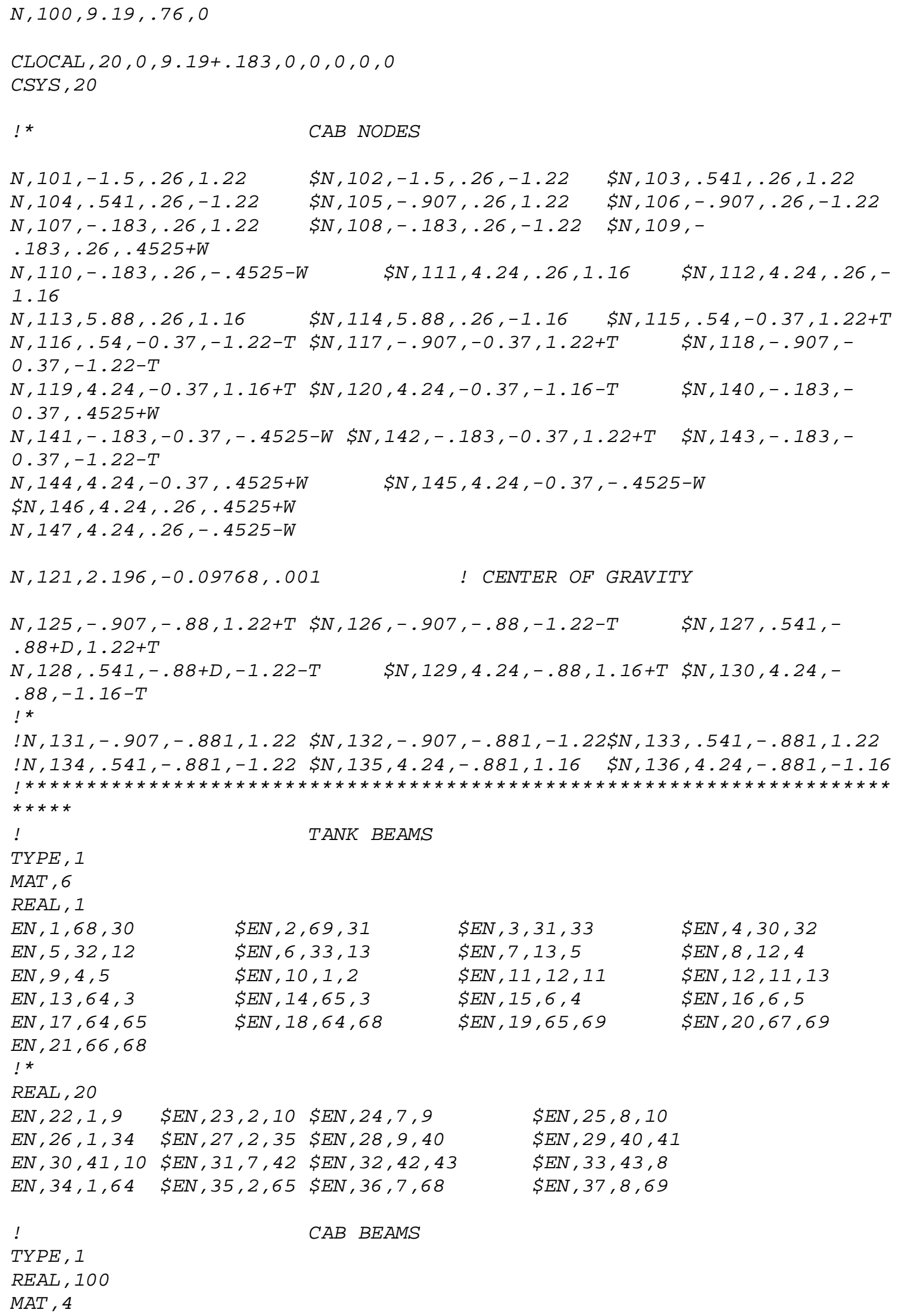

$\$ E N, 3,31,33$ SEN, 7, 13, 5 $\$ E N, 11,12,11$ $\$ E N, 15,6,4$ $\$ E N, 19,65,69$ $\$ E N, 18,64,68$

$\$ E N, 2,69,31$ $\$ E N, 6,33,13$ SEN, 10, 1, 2

$$
\begin{aligned}
& \text { SEN, 4, 30, } 32 \\
& \$ E N, 8,12,4 \\
& \$ E N, 12,11,13 \\
& \$ E N, 16,6,5 \\
& \$ E N, 20,67,69
\end{aligned}
$$

$!$

TYPE, 1

$R E A L, 100$

$M A T, 4$

$\$ E N, 25,8,10$

$\$ E N, 29,40,41$

$\$ E N, 33,43,8$

$\$ E N, 37,8,69$ 


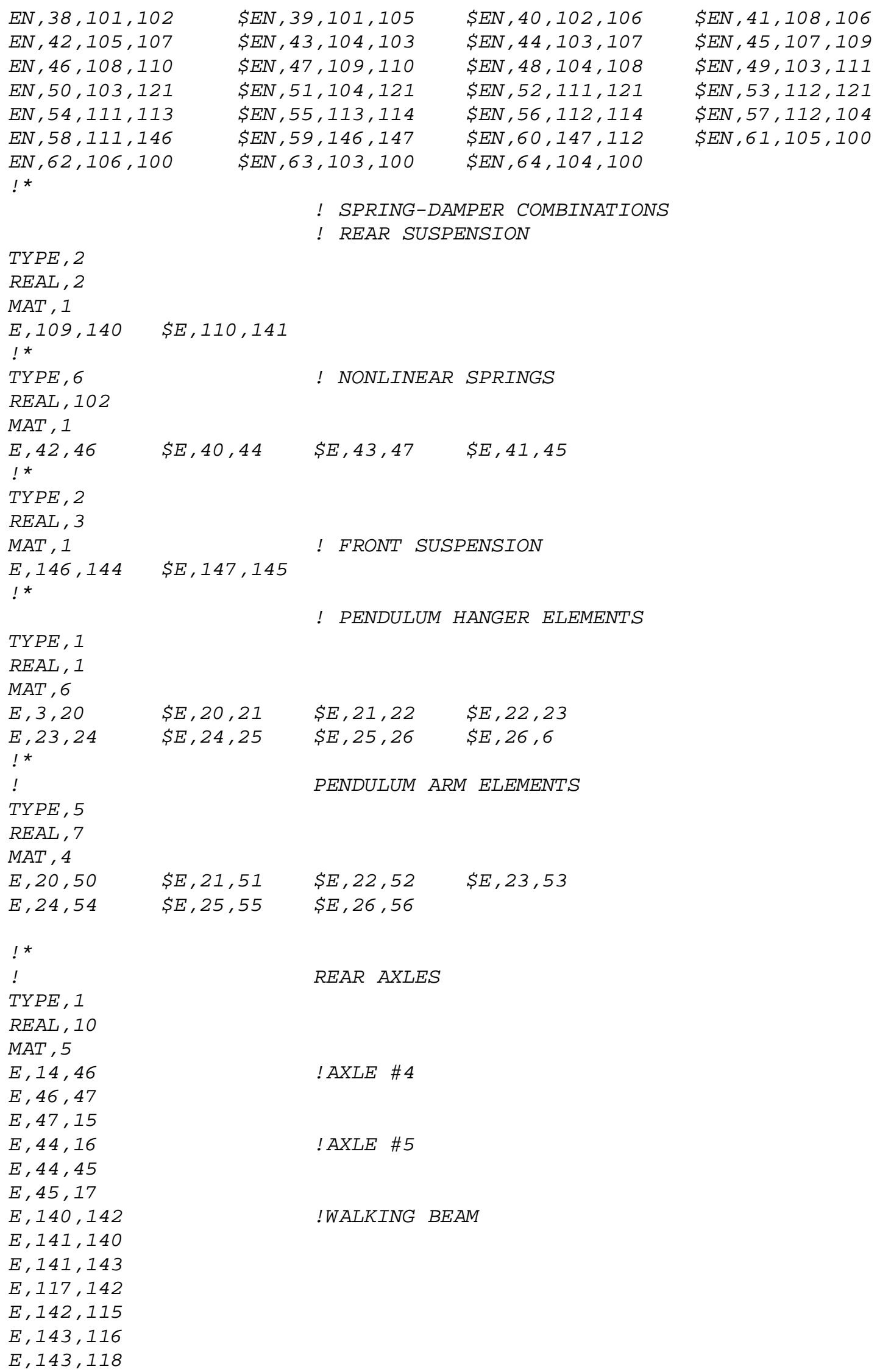

$\$ E N, 39,101,105$

$\$ E N, 43,104,103$

$\$ E N, 47,109,110$

$\$ E N, 51,104,121$

$\$ E N, 55,113,114$

SEN, 59, 146, 147

$\$ E N, 63,103,100$

\$EN, 40,102, 106

$\$ E N, 44,103,107$

$\$ E N, 48,104,108$

$\$ E N, 52,111,121$

$\$ E N, 56,112,114$

$\$ E N, 60,147,112$

\$EN, 64, 104, 100

SEN, 41, 108, 106

$\$ E N, 45,107,109$

$\$ E N, 49,103,111$

$\$ E N, 53,112,121$

$\$ E N, 57,112,104$

$\$ E N, 61,105,100$

! SPRING-DAMPER COMBINATIONS

! REAR SUSPENSION

REAR AXLES

! AXLE \#4

! AXLE \#5

!WALKING BEAM 


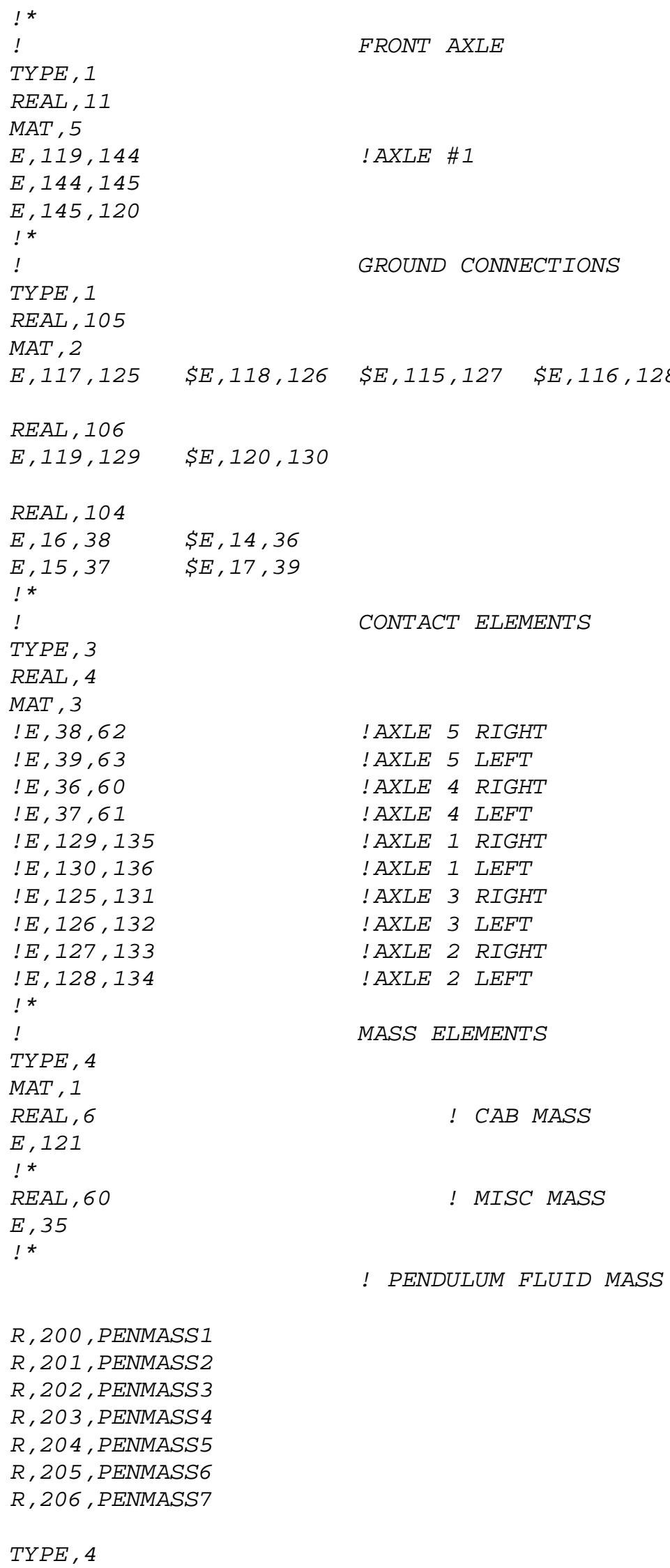

$R, 200, P E N M A S S 1$

$R, 201, P E N M A S S 2$

$R, 202, P E N M A S S 3$

$R, 203, P E N M A S S 4$

$R, 204, P E N M A S S 5$

$R, 205, P E N M A S S 6$

$R, 206, P E N M A S S 7$

TYPE, 4 
$M A T, 1$

REAL, 200

$E, 50$

REAL, 201

$E, 51$

$R E A L, 202$

$E, 52$

$R E A L, 203$

$E, 53$

REAL, 204

$E, 54$

$R E A L, 205$

$E, 55$

$R E A L, 206$

$E, 56$

!*

$R, 207, F I X M A S S 1$

$R, 208, F I X M A S S 2$

$R, 209, F I X M A S S 3$

$R, 210, F I X M A S S 4$

$R, 211, F I X M A S S 5$

$R, 212$, FIXMASS 6

$R, 213, F I X M A S S 7$

TYPE, 4

REAL, 207

$E, 20$

REAL, 208

$E, 21$

REAL, 209

$E, 22$

$R E A L, 210$

$E, 23$

REAL, 211

$E, 24$

$R E A L, 212$

$E, 25$

$R E A L, 213$

$E, 26$

!*

TYPE, 4

$R E A L, 61$

$M A T, 1$

$E, 14 \$ E, 15$

$E, 17$ \$E, 115

$E, 117 \$ E, 118$

!*

TYPE, 4

$R E A L, 62$

$M A T, 1$

$E, 119 \$ E, 120$

!*

$T Y P E, 4$

REAL, 63

$M A T, 1$

$E, 140$

$E, 141$
! FIXED FLUID MASS

! DUAL WHEEL MASS

$\$ E, 16$

$\$ E, 116$

! DIFFERENTIAL MASS 
TYPE, 4

$R E A L, 64$

$E, 48$

TYPE, 1

$R E A L, 1$

$M A T, 4$

$E, 30,48$

$E, 31,48$

$E, 5,48$

$E, 4,48$

TYPE, 7

$R E A L, 8$

$M A T, 4$

$E, 35,16$

$E, 35,15$

$E, 142,111$

$E, 103,119$

!*

$E, 35,38$

$E, 35,37$

$E, 101,126$

$E, 104,126$

$E, 103,129$

!*

TYPE, 8

REAL, 103

! $E, 11,100$
! EXTRA BALANCING ELEMENT

! CONTROL A ARM ELEMENTS

$C P, 1, U X, 11,100$

$\$ E, 7,16 \quad \$ E, 34,39 \quad \$ E, 8,39$

$\$ E, 7,15 \quad \$ E, 34,14 \quad \$ E, 8,14$

$\$ E, 143,112 \$ S, 142,106 \$ \$ E, 143,105$

$\$ E, 112,119$

$\$ E, 104,120$

$\$ E, 111,120$

$S E, 7,38$

$\$ E, 7,37$

$\$ E, 34,17$

$\$ E, 8,17$

$S E, 102,125$

$\$ E, 34,36$

$\$ E, 8,36$

$\$ E, 103,125$

$\$ E, 102,128$

$\$ E, 101,127$

$\$ E, 103,128$

$\$ E, 104,127$

$\$ E, 112,129$

$\$ E, 104,130$

$\$ E, 111,130$

! KINGPING ELEMENT

$C P, 3, U Z, 11,100$

$C P, 4, R O T Z, 11,100$

$C P, 5$, ROTX, 11, 100

$! *$

SAVE

FINISH

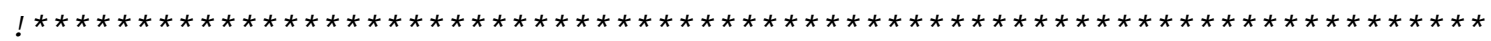

! THIS SECTION IS THE SOLUTION PHASE

! PLEASE NOTE THAT ONLY ONE SOLUTION IS RUN AT A TIME

! BOTH TYPES OF SOLUTIONS RUN DURING THE RESEARCH ARE EXPLAINED

$! * * * * * * * * * * * * * * * * * * * * * * * * * * * * * * * * * * * * * * * * * * * * * * * * * * * * * * * * * * * * * * * * * * * * * *$

! FOR STATIC SOLUTIONS THE CODE IS WRITTEN AS FOLLOWS ISOLU

D, 36,UX, , 39, 1,UY,UZ ! RESTRAINS NODES 36-39 IN ALL TRANSLATIONS

D, 125, UY, , 130, 1, UX, UZ ! RESTRAINS NODES 125-130 IN ALL TRANSLATIONS

!*

ANTYPE, STATIC ! SETS THE ANALYSIS FOR STATIC

ACEL, 0,9.81,0 ! GRAVITY IS APPLIED OPPOSITE TO THE DIRECTION

! OF THE GRAVITATIONAL FORCE

SOLVE

! LETS SEE WHAT HAPPENS 


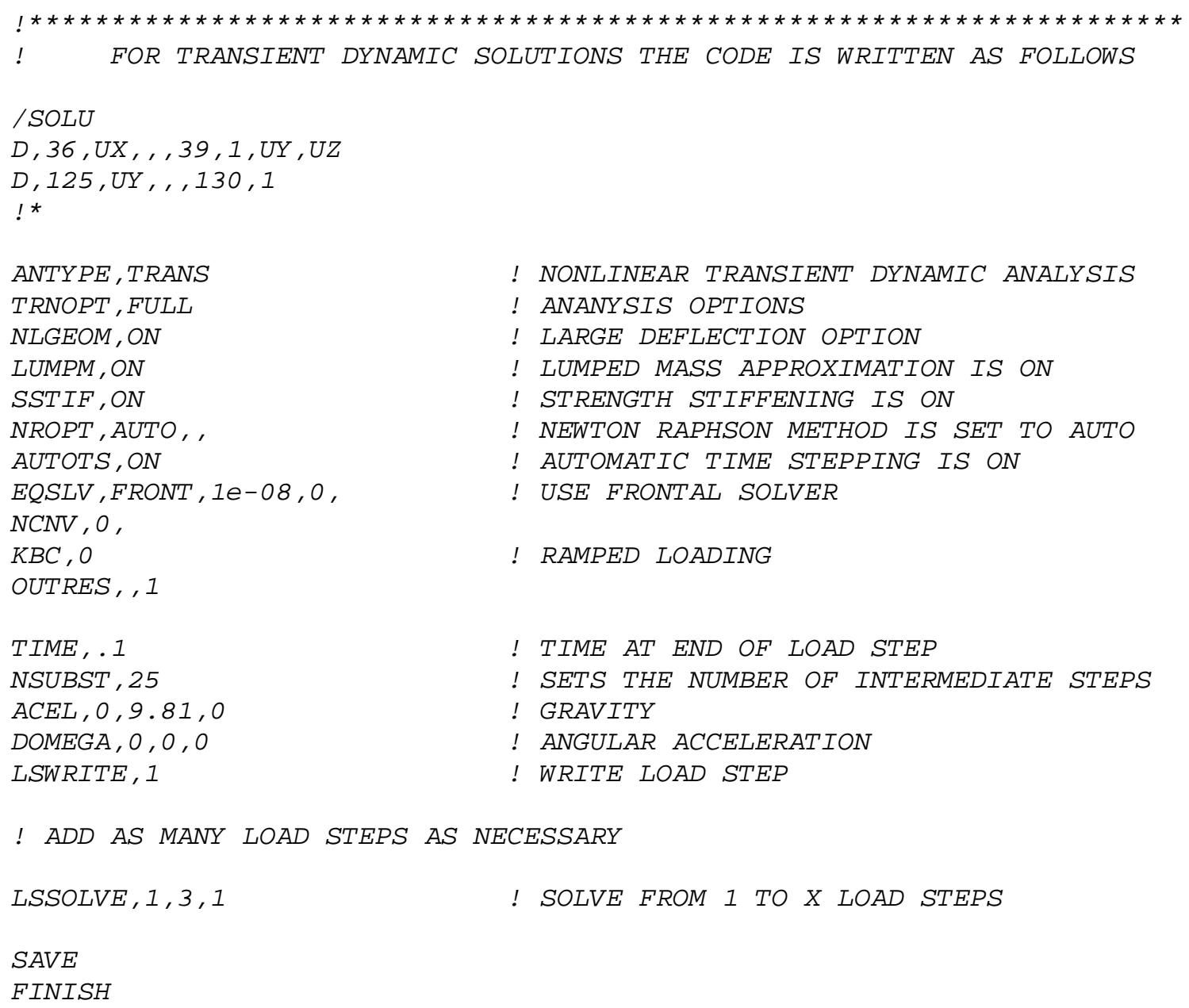

SIMPLE 2D PENDULUM SWINGSET MODEL

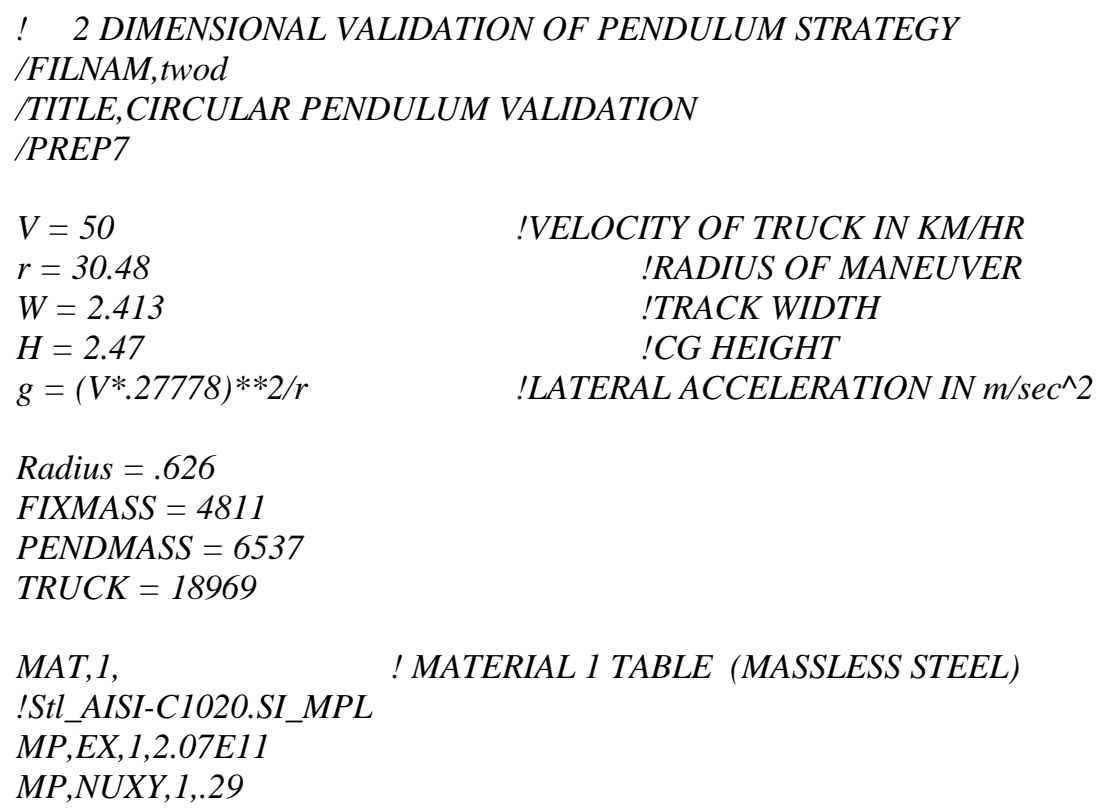

$V=50$

$r=30.48$

$W=2.413$

$H=2.47$

$g=\left(V^{*} .27778\right) * * 2 / r$

Radius $=.626$

FIXMASS $=4811$

PENDMASS $=6537$

TRUCK $=18969$

$M A T, 1$, !Stl_AISI-C1020.SI_MPL

$M P, E X, 1,2.07 E 11$

$M P, N U X Y, 1, .29$

!VELOCITY OF TRUCK IN KM/HR !RADIUS OF MANEUVER !TRACK WIDTH !CG HEIGHT

!LATERAL ACCELERATION IN m/sec ${ }^{\wedge} 2$

! MATERIAL 1 TABLE (MASSLESS STEEL) 


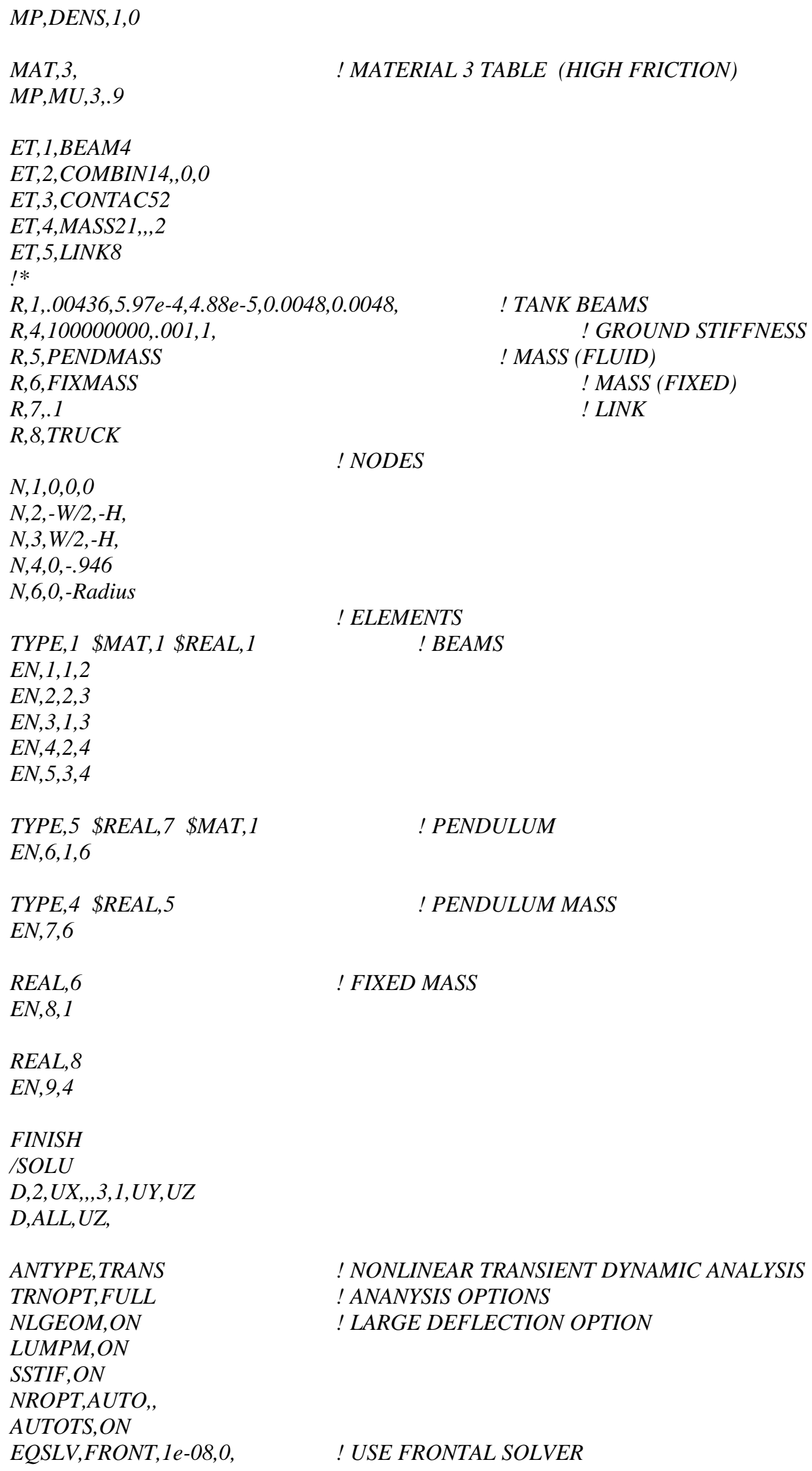


NCNV,O,

$\mathrm{KBC}, \mathrm{O}$

OUTRES, 1

!*

TIME,. 1

NSUBST,25

ACEL,0,9.81,0

LSWRITE, 1

!*

TIME, 1

NSUBST, 100

ACEL, g,9.81,0

LSWRITE, 2

!*

TIME, 4

ACEL, g,9.81,0

LSWRITE,3

!*

!LSSOLVE, 1,3,1

I*

FINISH

/POST26

RFORCE,2,2,F,Y,LEFT

RFORCE,3,3,F,Y,RIGHT

ADD 4,2,3, ,TOTAL, , , 1,1,1,

PLVAR, 2,3,4 


\section{APPENDIX C}

\section{CODES FROM OTHER COMPUTER PROGRAMS}

\section{FORTRAN PROGRAM TO FORMAT DATA}

character*20 line, outfile, input integer I,line 1

REAL Time, yacc,yaw

* Enter the input file name

Print*, 'Enter the input file (with ext)'

Read(*,115), input

* Enter the Output file name

Print*,'Enter the output file (with ext)'

$\operatorname{Read}(*, 115)$, outfile

* Enter the number of lines in the input file

Print*,'Enter the Number of line in the file'

Print*, 'Note: The frist line is labels for the colums'

Read* $^{*}$ line 1

Print*, input

* opens the input and output for

Open $\left(\right.$ Unit $=13$, File $=$ input,Status $={ }^{\prime}$ Old $\left.{ }^{\prime}\right)$

Open (Unit=14,File $=$ outfile, Status $=$ 'unknown')

$I=1$

* read labels from file

READ (13,115) line

115 format (a20)

* Writes the ansys B.C. Files

$10 \quad I=I+1$

READ (13,*) Time, yacc, yaw, angle

Print*, I,Time, yacc, yaw

write $(14, *)$ 'Time, , Time, '+2'

write $(14, *)$ 'ACEL,0,9.81, ', yacc

write $\left(14,{ }^{*}\right)$ 'DOMEGA, 0, , yaw, ',0'

write $\left(14,{ }^{*}\right)^{\prime} D, 100, R O T Y,{ }^{\prime}$, angle

write $\left(14,{ }^{*}\right)$ 'LSWRITE, ',I-1

IF (I.LT.(line 1-1)) THEN

GOTO 10

ENDIF

close $($ unit $=13$, status $=$ 'Keep' $)$

close $\left(\right.$ unit $=14$, status $={ }^{\prime}$ Keep $\left.{ }^{\prime}\right)$

END

\section{MATLAB FILTERING PROGRAM}

\%This File Has a Low Band Buttress Filter To Filter

$\%$ The experemenatl Results of ATC

$\%$ Constructed on 12/1/1998

$\%$ By Mohamed Salem

close all

clear

filename=input('Input file name of the data that needs to be filtered without extension ', 's'); 


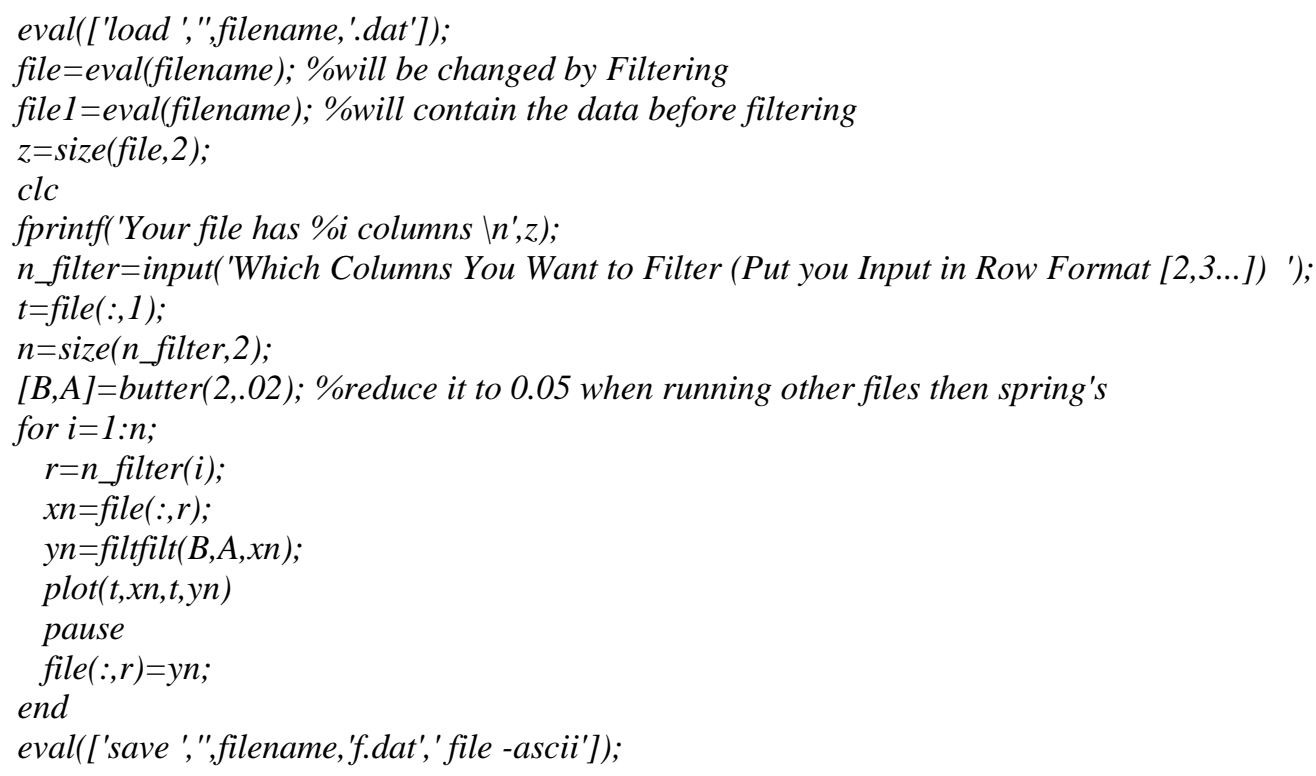




\section{APPENDIX D}

\section{ELLIPTICAL PENDULUM SECTION}

\section{Trammel Mechanism Formulation}

The elliptical trammel pendulum was an idea inspired by Leonardo DeVinci, which he used to trace an elliptical path on paper. The mechanism is quite simple. Take three points on a line. Fix one point to slide vertically only, fix the next point to slide horizontally only. The last point is the tracer point, it will trace an ellipse with major and minor axes corresponding to the spacing of the three points. The mechanism is shown in Figure 33 [12]. The ANSYS swingset is shown in Figure 34.

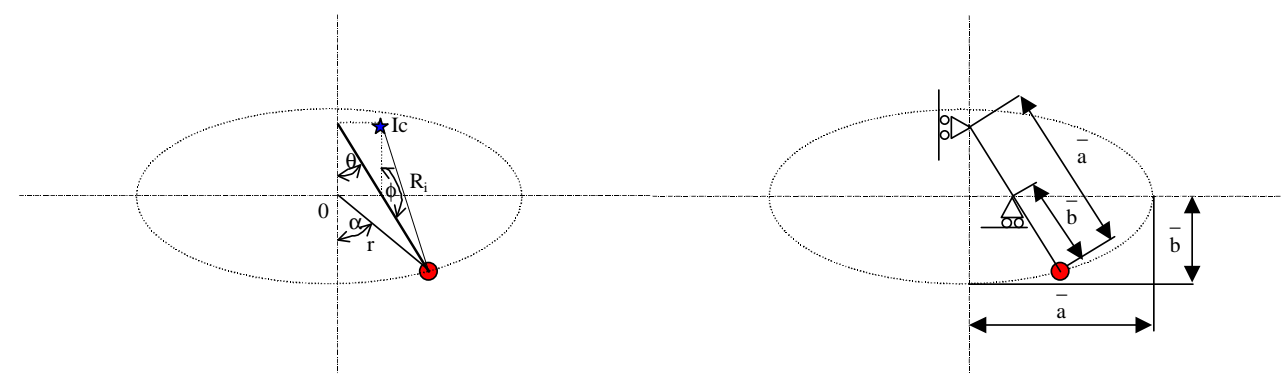

Figure 33. Trammel pendulum sketch [12].

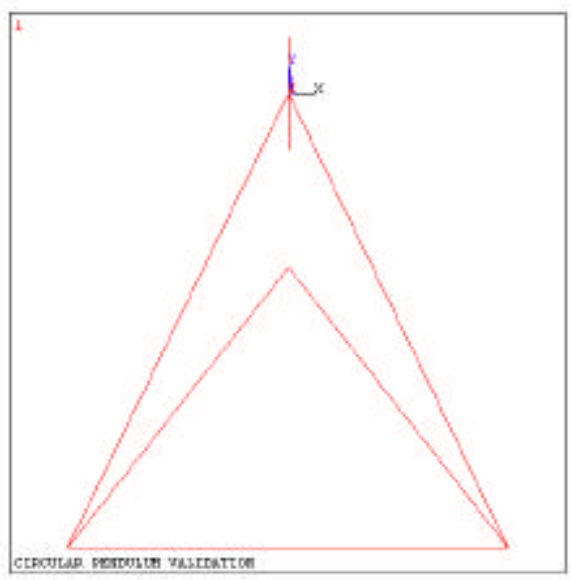

Figure 34. Trammel pendulum swingset model in ANSYS. 
As before, ANSYS results were compared with the analytical model [12]. In this case, the reaction forces also matched the results found with the analytical model. The critical velocity curve was made using the swingset model with an elliptical trammel pendulum. The results from the ANSYS model are shown in Figure 36. The corresponding analytical results are shown in Figure 35.

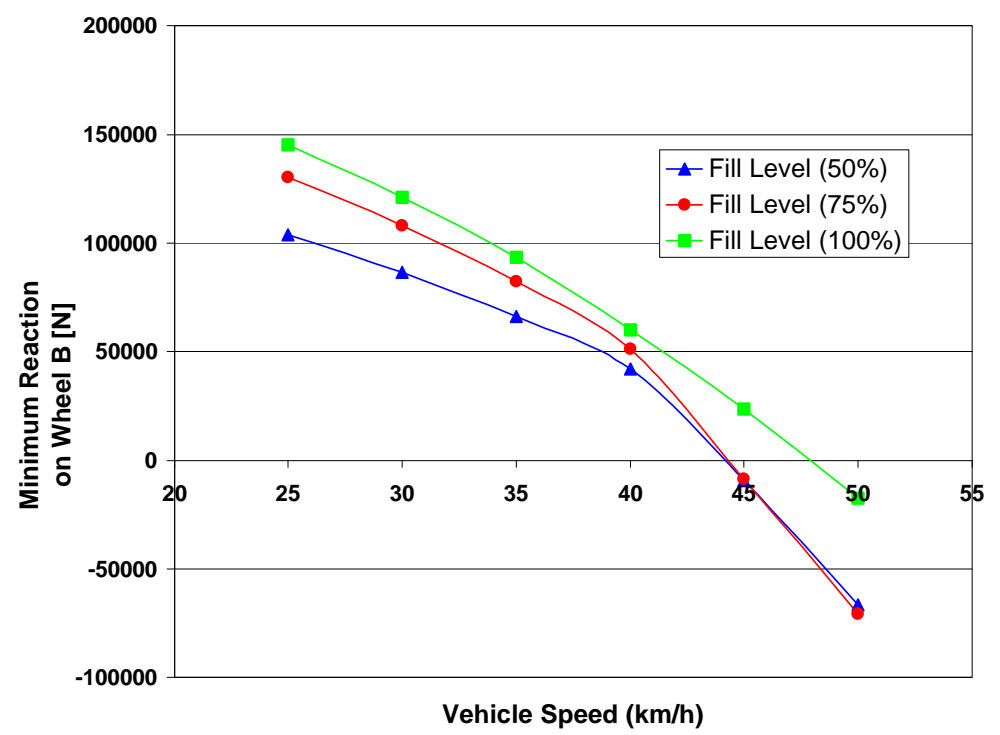

Figure 35. Critical velocity curve for elliptical 2D analytical model [12].

Rollover Limits for Elliptical Tank

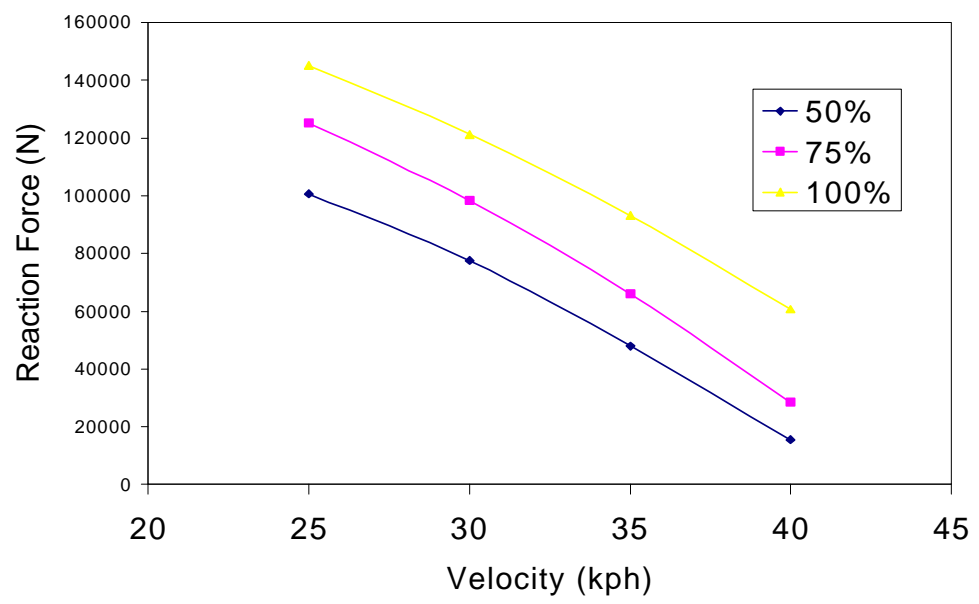

Figure 36. Critical velocity curve for elliptical 2D model in ANSYS. 


\section{Constant Radius Turn}

Critical velocity curves were generated for three different percent full conditions: $50 \%, 75 \%$ and $100 \%$, using the elliptical pendulum in the full truck model. The results show close correlation between the experimental skid-pad maneuver and the model, especially for the 75 percent full condition. The error examined at 75 percent was only 2.7 percent. It is worth noting that 60 to 70 percent full tanks represent the most critical level of fill for elliptical tankers, according to the literature. The 50 percent full tanker showed rollover at $33.75 \mathrm{kph}$, a little lower than the experimental $38 \mathrm{kph}$, giving an error of -11.2 percent. Lastly is the case of the 100 percent full tanker, the largest deviation from the experimental data was obtained showing that rollover will occur at $44.75 \mathrm{kph}$ instead of $38 \mathrm{kph}$ obtained experimentally. This value has an error of 17.8 percent. Figure 37 shows the critical velocity for the given percent full tanker models.

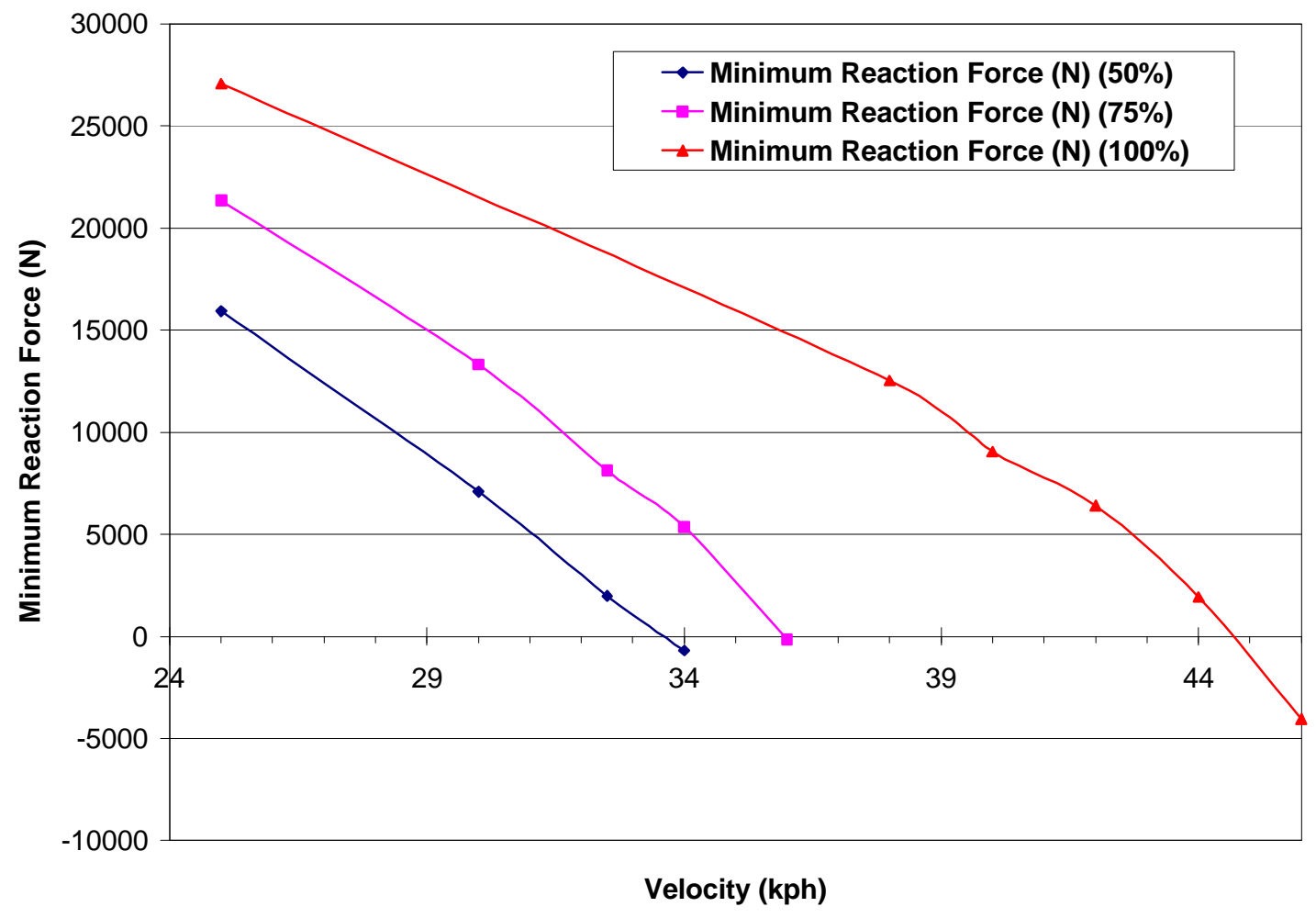

Figure 37. Critical velocity curve for full truck model with elliptical pendulums.

The results from this test vary greatly from the results generated using cylindrical pendulums. As can be seen, the cylindrical pendulums (Figure 17) show a high 
consistency throughout fill levels. This correlates better with the experimental data, which concluded that the tanker truck rolled over at approximately $38 \mathrm{kph}$ for all fill level conditions. This conclusion lead to skepticism of the elliptical pendulum's parameters.

\section{ATC Double Lane Change}

Figures 38 through 40 show the load on the left and right side wheels of the tanker during the TOP lane change test using the data supplied by ATC. The results match those taken from the cylindrical model in the trends leading toward rollover. It appears, however, that the elliptical pendulums are more active than the cylindrical pendulums. The cylindrical pendulums correlated better with the data received from ATC and they had been validated analytically by Ranganathan [8]. For these reasons, it is believed that the elliptical pendulum parameters need to be further investigated.

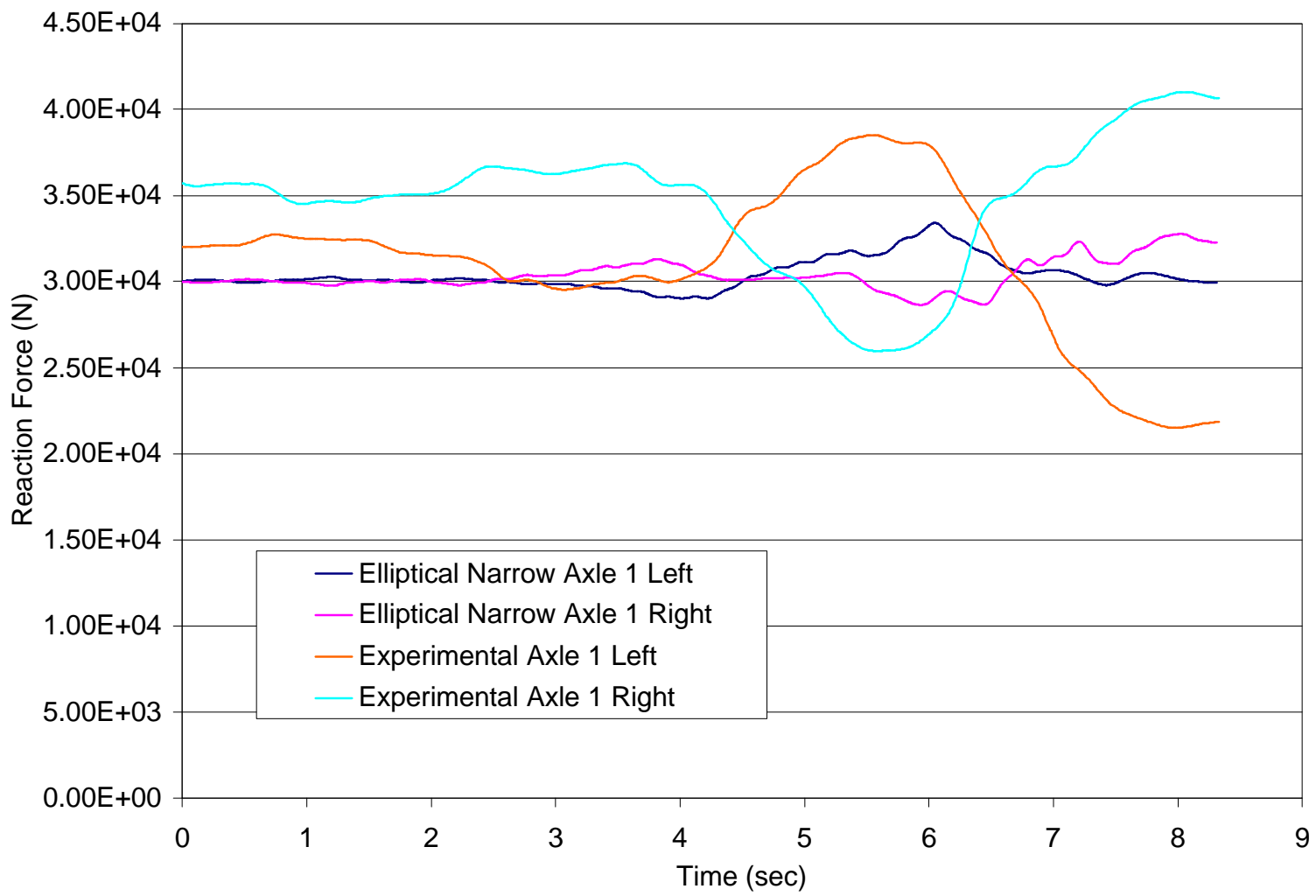

Figure 38. Comparison of reaction forces from experimental to elliptical tank model results on axle 1 . 


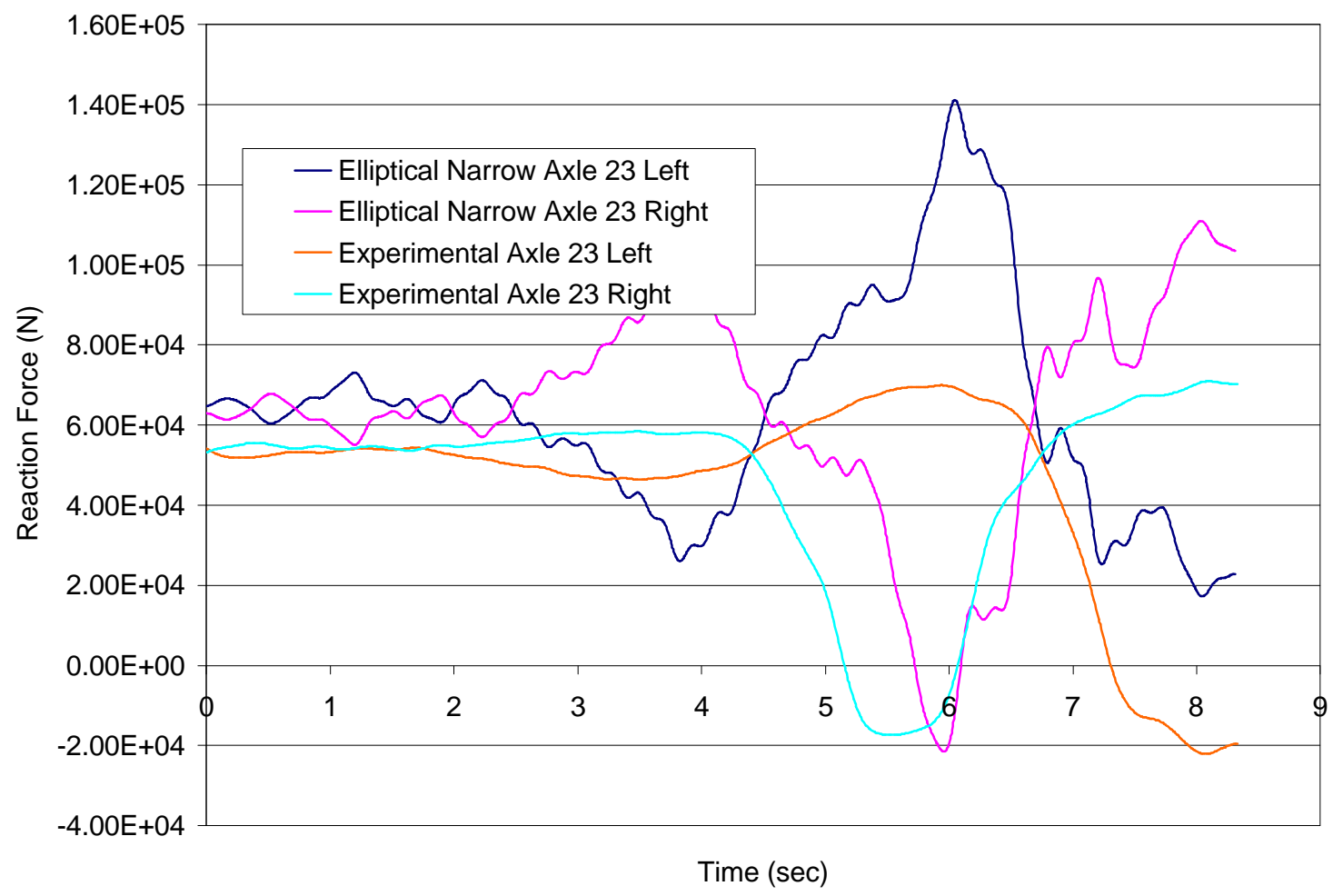

Figure 39. Comparison of reaction forces from experimental to elliptical tank model results on axle 23 combined.

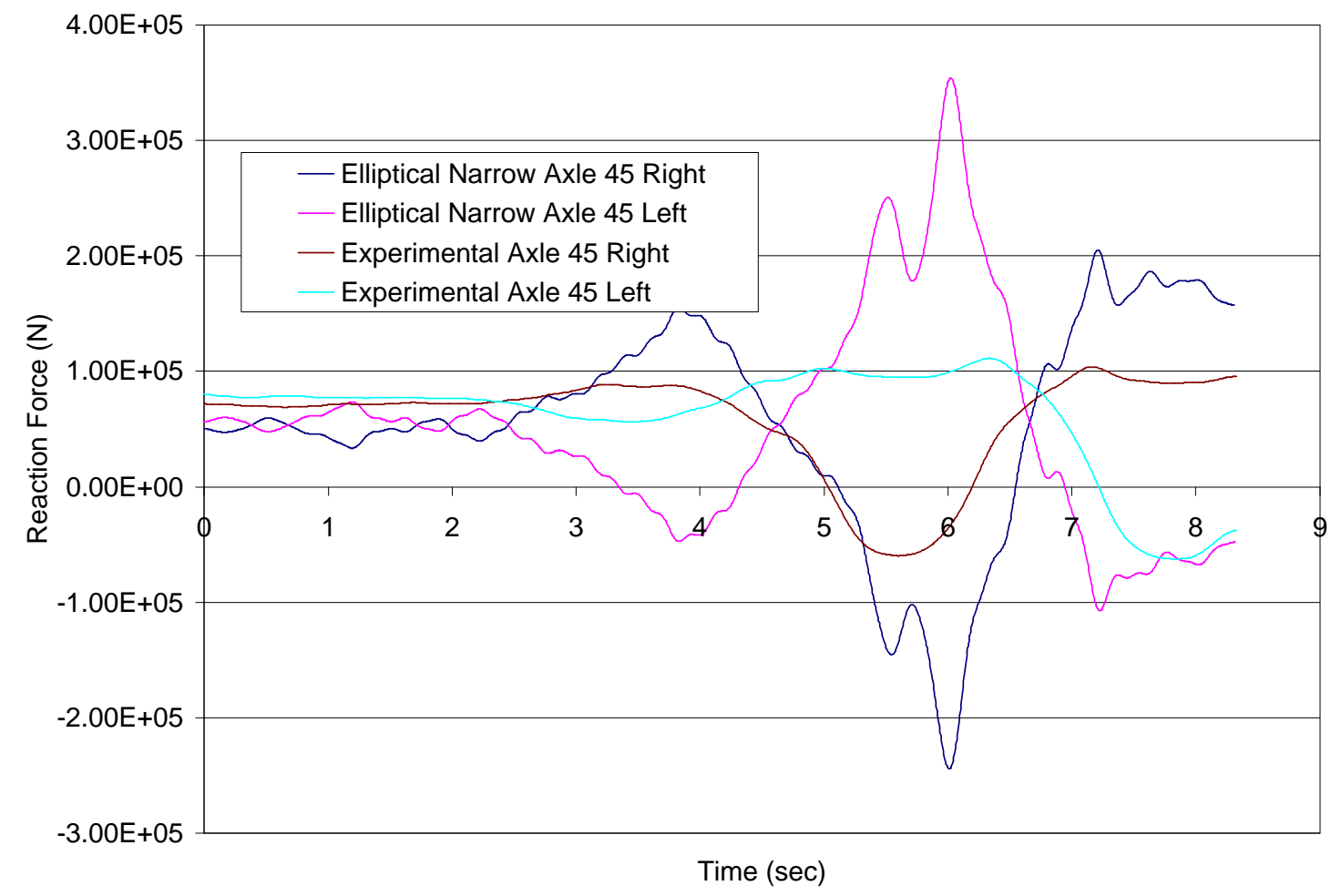

Figure 40. Comparison of reaction forces from experimental to elliptical tank model results on axle 45 combined. 
ANSYS Code for Elliptical Full Truck Model

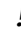

!

TRAMMEL PENDULUM WIREFRAME MODEL FOR SUBMISSION TO ATC

GAP ELEMENTS INCLUDED BUT COMMENTED OUT

/FILNAM, "INSERT SOME RUN NAME HERE"

/CONFIG, NRES, 10000

!ALLOWS ANSYS TO READ ALL 835 LOAD CURVES

/TITLE, Tanker Truck Stability

/PREP 7

$! \star$

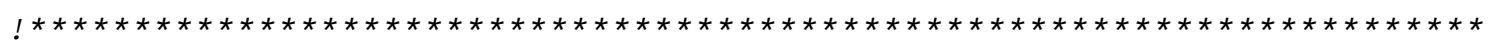

$A=.8784 \quad !$ PENDULUM PARAMETERS A AND B (VARY WITH

$B=.4462$ ! PERCENTAGE OF FILL)

PENMASS $=933.9$ ! PENDULUM FLOATING MASS (MASS AT END OF PENDULUM)

FIXMASS $=687.3$ ! PENDULUM FIXED MASS (MASS FIXED TO FRAME OF TRUCK)

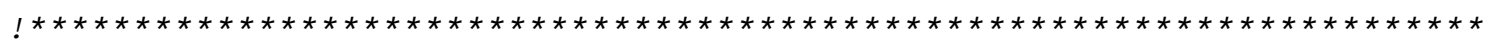

$! \star$

$M A T, 1$,

! MATERIAL 1 TABLE (NORMAL STEEL)

!StI_AISI-C1020.SI_MPL

$M P, E X, 1,2.07 E 11$

$M P, N U X Y, 1, .29$

$M P, D E N S, 1,7850$

!*

$M A T, 2$,

! MATERIAL 2 TABLE (MASSLESS)

$M P, D E N S, 2,0$

$M P, E X, 2,2.07 E 11$

$M P, N U X Y, 2, .29$

!*

$M A T, 3$,

$M P, M U, 3, .9$

! MATERIAL 3 TABLE (HIGH FRICTION)

$! *$

$M A T, 4$,

!St1_AISI-C1020.SI_MPL

$M P, E X, 4,2.07 E 14$

$M P, N U X Y, 4, .29$

$M P, D E N S, 4,0$

$! *$

$M A T, 5$,

!St1_AISI-C1020.SI_MPL

! MATERIAL 5 TABLE (RIGID)

$M P, E X, 5,2.07 E 14$

$M P, N U X Y, 5, .29$

$M P, D E N S, 5,7850$

$M A T, 6$

! MATERIAL 6 TABLE (LIGHT STEEL)

$M P, E X, 6,2.07 e 11$

$M P, N U X Y, 6, .29$

$M P, D E N S, 6,13000$

\begin{tabular}{|c|c|}
\hline$!$ & ELEMENT TYPES \\
\hline$E T, 1, B E A M 4$ & ! 3-D BEAM \\
\hline$E T, 2, C O M B I N 14,0,0$ & ! SPRING/DAMPER COMBINATION (LONGITUDINAL) \\
\hline ET, 3, CONTAC52 & ! CONTACT ELEMENT \\
\hline$E T, 4, M A S S 21,1,2$ & ! LUMPED MASS \\
\hline
\end{tabular}




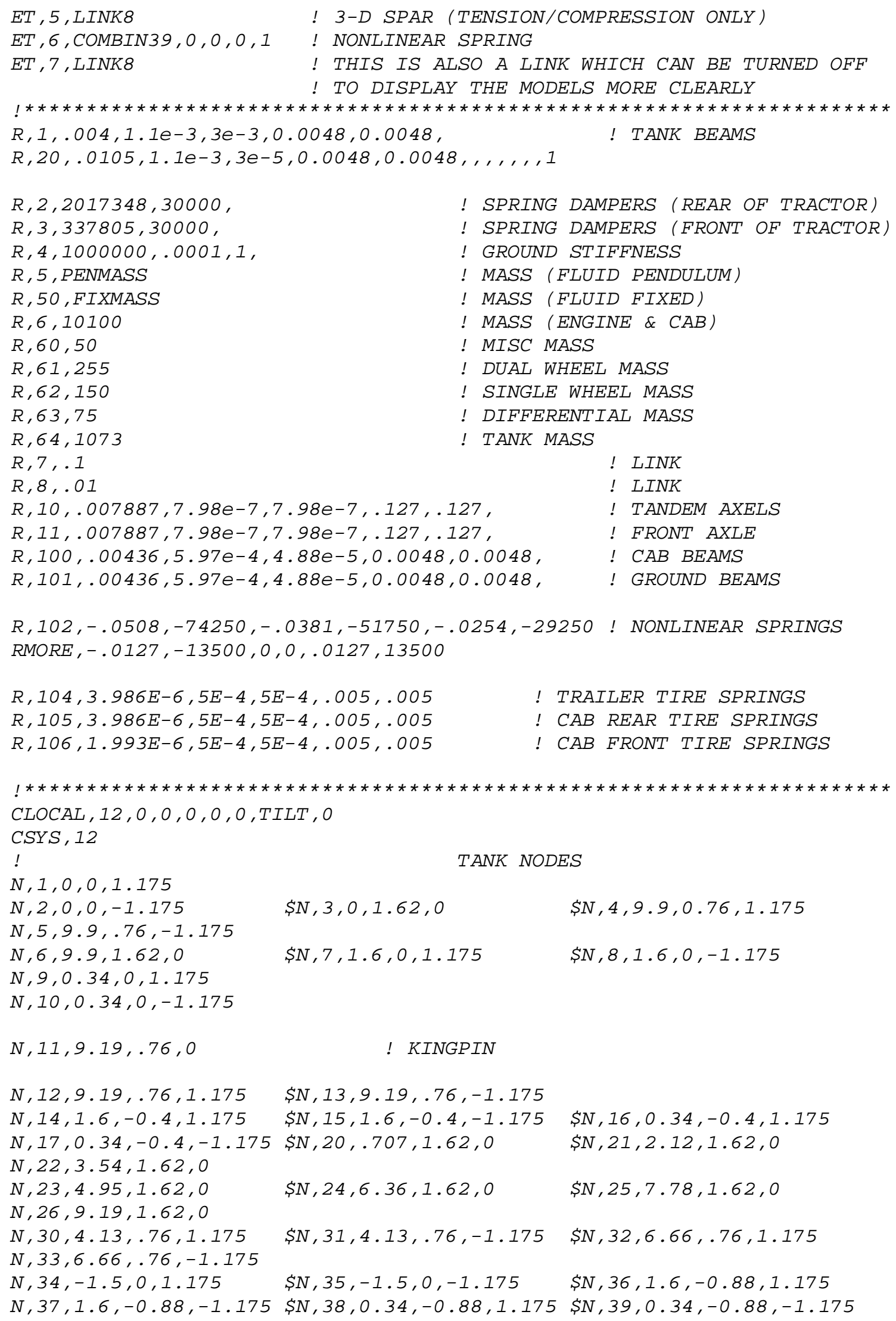


$N, 40,0.34,0, .485$

$N, 43,1.6,0,-.485$

$N, 44,0.34,-.37, .485$

$N, 47,1.6,-.37,-.485$

$N, 48,7.5,2.4,-.125$

$N, 50, .707,1.62-B, 0$

$N, 53,4.95,1.62-B, 0$

$N, 56,9.19,1.62-B, 0$
$\$ N, 41,0.34,0,-.485 \quad \$ N, 42,1.6,0, .485$

$\$ N, 45,0.34,-.37,-.485 \$ N, 46,1.6,-.37, .485$

! EXTRA BALANCING ELEMENT

$\$ N, 51,2.12,1.62-B, 0 \quad \$ N, 52,3.54,1.62-B, 0$

$\$ N, 54,6.36,1.62-B, 0 \quad \$ N, 55,7.78,1.62-B, 0$
$!$

$! N, 60,1.6,-0.881,1.175$

$! N, 62,0.34,-0.881,1.175$

$N, 64,0, .76,1.175$

$N, 67,0.34, .76,-1.175$

$N, 70, .707,1.62,0$

$N, 73,4.95,1.62,0$

$N, 76,9.19,1.62,0$

$N, 80, .707,1.62+A, 0$

$N, 83,4.95,1.62+A, 0$

$N, 86,9.19,1.62+A, 0$

$N, 100,9.19, .76,0$

CLOCAL, 20, 0, 9.19.183, 0, 0, 0, 0, ROT

CSYS, 20
CAB NODES

$N, 101,-1.5, .26,1.22$

$N, 104, .541, .26,-1.22$

$N, 107,-.183, .26,1.22$

$N, 110,-.183, .26,-.4525$

$N, 113,5.88, .26,1.16$

$N, 116, .54,-0.37,-1.22$

$N, 118,-.907,-0.37,-1.22$

$N, 119,4.24,-0.37,1.16$

$N, 140,-.183,-0.37, .4525$

$N, 141,-.183,-0.37,-.4525 \$ N, 142,-.183,-0.37,1.22$

$N, 143,-.183,-0.37,-1.22$

$N, 144,4.24,-0.37, .4525$

$N, 147,4.24, .26,-.4525$

$N, 121,1.996+.2,-0.09768, .001$

$\$ N, 102,-1.5, .26,-1.22$

$\$ N, 105,-.907, .26,1.22$

$\$ N, 108,-.183, .26,-1.22$

$\$ N, 111,4.24, .26,1.16$

$\$ N, 114,5.88, .26,-1.16$

$\$ N, 117,-.907,-0.37,1.22$

$\$ N, 120,4.24,-0.37,-1.16$

$\$ N, 145,4.24,-0.37,-.4525 \$ N, 146,4.24, .26, .4525$

$N, 125,-.907,-.88,1.22$

$N, 128, .541,-.88,-1.22$

!*

$! N, 131,-.907,-.881,1.22 \$ N, 132,-.907,-.881,-1.22 \$ N, 133, .541,-.881,1.22$

$! N, 134, .541,-.881,-1.22 \$ N, 135,4.24,-.881,1.16 \$ N, 136,4.24,-.881,-1.16$

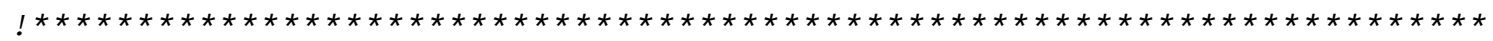
$!$
$\$ N, 103, .541, .26,1.22$

$\$ N, 106,-.907, .26,-1.22$

$\$ N, 109,-.183, .26, .4525$

$\$ N, 112,4.24, .26,-1.16$

$\$ N, 115, .54,-0.37,1.22$
! CENTER OF GRAVITY

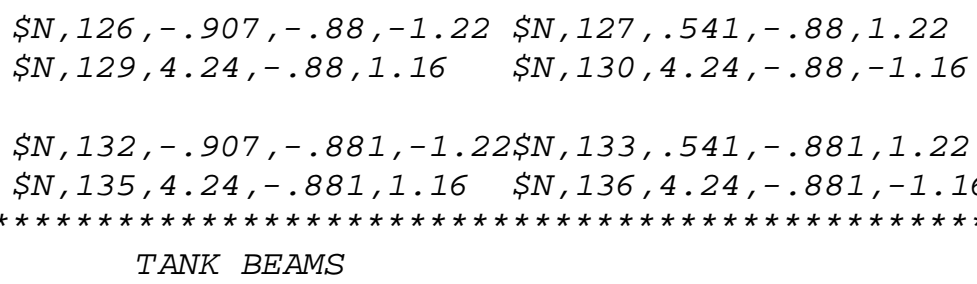

TANK BEAMS

$\$ N, 82,3.54,1.62+A, 0$

$\$ N, 85,7.78,1.62+A, 0$ 


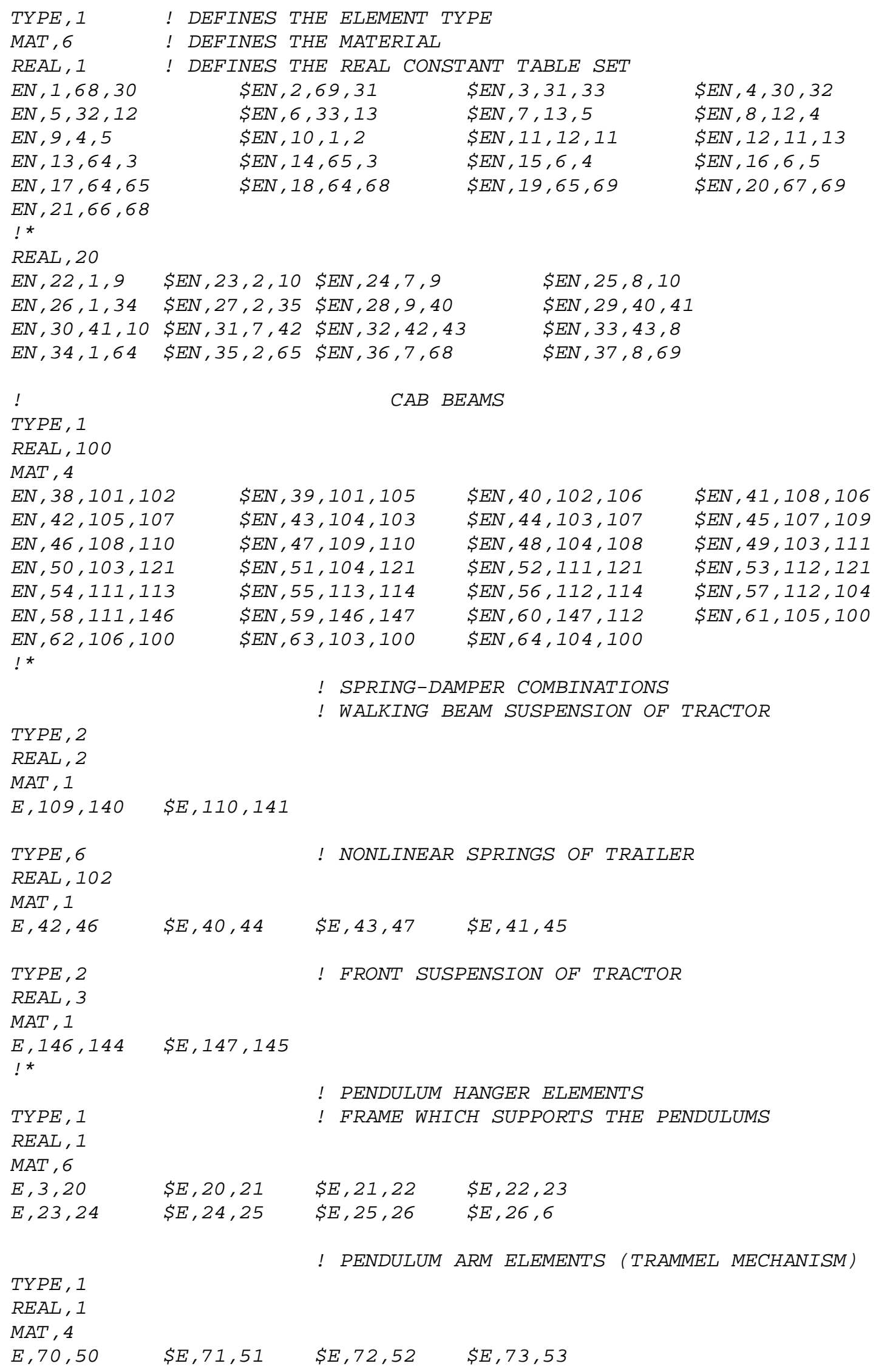




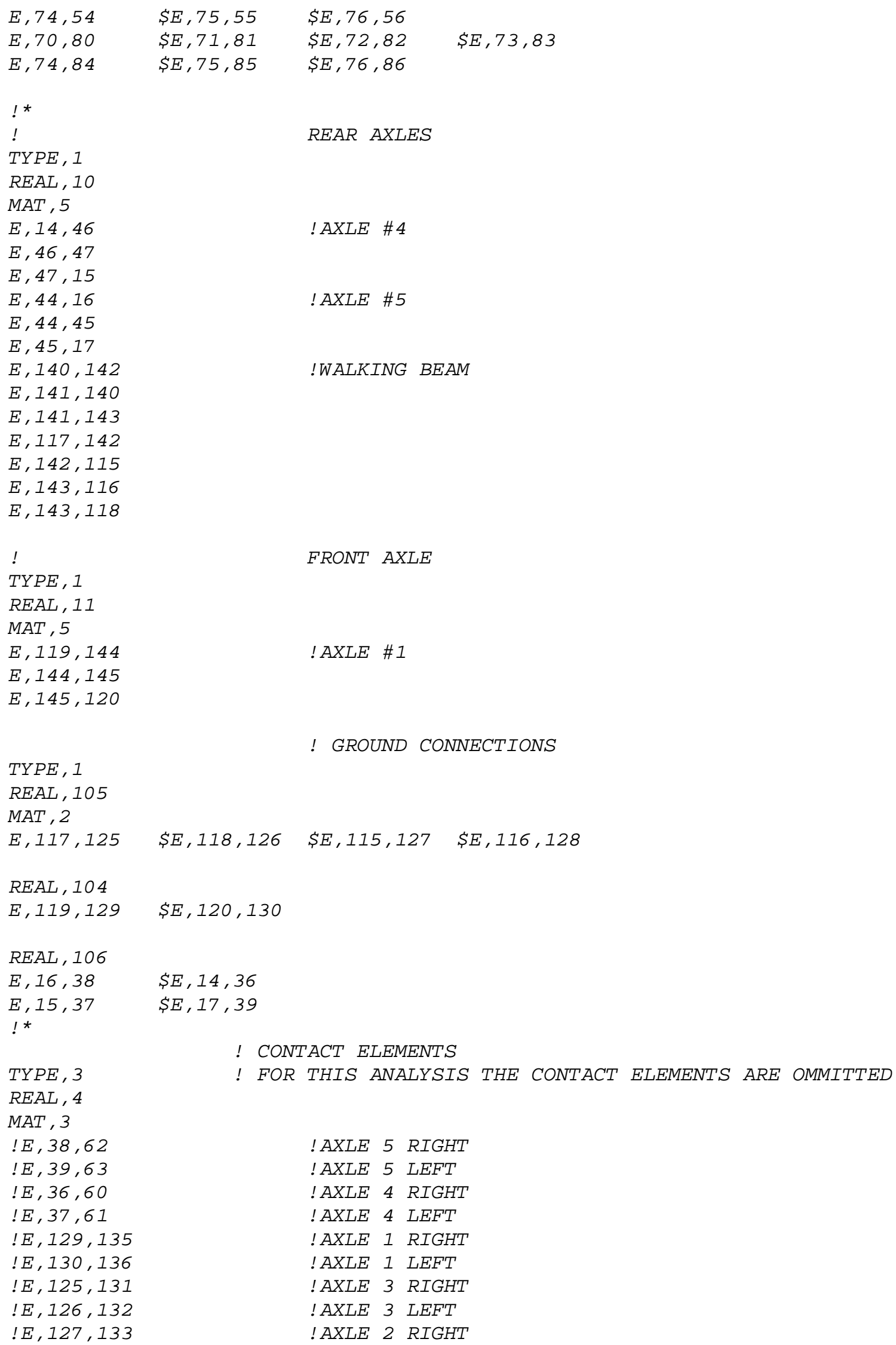




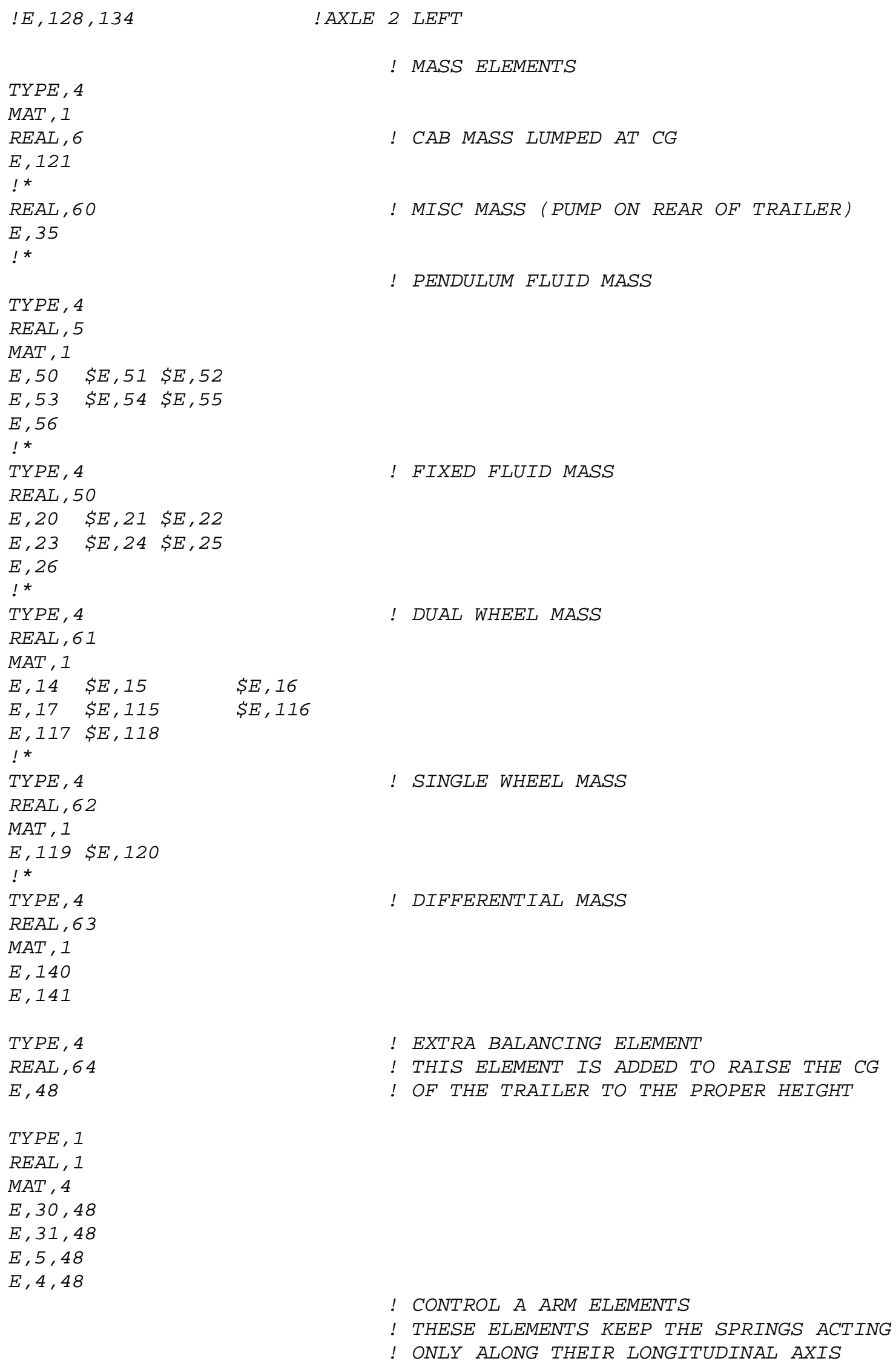


TYPE, 7

REAL, 8

$M A T, 4$

$E, 35,1$

SE, 7, 16

$\$ E, 34,39$

$\$ E, 8,39$

$E, 35,15$

$\$ E, 7,15$

$\$ E, 34,14$

$\$ E, 8,14$

$E, 142,111$

$\$ E, 143,112$

$\$ E, 142,106$

$\$ E, 143,105$

$E, 103,119$

$\$ E, 112,119$

$\$ E, 104,120$

$\$ E, 111,120$

$E, 35,38$

SE, 7, 38

$\$ E, 34,17$

SE, 8, 17

$E, 35,37$

$\$ E, 7,37$

$\$ E, 34,36$

$\$ E, 8,36$

$S E, 102,125$

$\$ E, 102,128$

$E, 101,126$

SE, 103, 125

$E, 103,129$

$S E, 112,129$

$\$ E, 103,128$

$\$ E, 101,127$

104,127

$\$ E, 104,130 \$ E, 111,130$

$C P, 1, U X, 11,100$

! NODAL COUPLES

$C P, 2, U Y, 11,100$

! KINGPIN COUPLES

$C P, 3, U Z, 11,100$

$C P, 4, R O T Z, 11,100$

$C P, 5, R O T X, 11,100$

$C P, 6, U Y, 70,20$

! TRAMMEL MECHANISM CONSTRAINTS

$C P, 7, U X, 70,20,80$

$C P, 9, U Z, 80,20$

$C P, 10, U Y, 71,21$

$C P, 11, U X, 71,21,81$

$C P, 13, U Z, 81,21$

$C P, 14, U Y, 72,22$

$C P, 15, U X, 72,22,82$

$C P, 17, U Z, 82,22$

$C P, 18, U Y, 73,23$

$C P, 19, U X, 73,23,83$

$C P, 21, U Z, 83,23$

$C P, 22, U Y, 74,24$

$C P, 23, U X, 74,24,84$

$C P, 25, U Z, 84,24$

$C P, 26, U Y, 75,25$

$C P, 27, U X, 75,25,85$

$C P, 29, U Z, 85,25$

$C P, 30, U Y, 76,26$

$C P, 31, U X, 76,26,86$

$C P, 33, U Z, 86,26$

SAVE

FINISH

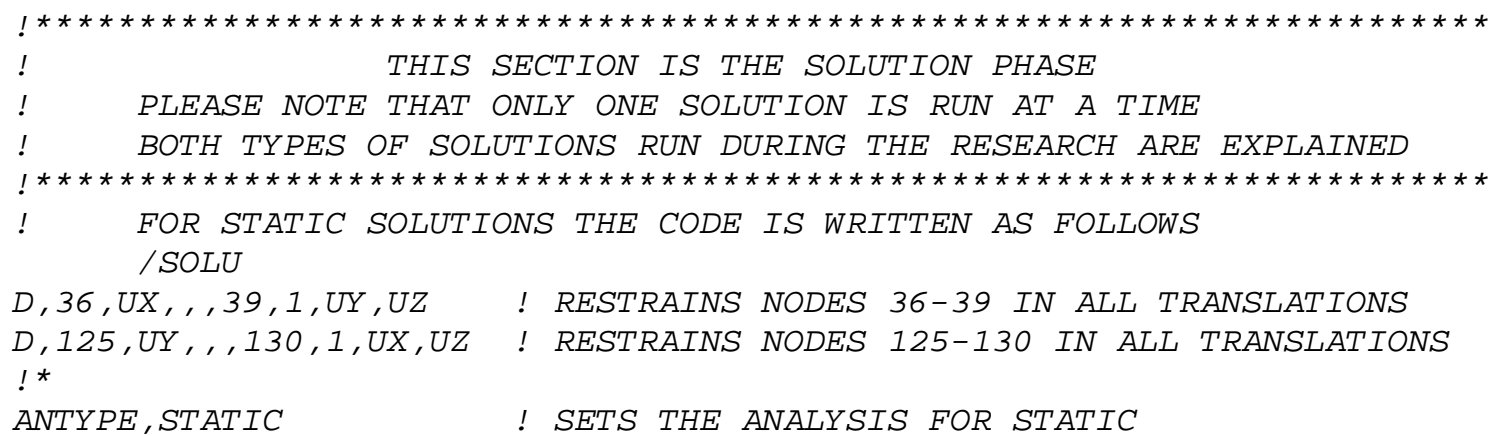

ANTYPE, STATIC

! SETS THE ANALYSIS FOR STATIC 


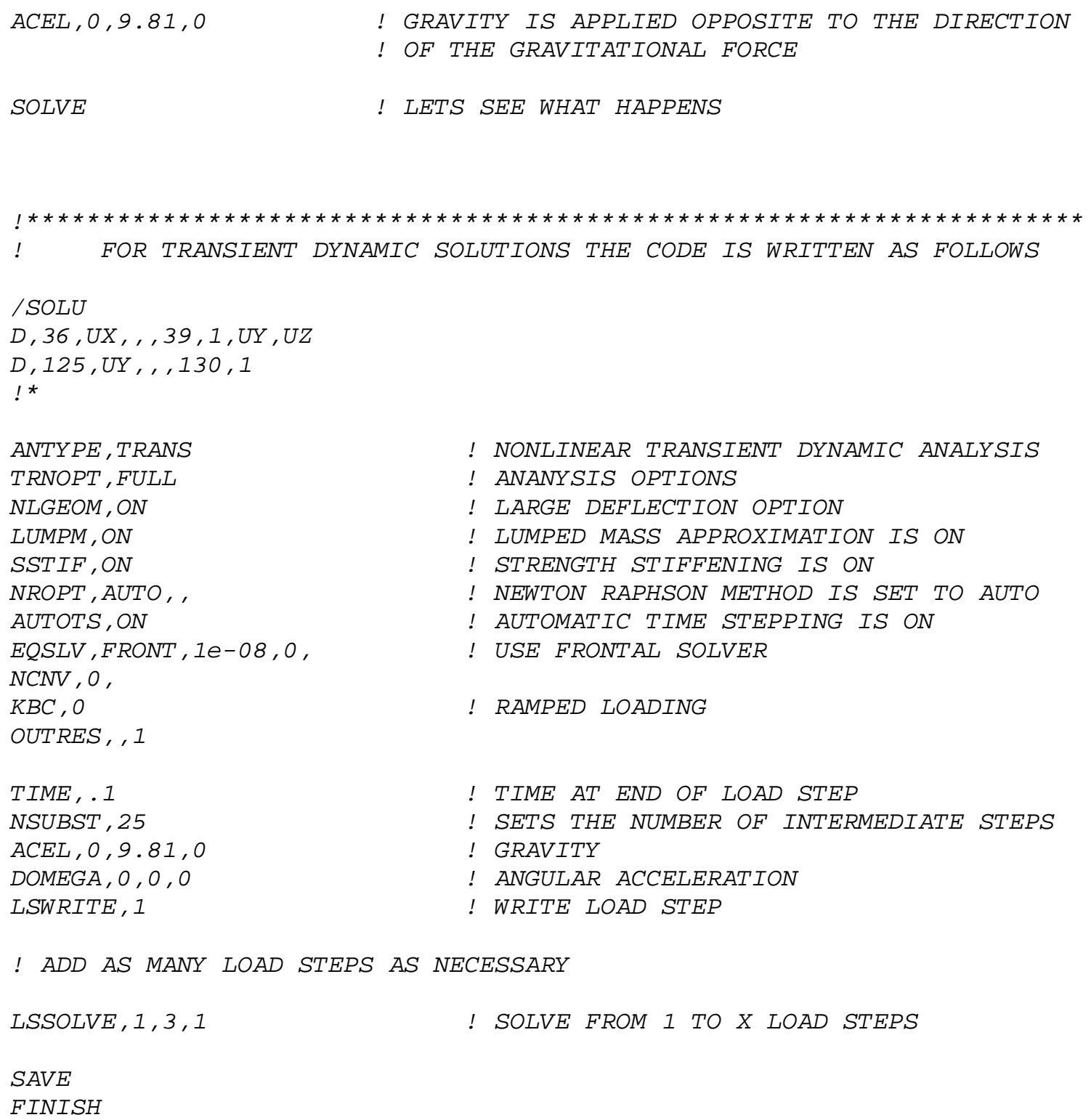

